\title{
Analgesic Potential of Terpenes Derived from Cannabis sativa
}

\author{
Erika Liktor-Busa ${ }^{1}$, Attila Keresztes ${ }^{1}$, Justin LaVigne ${ }^{1}$, John M. Streicher, and Tally M. Largent-Milnes \\ Department of Pharmacology, University of Arizona, Tucson, Arizona
}

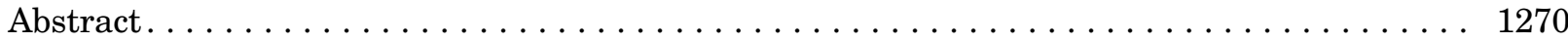

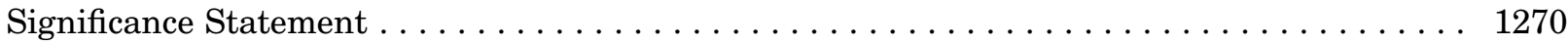

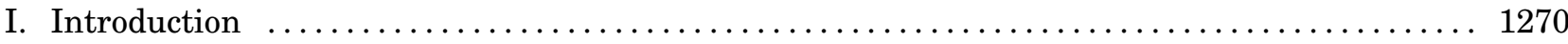

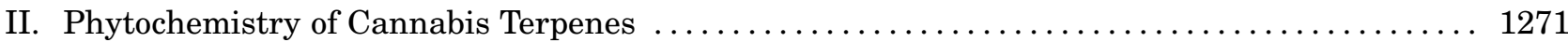

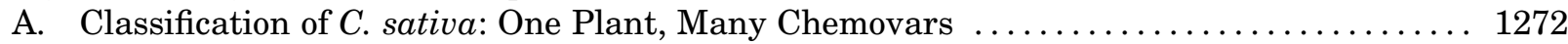

B. Chemical Diversity of $C$. sativa with Special Emphasis on Terpenes . ............. 1272

III. Molecular Targets of Terpenes from C. sativa and Preclinical Studies . ................ 1275

A. Monoterpenes with Analgesic and Anti-Inflammatory Activities $\ldots \ldots \ldots \ldots \ldots \ldots \ldots \ldots \ldots$

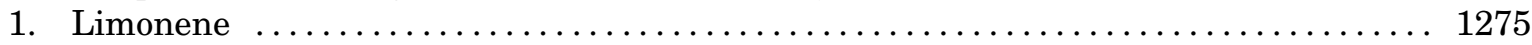

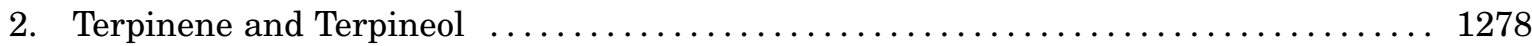

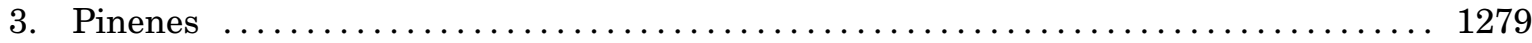

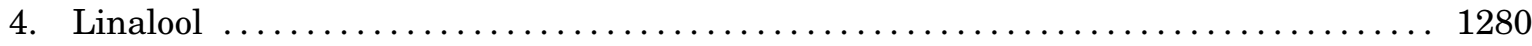

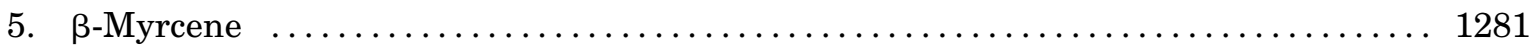

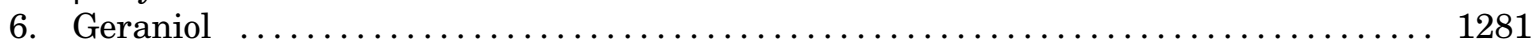

B. Sesquiterpenes with Analgesic and

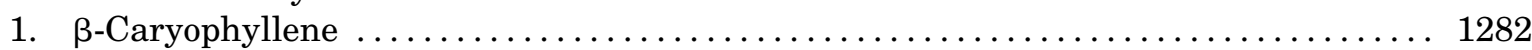

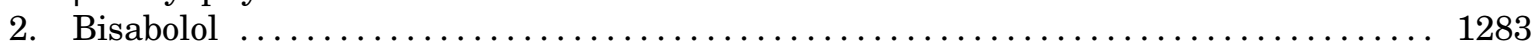

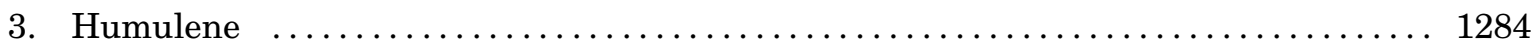

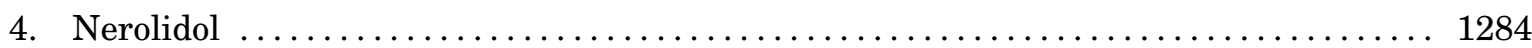

IV. Structure-Activity Relationships of Cannabis Terpenes and Terpene Analogs . . .......... 1284

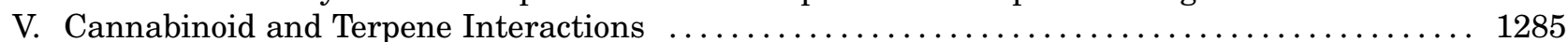

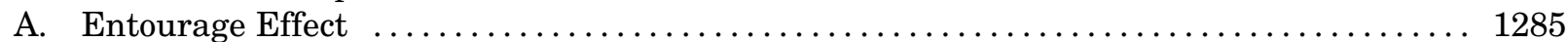

B. $\Delta^{9}$-Tetrahydrocannabinol and Terpene Interactions $\ldots \ldots \ldots \ldots \ldots \ldots \ldots \ldots \ldots \ldots \ldots \ldots$

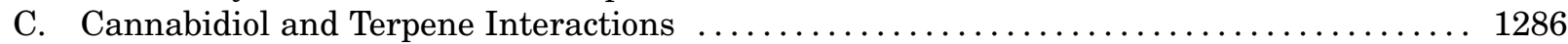

D. Terpene Interactions with Other Analgesics $\ldots \ldots \ldots \ldots \ldots \ldots \ldots \ldots \ldots \ldots \ldots \ldots \ldots \ldots$

E. Considerations for Interpreting Terpene Findings $\ldots \ldots \ldots \ldots \ldots \ldots \ldots \ldots \ldots \ldots \ldots \ldots \ldots$

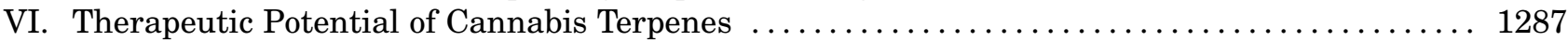

VII. Pharmacokinetics of Cannabis Terpenes and Impact on Pain Treatment $\ldots \ldots \ldots \ldots \ldots \ldots . . .1288$

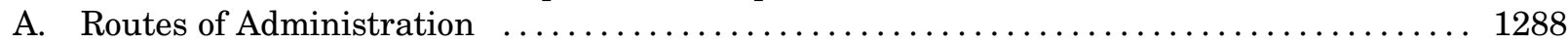

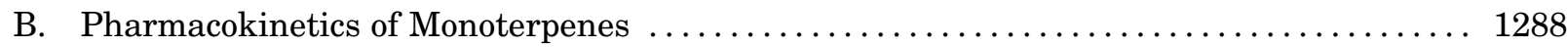

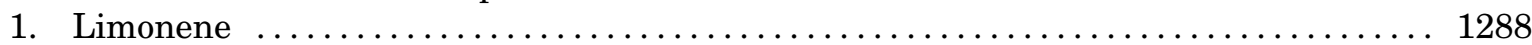

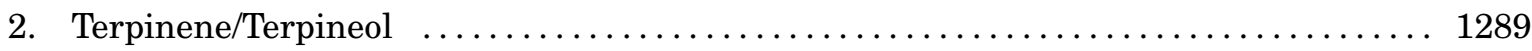

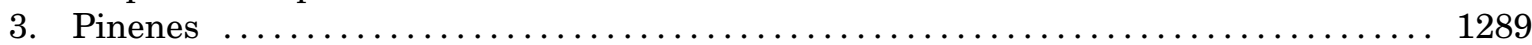

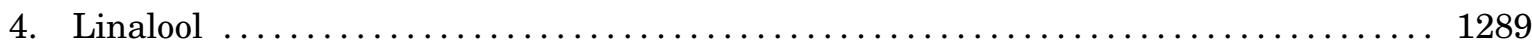

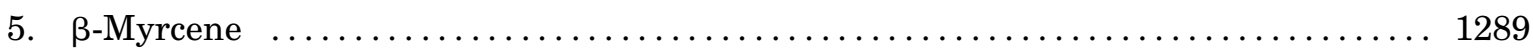

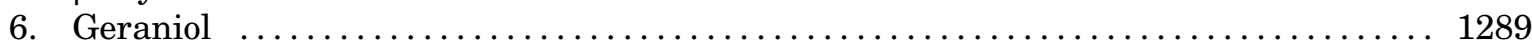

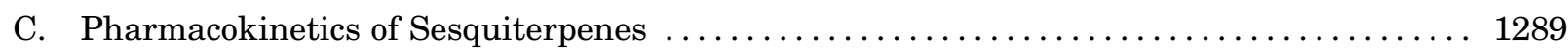

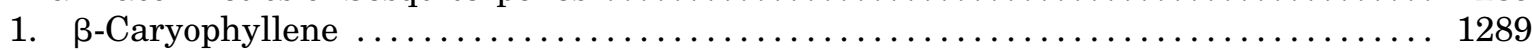

Address correspondence to: Dr. Tally M. Largent-Milnes, 1501. N. Campbell Ave., Tucson, AZ-85724. E-mail: tlargent@email. arizona.edu

This paper received no external funding.

No author has an actual or perceived conflict of interest with the contents of this article.

${ }^{1}$ E.L.-B., A.K., and J.L. contributed equally to this work as first authors.

https://doi.org/10.1124/pharmrev.120.000046 
2. Bisabolol ................................................ 1289

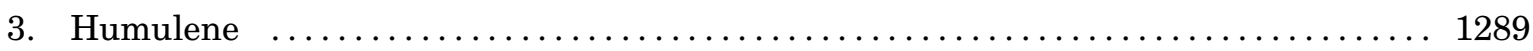

4. Nerolidol ................................................... 1290

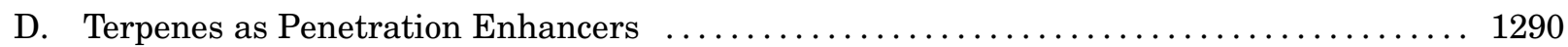

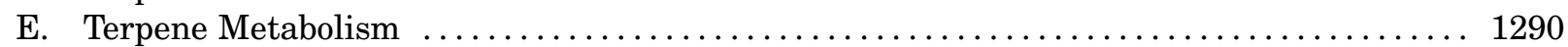

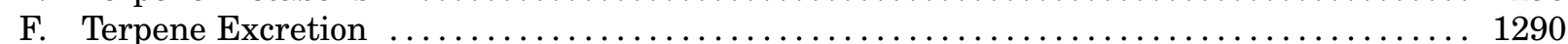

VIII. Clinical Evidence for Terpene Efficacy in Pain . . . . . . . . . . . . . . . . . . . . . . . . . . . . 1290

IX. Conclusions and Further Research f . . . . . . . . . . . . . . . . . . . . . . . . . . . . . . . . . . 1292

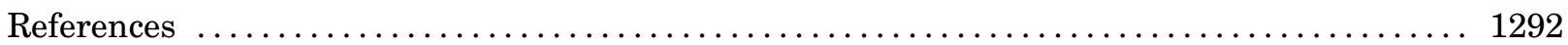

\begin{abstract}
Pain prevalence among adults in the United States has increased $25 \%$ over the past two decades, resulting in high health-care costs and impacts to patient quality of life. In the last 30 years, our under standing of pain circuits and (intra)cellular mechanisms has grown exponentially, but this understanding has not yet resulted in improved therapies. Options for pain management are limited. Many analgesics have poor efficacy and are accompanied by severe side effects such as addiction, resulting in a devastating opioid abuse and overdose epidemic. These problems have encouraged scientists to identify novel molecular targets and develop alternative pain therapeutics. Increasing preclinical and clinical evidence suggests that cannabis has several beneficial pharmacological activities, including pain relief. Cannabis sativa contains more than 500 chemical compounds, with two principle phytocannabinoids, $\Delta^{9}$-tetrahydrocannabinol ( $\Delta^{\mathbf{9}}$-THC) and cannabidiol (CBD). Beyond phytocannabinoids, more than 150 terpenes have been identified in different cannabis chemovars. Although the predominant cannabinoids, $\Delta^{9}$-THC and CBD, are thought to be the
\end{abstract}

primary medicinal compounds, terpenes including the monoterpenes $\beta$-myrcene, $\alpha$-pinene, limonene, and linalool, as well as the sesquiterpenes $\beta$-caryophyllene and $\alpha$-humulene may contribute to many pharmacological properties of cannabis, including anti-inflammatory and antinociceptive effects. The aim of this review is to summarize our current knowledge about terpene compounds in cannabis and to analyze the available scientific evidence for a role of cannabis-derived terpenes in modern pain management.

Significance Statement_-Decades of research have improved our knowledge of cannabis polypharmacy and contributing phytochemicals, including terpenes. Reform of the legal status for cannabis possession and increased availability (medicinal and recreational) have resulted in cannabis use to combat the increasing prevalence of pain and may help to address the opioid crisis. Better understanding of the pharmacological effects of cannabis and its active components, including terpenes, may assist in identifying new therapeutic approaches and optimizing the use of cannabis and/or terpenes as analgesic agents.

\section{Introduction}

Pain, defined by the International Association for the Study of Pain as "an unpleasant sensory and emotional experience associated with, or resembling that associated with, actual or potential tissue damage," is a prominent and common symptom underlying many different disorders. Chronic pain is one of the most frequent reasons for adults to seek medical care (Schappert and Burt, 2006). Restrictions on daily activities, dependence on opioids, and reduced quality of life are all linked to chronic pain (Gureje et al., 1998; Smith et al., 2001). In 2016, an estimated $20.4 \%$ of adults in the United States had chronic pain, with $8.0 \%$ of adults in the United States reporting high-impact chronic pain (Dahlhamer et al., 2018). Chronic pain contributes to an estimated
$\$ 560$ billion each year in direct medical costs, lost productivity, and disability programs (Gaskin and Richard, 2012); this cost has likely increased over the last 8 years. The Medical Expenditure Panel Survey revealed that noncancer pain prevalence among adults in the United States increased 25\% over the past two decades (Nahin et al., 2019). Over this time period, as the prevalence of pain has exploded, the opioid epidemic has escalated, with numerous adverse consequences (Manchikanti et al., 2012). The National Survey on Drug Use and Health has recently shown that among the estimated 22.6 million Americans, aged 12 or older, who were current or past-month illicit drug users, 5.1 million had used pain relievers. These numbers provide clear evidence that pain is a significant public health problem in

ABBREVIATIONS: A2a, adenosine-2a receptor; AMPA, $\alpha$-amino-3-hydroxy-5-methyl-4-isoxazoleproprionic acid; AP-1, activator protein 1 ; BCP, $\beta$-caryophyllene; CB1, cannabinoid receptor 1; CB2, cannabinoid receptor 2; CBD, cannabidiol; CCI, chronic constriction injury; COX, cyclooxygenase; CP55,940, 2-[(1R,2R5R)-5-hydroxy-2-(3-hydroxypropyl)cyclohexyl]-5-(2-methyloctan-2-yl)phenol; DbcAMP, dibutyryl cyclic adenosine monophosphate; EOVAC, extract from Vitex agnus-castus; ERK, extracellular signal-regulated kinase; GC, Gas Chromotography; GPCR, G-protein-coupled receptor; IL-10, interleukin-10; IL-1 $\beta$, interleukin-1 $\beta$; IL-6, interleukin-6; iNOS, inducible nitric oxide synthase; JNK, c-Jun N-terminal kinase; L-NAME, N(G)-nitro-L-arginine methyl ester; LPS, lipopolysaccharide; MAPK, mitogen-activated protein kinase; NF- $\kappa \mathrm{B}$, nuclear factor $\kappa$-light-chain-enhancer of activated B cells; NMDA, $N$-methyl-D-Aspartate; NO, nitrogen monoxide; Nrf-2, nuclear factor erythroid 2-related factor 2; $\mathrm{PGE}_{2}$, prostaglandin $\mathrm{E}_{2}$; P-GP, P-glycoprotein; PK, pharmacokinetic; SCI, spinal cord injury; SNL, sciatic nerve ligation; $t_{1 / 2}$, half-life; $\Delta^{9}$-THC, (-)-trans- $\Delta^{9}$-tetrahydrocannabinol or $(6 \mathrm{a} R, 10 \mathrm{a} R)$ - $\Delta-9$-tetrahydrocannabinol; TLR4, toll-like receptor 4; TNF- $\alpha$, tumor necrosis factor- $\alpha$; TRP, transient receptor potential; TRPA1, transient receptor potential cation channel subfamily a member 1 or transient receptor potential ankyrin 1; TRPV1, transient receptor potential cation channel subfamily V member 1 . 
the United States, and worldwide statistics show similar trends (Langley, 2011; Henschke et al., 2015).

Despite the high prevalence of pain-related disorders, effective management of certain types of pain is still a challenge for health-care providers (Thomas MA, 2003; Polacek et al., 2020). In the last few decades, neuroscientists have made significant advances in understanding the circuit, cellular, subcellular, and signaling mechanisms underlying pain pathologies (Peirs and Seal, 2016). However, this deeper understanding of those mechanisms has yielded few new or improved therapies. The three-step medication ladder established by the World Health Organization in 1985 is still considered the gold standard in pain management (Ventafridda et al., 1985; Ballantyne et al., 2016). Many currently available analgesic medications possess poor efficacy and are accompanied by severe side effects, such as dependence and addiction, which have contributed to a nationwide opioid epidemic (Vadivelu et al., 2018; Yang et al., 2020). Thus, innovative therapeutic options with higher efficacy and fewer side effects are in high demand.

Cannabis sativa has been used for medical, recreational, and spiritual purposes for thousands of years (Russo, 2007). Modern scientific studies have provided increasing amounts of preclinical and clinical evidence about its beneficial pharmacological effects, including pain relief (Koppel et al., 2014; Russo and Marcu, 2017). Recent changes in the legislation of cannabis usage and possession have resulted in cannabis-based products becoming widely used alternatives in fighting against many different illnesses (Schmitz and Richert, 2020). Medical marijuana has been applied to treat a host of indications, but the most frequent, and evidence-backed indication, is pain (Hill, 2015). Despite controversial scientific reports about the therapeutic potential of $C$. sativa (Maule, 2015; Romero-Sandoval et al., 2018), the usage of cannabis in patient populations is continuously growing (Carliner et al., 2017).

Among hundreds of compounds identified in cannabis so far, two phytocannabinoids, $\Delta^{9}$-tetrahydrocannabinol ( $\Delta^{9}$-THC) and cannabidiol (CBD), are considered the primary active components of $C$. sativa and have been shown to produce pain relief in animal models (Hill, 2015; Romero-Sandoval et al., 2018). Patient reports and growing clinical evidence suggest the possible positive effect of medical marijuana, THC, and CBD for a variety of conditions, including pain; however, current evidence is not strong enough for Food and Drug Administration-approved applications (Johnson et al., 2010; Aviram and SamuellyLeichtag, 2017; Mücke et al., 2018; van de Donk et al., 2019; VanDolah et al., 2019; Capano et al., 2020). Only a single cannabinoid drug has been approved: the CBD-based drug Epidiolex, which is used for the treatment of rare, severe epilepsy.

On the other hand, numerous scientific papers showed that cannabis usage is associated with side effects, for instance, psychotropic activity and addictive potential, which are mainly attributed to $\Delta^{9-} \mathrm{THC}$ acting through cannabinoid type 1 receptors (CB1) (Volkow et al., 2014; Ford et al., 2017). New approaches are thus needed to either modulate/improve the side effects of cannabis $/ \Delta^{9-} \mathrm{THC}$ use or to produce pain relief without these side effects. One such potential class of compounds is terpenes, which may also contribute to the overall effect of cannabis (Russo and McPartland, 2003; Nuutinen, 2018; Booth and Bohlmann, 2019).

Several research and review papers have summarized current knowledge about the phytocannabinoid components of C. sativa (Morales et al., 2017; Turner et al., 2017; Maroon and Bost, 2018; Alves et al., 2020), but very few publications have focused on terpenes. The aim of this review is to collate available scientific evidence about the most common terpenes found in cannabis with special emphasis on their possible effect against pain. We summarize the most up-to-date knowledge about their analgesic and antiinflammatory potential, along with their pharmacokinetics and how their pharmacokinetics impact on their pharmacological effects. We provide a critical overview of the possible interaction between terpenes and classic cannabinoids. The overall goal of this review is to enhance the scientific understanding about cannabis-derived terpenes and their potential pharmacological effects in pain treatment.

The literature was searched using PubMed, Medline, Scopus, and Cochrane databases, with only peerreviewed articles considered as source material. The publications with the most up-to-date information were selected for inclusion. Key words included, but were not limited to, a combination of terpene, pain, cannabis, pharmacokinetic, phytochemistry, in vitro, in vivo, and clinical.

\section{Phytochemistry of Cannabis Terpenes}

C. sativa L., hereafter referred to as cannabis for brevity, is thought to originate from central Asia and has been cultivated for thousands of years, primarily as a source of stem fiber and resinous intoxicant (Russo et al., 2008; Bonini et al., 2018). The morphology, chemistry, distribution, and ecology of cultivated forms have been modified during domestication when compared with the original wild plants. These changes have resulted in a multitude of chemovars with unique compositions of terpene compounds. 


\section{A. Classification of C. sativa: One Plant, Many Chemovars}

Cannabis is an annual dioecious plant belonging to the family Cannabaceae; dioecious means the male plants are distinct from the female plants. An early classification system distinguished $C$. sativa and Cannabis indica (McPartland, 2017). Their morphology (C. sativa being taller and more highly branched and C. indica being shorter with broader leaves), their original geographic range (C. sativa originated from Europe and $C$. indica from Asia), and the composition of their secondary metabolites (secondary plant metabolites are large numbers of chemical compounds produced by plant cells, using biosynthetic enzymes and building blocks derived from primary plant metabolic pathways) all showed differences, but the dilemma about their taxonomical separation, whether they are separate species or subspecies, continues to the present day (Russo, 2007; Small, 2015; Pollio, 2016). Several review and research papers have provided detailed reports about the classification and nomenclature of cannabis (Fischedick et al., 2010; Pollio, 2016; McPartland, 2017, 2018). The current consensus is that $C$. sativa and $C$. indica should not be considered different species. Therefore, cannabis is monotypic and consists of only one highly polymorphic speciesnamely, C. sativa L.-which is divided into subdivisions (Hazekamp and Fischedick, 2012; Hazekamp et al., 2016; Chandra et al., 2017; McPartland, 2018). For forensic and legislative purposes, the most important subdivisions are commonly made based on the $\Delta^{9}$-THC content. The high content of $\Delta^{9}$-THC classifies as drug-type cannabis (marijuana), whereas a low content is found in fiber-type cannabis (hemp) (Small and Beckstead, 1973). This fiber-type cannabis is characterized by a higher level of CBD, and the maximum $\Delta^{9}$-THC content of this type of cannabis was defined as $0.2 \%-0.3 \%$ of dry matter (McPartland, 2017). Chemotaxonomic evaluation has led to the recognition of an intermediate type with similar levels of $\Delta^{9}$-THC and CBD (Fischedick et al., 2010).

Most cannabis plants that are commercially available are in fact a hybrid or crossbreed of Sativa and Indica ancestors, which has led to countless cultivated varieties with unstable taxonomic foundations. More than 700 different cultivated varieties (cultivars) of cannabis have already been cataloged (Hazekamp and Fischedick, 2012). Moreover, plant breeders and recreational consumers created a vernacular classification of cannabis, independent from scientific and taxonomical classification, which makes the exact identification of individual strains extremely difficult (Erkelens and Hazekamp, 2014). The recent growth of the medicinal use of cannabis has underlined a need to clearly distinguish these different types. The critical evaluation and comparison of strains, including preclinical and clinical studies conducted with different cannabis types, are questionable without a clear identification system.

Several scientific attempts have been made to classify cannabis plants based on their phytochemical composition. Cannabis products used for medicinal purposes usually contain a high content of the biologically active $\Delta^{9}$-THC, but it is becoming clear that multiple cannabis compounds are involved in its various therapeutic effects (Russo and McPartland, 2003). High-throughput genotyping of a diverse collection of cannabis germplasm showed that genetic differences between hemp and marijuana are not limited to genes involved in $\Delta^{9}$-THC production (Sawler et al., 2015). Moreover, the Sativa versus Indica types of cannabis tend to have a different smell, which reflects a different terpene profile. Several research papers have described how terpene content can contribute to the overall effect of cannabis; therefore, the classification system of cannabis should take terpenes into account (Andre et al., 2016). Comprehensive taxonomical, chemical, and pharmacological studies of the cannabis plant led to the idea that it should be identified by its chemical fingerprint rather than being characterized as Sativa or Indica (Hazekamp and Fischedick, 2012; McPartland, 2017; Hazekamp et al., 2016). Thus, the nomenclature has shifted from cultivar to chemovar, and emphasis has shifted to identifying cannabis based on its cannabinoid and terpene profile (Hillig, 2004; Hillig and Mahlberg, 2004; Elzinga et al., 2015). A comprehensive overview of chemical diversity is mandatory for quality control of plant material and the critical evaluation of the therapeutic value of cannabis.

\section{B. Chemical Diversity of C. sativa with Special Emphasis on Terpenes}

To date, more than 500 different constituents have been identified in cannabis resin, including 150 different terpenes and approximately 100 different cannabinoids (Flores-Sanchez and Verpoorte, 2008). Figure 1 presents the structures of the most frequently reported mono- and sesquiterpenes in cannabis. The resin is produced and stored in glandular trichomes, which densely cover the surface of the female inflorescence.

Phytocannabinoids are a group of terpenophenolic compounds, generally classified into 10 subclasses (Hanuš et al., 2016). Among them, the most studied compounds are $\Delta^{9}$-THC and CBD. Phytocannabinoids are predominantly produced in cannabis, but $\mathrm{N}$-alkylamide-type compounds in Echinacea species, and other structurally different molecules in Radula and Helichrysum genera, also showed affinity to cannabinoid receptors (Gertsch et al., 2010; Pollastro et al., 2017; Hussain et al., 2018). Beyond the classic phytocannabinoids, terpenes represent the largest group of phytochemicals in cannabis (Andre et al., 2016). Although the odor and flavor of cannabis are attributed to terpene content, it is important to 


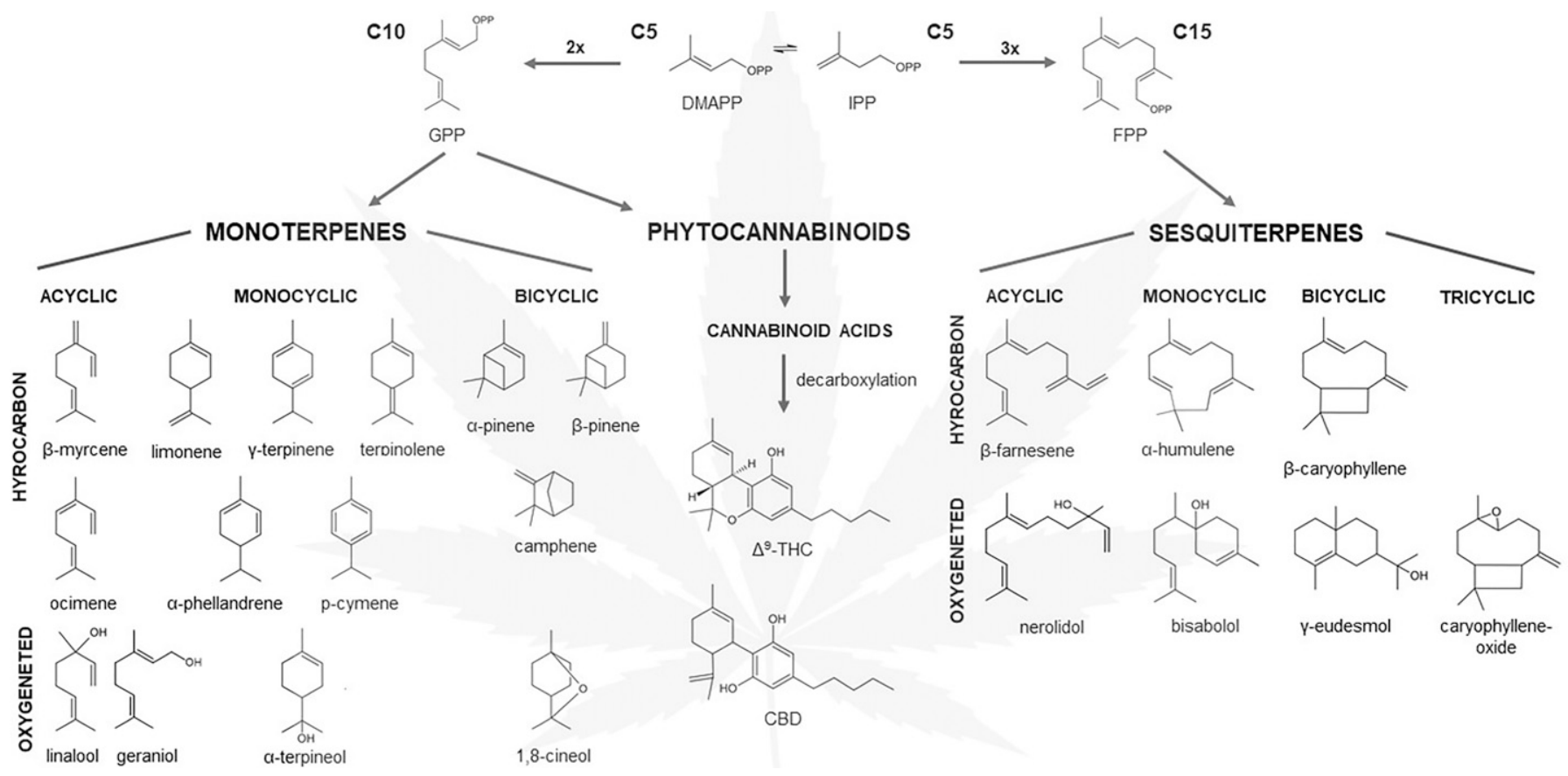

Fig. 1. Mono- and sesquiterpenes commonly encountered in cannabis with the two main phytocannabinoids, $\Delta^{9}$-THC and CBD. Monoterpenes and phytocannabinoids have a common 10-carbon isoprenoid precursor, geranyl diphosphate (GPP). The sesquiterpenes are biosynthesized from the 15carbon isoprenoid, called farnesyl diphosphate (FPP). Isopentenyl diphosphate (IPP) and dimethylallyl diphosphate (DMAPP) are the 5-carbon building blocks in the terpene and phytocannabinoid biosynthesis.

recognize that terpenes possess diverse pharmacological activities that play a role in the complex pharmacological profile of cannabis (Nuutinen, 2018).

Terpenes represent one of the largest groups of plantderived secondary metabolites and are assembled by five carbon isoprene units. Integration of terpenes can occur in thousands of different ways, providing complexity and diversity of this class, with over 80,000 structures reported so far (Mander and Liu 2010). Terpenes are hydrocarbons, composed of only two elements, carbon and hydrogen, whereas terpenoids are classified as modified terpenes with different functional groups at various positions. Here, the term "terpene" is used as a collective nomenclature of the entire group.

Terpenes are divided into subclasses depending on the number of their carbon units. The typical cannabis terpenes are mono- and sesquiterpenes, built up of two or three isoprene units, respectively. Monoterpenes contain 10 carbon atoms (C10) and are structurally divided into the acyclic, monocyclic, and bicyclic types. The molecules that belong to this class usually have a strong aroma, and they are usually present in the essential oils of plants. Sesquiterpenes are the class of secondary metabolites consisting of 15 carbon atoms (C15) and found in linear, mono-, bi-, and tricyclic forms in cannabis. Among the terpenes present in cannabis, many are produced by other plants, like $\alpha$ - and $\beta$-pinene in Pinus species, linalool in Lavandula and Ocimum species, limonene in citrus species, or $\beta$-caryophyllene in Carum and Syzygium species, to mention a few; however, the terpene biochemical diversity present in cannabis and their coexpression with phytocannabinoids is unique and remarkable.

The average terpene concentration in cannabis flowers were previously reported in the range of $1 \%-10 \%$, but due to selective breeding, the lower end of the average terpene content has increased up to $3.5 \%$ or even higher in modern chemovars (Fischedick et al., 2010; Lewis et al., 2018). Review papers published in the last decade revealed considerable variation in the terpene profile of cannabis and its products (Hillig, 2004; Fischedick et al., 2010; Casano et al., 2011; Da Porto et al., 2014; Elzinga et al., 2015; Aizpurua-Olaizola et al., 2016; Hazekamp et al., 2016; Fischedick, 2017; Jin et al., 2017; Richins et al., 2018; Mudge et al., 2019). The presence of one or two dominant terpenes is typical in other plant materials, but the terpene profile of cannabis inflorescence tends to be more complex. A study published by Allen et al. (2019) revealed that the dominant terpene contributed only around $35 \%$ of the total terpene content, and on average, the top four terpenes comprise just $72 \%$ of the total. However, more than 100 terpenes have been found in C. sativa, and 30-50 terpenes are routinely observed in cannabis samples. Mudge et al. (2019) investigated 33 cannabis chemovars and identified 29 monoterpenes and 38 sesquiterpenes. In total, $87.1 \%-99.5 \%$ of the terpene profiles were monoterpenes, whereas sesquiterpenes accounted for the remaining $0.5 \%-12.9 \%$. Three monoterpenes, limonene, $\beta$-myrcene, and $\alpha$-pinene, and two sesquiterpenes, 
$\beta$-caryophyllene and $\alpha$-humulene, were abundant in the majority of chemovars (Mudge et al., 2019). In North American chemovars, the following eight terpenes were predominant: $\beta$-myrcene, terpinolene, ocimene, limonene, $\alpha$-pinene, humulene, linalool, and $\beta$-caryophyllene (Giese et al., 2015). But the work of Allen et al. (2019) highlighted that the quantity of the common top five terpenes, including $\beta$-myrcene, $\alpha$-pinene, limonene, $\beta$-caryophyllene, and terpinolene, showed large variance; they can be the single most abundant terpene in certain chemovars, or minor components, or even under the limit of detection in other chemovars.

Several research groups have investigated the coexpression of certain terpenes with $\Delta^{9}$-THC or CBD, but a consensus pattern or a rigorous connection between terpene profile and $\Delta^{9}$-THC or CBD has not been published yet. Fischedick et al. (2010) found a positive correlation between higher levels of cannabinoids and higher levels of terpenes after analyzing 11 chemovars of cannabis. In another study, terpene profiles in 16 plants obtained from California dispensaries were investigated (Elzinga et al., 2015). The samples were separated based on their morphologic appearance and classified as "mostly indica" and "mostly sativa." The dominance of $\beta$-myrcene with limonene and $\alpha$-pinene was characteristic of mostly indica strains, whereas the terpene profile of mostly sativa strains were more complex, with some strains having $\alpha$-terpinolene or $\alpha$-pinene as dominant and some strains having $\beta$-myrcene with $\alpha$-terpinolene and $\beta$-ocimene as dominant terpenes. In contrast with this study, Hazekamp et al. (2016) found that drug-type cannabis samples showed much wider chemical diversity, including terpene profiles. The total terpene content was higher in drug-type cannabis with the dominant presence of hydroxylated terpenes. Aizpurua-Olaizola et al. (2016) studied the time evolution of cannabinoid and terpene content during the entire growth period, and they observed chemotype-dependent terpene distribution. Terpenes such as $\beta$-eudesmol, $\gamma$-eudesmol, guaiol, $\alpha$-bisabolene, $\alpha$-bisabolol, and eucalyptol were characteristic of fiber-type cannabis, whereas $\gamma$-selinene, $\beta$-selinene, $\alpha$-gurjunene, $\gamma$-elemene, selina-3,7(11)diene, and $\beta$-curcumene were much more pronounced in the drug-type plants (Aizpurua-Olaizola et al., 2016). Another paper, published by Mudge et al. (2019), investigated the association between terpenes and major cannabinoid content in 33 chemovars obtained from five licensed producers. Three monoterpenes, limonene, $\beta$-myrcene, and $\alpha-$

pinene, and two sesquiterpenes, $\beta$-caryophyllene and humulene, were abundant in the majority of chemovars. Eight sesquiterpenes $[\alpha$-amorphene, caryophyllene oxide, $\alpha$-cubenene, $\beta$-elemene, $\gamma$-elemene, (Z,Z)- $\alpha$-arsenene, germacrene $\mathrm{B}$, and $\beta$-sesquiphellandrene] and one monoterpene (2-carene) were present in $\Delta^{9}$-THC-dominant chemovars, and three monoterpenes (cis- $\beta$-ocimene, trans- $\beta$-ocimene, and sabinene) and four sesquiterpenes (alloaromadendrene, cis- $\alpha$-bisabolene, 10-epi- $\gamma$-eudes$\mathrm{mol}$, and guaiol) were predominantly found in CBD-containing chemovars (Mudge et al., 2019). Based on these studies, making conclusions about the typical terpene profile in CBD or $\Delta^{9}$-THC-dominant chemovars is not possible and requires further investigation.

Most terpenes found in Cannabis are hydrocarbons (containing carbon and hydrogen atoms only-see structure in Fig. 1), produced by terpene synthase enzymes (Booth et al., 2017; Booth and Bohlmann, 2019). The oxygen-containing functional group of simple terpene alcohols, such as linalool or bisabolol, probably derives from enzymatic activity in the cannabis plant. However, the presence of other derivatives, like caryophyllene oxide or $\beta$-elemene, can be explained by nonenzymatic oxidation caused by UV light or heat during processing or storage (Booth et al., 2017), drawing attention to the importance of standardized sample preparation. Only nine terpene synthase enzymes have been fully characterized, but 30 different genes coding for this type of enzyme were identified in the cannabis genome (Gunnewich et al., 2007; Booth et al., 2017). The diversity of terpene synthase enzymes and their multiproduct nature (each enzyme can produce various terpene products) provides a partial explanation of the chemical diversity of cannabis terpenes.

Environmental factors influence terpene composition, resulting from changing expression levels and activity of terpene synthase enzymes (Booth and Bohlmann, 2019). It is well known that terpenes play important roles in plant communication with its environment, including attraction of beneficial organisms, repelling harmful ones, and communication between plants (Paré and Tumlinson, 1999; Huang and Osbourn, 2019). Therefore, minor environmental changes can cause remarkable differences in the composition of terpene metabolites. However, some studies document reproducible terpene and cannabinoid profiles over different batches of cannabis with standardized environmental conditions and genetic background (Fischedick et al., 2010; Elzinga et al., 2015). Based on those findings, a consistent and reliable terpene profile can be achievable through standardization protocols.

The variability in terpene profiles can originate from different genetic backgrounds of plant materials, different environmental factors, and different handling procedures. Romano and Hazekamp (2013) demonstrated the importance of the application of a standardized extraction method for quantification of the terpene composition in cannabis. In their study, the authors compared several extraction protocols commonly used in the cannabis industry. They also studied the effects of preheating treatments of the starting material that can cause terpene loss by degradation or evaporation. 
Other caveats in the analysis of terpene profile, like lack of reliable standards, can also contribute to the large observed variance (Ross and ElSohly, 1996; Booth and Bohlmann, 2019). A recent review paper published by Micalizzi et al. (2021) summarized the current analytical approaches used for cannabinoid and terpene characterization. Both GC and high-performance liquid chromotography methods were applied to the analysis of cannabinoid, whereas terpene compounds were quantified by using GC techniques because of their volatile character. Interestingly, Bakro et al. (2020) recently reported the development and validation of an innovative analytical procedure capable of determining CBD and terpene content simultaneously by using a fast gas chromatography-flame ionization detection method. Several GC/MS techniques for terpene quantification described in this review article (Micalizzi et al., 2021) showed strong performance characteristics, such as excellent limits of detection and quantitation and high accuracy, selectivity, and precision. In rigorous analytical methods, the average recoveries of terpenes were over $95 \%$, with less than a $0.2-0.3 \mu \mathrm{g} / \mathrm{ml}$ limit of detection. However, several papers in the literature can be found without validation of analytical process, which could result in unreliable data. To increase the reproducibility of terpene profile analysis, rigorous studies need to be performed analyzing terpenes in plant materials produced under controlled environmental conditions, harvested in certain developmental stages, and analyzed using validated and standardized analytical methods (Giese et al., 2015; Ibrahim et al., 2019). Consistent cultivation and handling conditions must be applied to all plant materials used for medicinal purposes. Understanding the real value of cannabis terpenes requires standardization procedures including quantification of chemical compounds and a consistent chemical profile, accompanied with validated analytical methods. Without those rigorous chemical data the pharmacological results of cannabis products are not comparable and cannot be critically evaluated.

\section{Molecular Targets of Terpenes from C. sativa and Preclinical Studies}

Naturally occurring terpenes, including those in $C$. sativa, number in the hundreds, yet most of their pharmacology and signaling properties are poorly understood. Cannabis terpenes are reported to nonselectively target several G-protein-coupled receptors (GPCRs) (e.g., opioid receptors, CB1/2 receptors, G-proteincoupled receptor 55, dopamine, muscarinic, adrenergic, adenosine, etc.) and ion channels [e.g., transient receptor potential (TRPs), $N$-methyl-D-aspartate (NMDA), $\alpha$-amino-3-hydroxy-5-methyl-4-isoxazoleproprionic acid (AMPA), kainate, nicotinic, potassium] to exert their pharmacological activities [summarized in Fig. 2; for a full review, see Russo and Marcu (2017)]. Although multiple receptor types can be implicated, terpenes can activate anti- or proinflammatory pathways that can contribute to or reduce synaptic relay of nociceptive transmission (Russo and Marcu, 2017). Given the importance of target identification for understanding therapeutic efficacy, and reports of terpene-mediated relief in preclinical pain models, this section discusses known and recently identified molecular targets, preclinical studies, structure-activity relationships, and pharmacology of frequently observed cannabis monoterpenes and sesquiterpenes. Pharmacological and signaling properties of select cannabis terpenes are discussed below and summarized in Table 1.

\section{A. Monoterpenes with Analgesic and Anti-Inflammatory Activities}

1. Limonene. Limonene is a cyclic monoterpene commonly found in a large variety of different Citrus species and is a minor terpene component in several C. sativa chemovars. It has been widely studied and reported to have strong anxiolytic and anti-inflammatory activities. However, very limited information is available about its antinociceptive effects in various pain models.

When prophylactically used against chemical irritant-induced pain, limonene appears to be an effective analgesic. At doses of $50 \mathrm{mg} / \mathrm{kg}$ or greater, via oral or intraperitoneal administration, limonene was effective at blocking formalin-induced pain behaviors (do Amaral et al., 2007; Amorim et al., 2016) as well as mechanical allodynia and thermal hyperalgesia associated with acidic saline-induced muscle pain (Araújo-Filho et al., 2017). Complexing limonene to $\beta$-cyclodextrin, enhancing bioavailability, further increased its antinociceptive activity (Araújo-Filho et al., 2017). Furthermore, intraperitoneal injection of $5 \mathrm{mmol}$ limonene effectively blocked pain in the $\mathrm{H}_{2} \mathrm{O}_{2}$ model (Kaimoto et al., 2016). Of note, although intraperitoneal limonene was effective in the $\mathrm{H}_{2} \mathrm{O}_{2}$ pain model, the authors found that $5 \mathrm{mmol}$ limonene injected into the paw resulted in a significant pain response on its own, thus characterizing limonene as both a nociceptive and antinociceptive agent, at least at the dose and route used (Kaimoto et al., 2016).

The testing of limonene in neuropathic models of pain has been limited. One study utilizing the sciatic nerve ligation (SNL) model demonstrated that limonene was moderately effective at reducing mechanical allodynia but ineffective at blocking cold allodynia at $10 \mathrm{mg} / \mathrm{kg}$ by the oral route (Piccinelli et al., 2015); this could be ascribed to the lower dose used versus other studies. A second study using an identical dose and route found limonene to be effective against gp120-induced mechanical allodynia (a model for human immunodeficiency virus pain), an effect attributed to reductions in TNF- $\alpha$ and IL- $1 \beta$ (Piccinelli et al., 2017). Indeed, these authors determined limonene to 


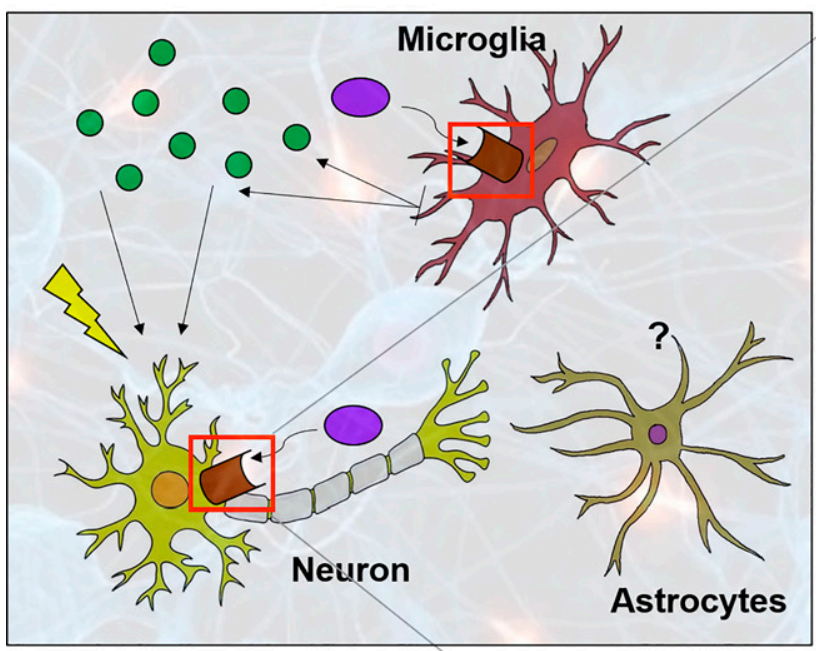

- Terpene

$\square$ - Receptor or ion channel

Pro-inflammatory cytokines or inflammatory modulators

Firing or depolarization of neurons

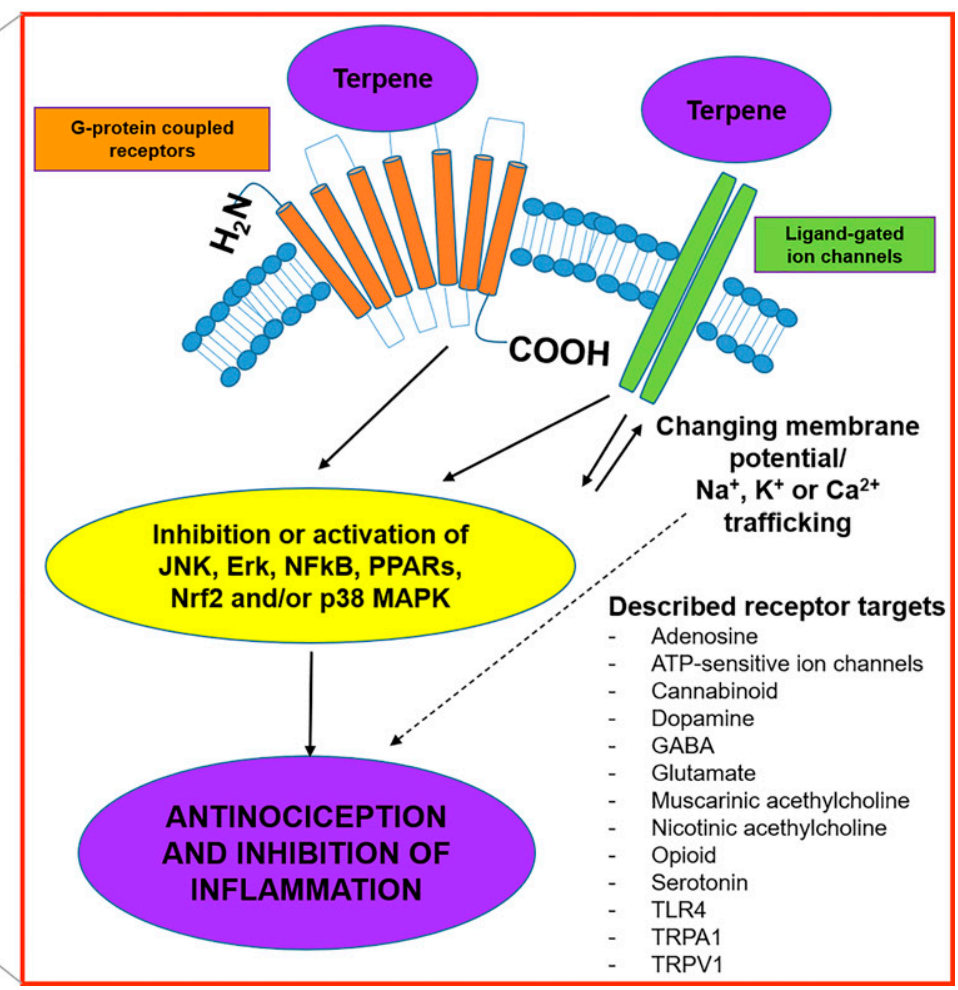

Fig. 2. Molecular targets and signaling molecules implicated in terpene signaling. Cannabis terpenes are reported to nonselectively target several GPCRs (e.g., opioid receptors, CB1/2 receptors, G-protein-coupled receptor 55, dopamine, muscarinic, adrenergic, adenosine, etc.) and ion channels (e.g., TRPs, NMDA, AMPA, kainate, nicotinic, potassium). Terpenes simultaneously activate anti-inflammatory pathways to suppress proinflammatory cytokine production and reduce synaptic relay of nociceptive transmission.

be effective against pain produced by direct intrathecal injection of TNF- $\alpha$ and IL- $1 \beta$ as well.

Although positive results came from limited studies on limonene in several chemically induced pain models and neuropathic models, the results on thermal nociception using the hot-plate method are not as promising. Limonene was ineffective in the hot-plate method after topical administration (Huang et al., 2019), although it should be noted that the dosing was quite low. When used systemically at doses that effectively blocked other pain behaviors described above, limonene was not antinociceptive in the hotplate assay and trended toward increasing sensitivity (do Amaral et al., 2007). These results suggest some ambiguity in the literature on whether limonene is an effective antinociceptive compound, perhaps only in certain models. The nociceptive (Kaimoto et al., 2016), and potential nociceptive (do Amaral et al., 2007), properties of limonene described should also be considered during future studies. Alternatively, limonene may not have effect in nociceptive pain, as these hot-plate studies were performed in uninjured animals, whereas the chemical and injury models tested above all contain a significant inflammatory component. Kim et al. (2013) have studied essential oil from fingered citron (Citrus media L. var sarcodactylis), which contains limonene $(52.44 \%)$ as a major constituent. In line with previous findings showing anti-inflammatory properties for this terpene in vivo, the extract inhibited NO, $\mathrm{PGE}_{2}, \mathrm{TNF}-\alpha$, IL- $1 \beta$, and IL- 6 production and blocked JNK, ERK, and NF- $\kappa$ B signaling in LPS-challenged RAW 264.7 cells.

In a recent study, de Almeida et al. (2017) tested the anti-inflammatory and antinociceptive ability of an oxidized limonene derivative, (+)-limonene epoxide, and suggested a mechanism of action. Antinociceptive effects were evaluated by the writhing test induced by acetic acid, formalin, and hot-plate assays, and they also investigated the involvement of the opioid pathways. Animals pretreated with (+)-limonene epoxide showed dose-dependent reductions in carrageenan-induced paw edema, suggesting anti-inflammatory activity. Furthermore, at the highest dose tested ( $75 \mathrm{mg} / \mathrm{kg})$ it reduced histamine, compound $48 /$ 80, prostaglandin $\mathrm{E}_{2}$, and serotonin-induced edema. (+)-Limonene epoxide also reduced migration of leukocytes and neutrophils, vascular permeability, and myeloperoxidase activity, common indicators of local inflammation. When tested for antinociceptive activity, (+)-limonene epoxide reduced pain behaviors after formalin injection, acetic acid-induced writhing, and hot-plate-induced paw licking. The effect on formalin pain behaviors could be partially blocked by the opioid antagonist naloxone but did not completely reduce 
TABLE 1

Summary of the pharmacological properties and preclinical studies of selected Cannabis terpenes

\begin{tabular}{|c|c|c|c|}
\hline Monoterpene & $\begin{array}{c}\text { Proposed Molecular Targets and } \\
\text { Mechanisms }\end{array}$ & Preclinical Models and In Vivo Effects & References \\
\hline Limonene & $\begin{array}{c}\text { - Elevated superoxide dimutase } \\
\text { (SOD) expression } \\
\text { - Inhibition of TNF- } \alpha \text {, IL-1 } \beta \text {, and } \\
\text { IL-10 cytokine production } \\
\text { - Modulation of TRPA1 channel } \\
\text { activity } \\
\text { - Activation of the NO/cGMP } \\
\text { pathway } \\
\text { - Reduced leukocyte and } \\
\text { neutrophil migration, vascular } \\
\text { permeability, and } \\
\text { myeloperoxidase activity }\end{array}$ & $\begin{array}{l}\text { - Dose-dependent, naloxone- } \\
\text { insensitive (occasionally sensitive) } \\
\text { - Acute and chronic } \\
\text { antinociception in various pain } \\
\text { (acetic acid, hot-plate, formalin, } \\
\text { histamine, PGE } \text { PG }_{2} \text { and serotonin) } \\
\text { and anti-inflammatory (SNI, } \\
\text { carrageenan) models } \\
\text { - Anti-hyperalgesic, anti- } \\
\text { inflammatory properties }\end{array}$ & $\begin{array}{l}\text { de Almeida et al., } 2017 \\
\text { do Amaral et al., } 2007 \\
\text { Kaimoto et al., } 2016 \\
\text { Khodabakhsh et al., } 2015 \\
\text { Piccinelli et al., } 2015 \\
\text { Piccinelli et al., } 2017\end{array}$ \\
\hline Terpinene Terpineol & $\begin{array}{l}\text { - Inhibition of NO, } \mathrm{PGE}_{2}, \mathrm{TNF}-\alpha \text {, } \\
\text { IL-1 } \beta \text {, and IL- } 6 \text { production } \\
\text { - Blockage of JNK, Erk, and } \\
\text { NF-kB signaling in LPS- } \\
\text { challenged RAW } 264.7 \text { cells } \\
\text { - Reduced neutrophil and } \\
\text { microglial migration } \\
\text { - Activation of the arginine/SNAP/ } \\
\text { NO/cGMP/K }\end{array}$ & $\begin{array}{c}\text { - Multitargeting, dose-dependent } \\
\text { - Opioid-, ATP-sensitive } \\
\text { potassium channel-, muscarinic } \\
\text { acetylcholine receptor-, nicotinic } \\
\text { acetylcholine receptor-dependent } \\
\text { antinociception } \\
\text { - Acute pain (formalin, glutamate, } \\
\text { writhing, and capsaicin) and } \\
\text { inflammatory (carrageenan and } \\
\text { CCI) models } \\
\text { - Reduced hyperalgesia without } \\
\text { motor impairment }\end{array}$ & $\begin{array}{c}\text { Passos et al., } 2015 \\
\text { de Oliveira et al., } 2012 \\
\text { Kim et al., 2013 } \\
\text { Nogueira et al., } 2014 \\
\text { Quintans-Junior et al., } 2011 \\
\text { Ramalho et al., } 2015 \\
\text { Safaripour et al., } 2018 \\
\text { Soleimani et al., } 2019\end{array}$ \\
\hline Pinenes & $\begin{array}{c}\text { - Inhibition of IL- } 6 \text {, TNF- } \alpha \text {, and } \\
\text { NO production } \\
\text { - Suppression of MAPK and } \\
\text { NF- } \kappa \text { B activities in peritoneal } \\
\text { macrophages } \\
\text { - No direct CB } 1 \text { or CB } 2 \text { receptor } \\
\text { activation based on potassium } \\
\text { channel activity measurement }\end{array}$ & $\begin{array}{c}\text { - Dose-dependent } \\
\text { - Naloxone and atropine-sensitive } \\
\text { analgesia } \\
\text { - Various pain models (formalin, } \\
\text { acetic acid, hot-plate, and } \\
\text { tail-flick) } \\
\text { - Anti-inflammatory in LPS and } \\
\text { carrageenan models } \\
\text { - Involvement of the opioid, } \\
\text { cholinergic and possibly the } \\
\text { serotonergic system }\end{array}$ & $\begin{array}{c}\text { Huang et al., } 2019 \\
\text { Khalilzadeh et al., } 2015 \\
\text { Kim et al., } 2015 \\
\text { Liapi et al., } 2007 \\
\text { Martinez et al., } 2009 \\
\text { Popovic et al., } 2014 \\
\text { Santiago et al., } 2019 \\
\text { Sousa et al., } 2008\end{array}$ \\
\hline Linalool & $\begin{array}{c}\text { - Regulation of } \mathrm{K}^{+} \text {, voltage-gated } \\
\mathrm{Na}^{+} \text {, and } \mathrm{Ca}^{2+} \text { channels } \\
\text { - Activation of the Akt signaling } \\
\text { pathway }\end{array}$ & $\begin{array}{c}\text { - Antiallodynic and anti- } \\
\text { hyperalgesic effect in various } \\
\text { acute and chronic pain and } \\
\text { inflammatory models (SNL, } \\
\text { fibromyalgia, glutamate) } \\
\text { - Reduces morphine tolerance and } \\
\text { dependence } \\
\text { - Multiple possible targets and } \\
\text { mechanisms including possible } \\
\text { interactions with the opioid, } \\
\text { dopaminergic, cholinergic, } \\
\text { glutamatergic, cannabinoid, } \\
\text { GABAergic, and adenosine- } \\
\text { receptor systems }\end{array}$ & $\begin{array}{c}\text { Batista et al., } 2008 \\
\text { Berliocchi et al., } 2009 \\
\text { Brum et al., } 2001 \\
\text { Donatello et al., } 2020 \\
\text { Elisabetsky et al., } 1999 \\
\text { Katsuyama et al., 2012, } 2015 \\
\text { Leal-Cardoso et al., } 2010 \\
\text { Li et al., 2020 } \\
\text { Nascimento et al., } 2014 \\
\text { Peana et al., } 2003,2004 \mathrm{a}, \mathrm{b}, \\
2006 \\
\text { Brum et al., } 2001\end{array}$ \\
\hline$\beta$-Myrcene & $\begin{array}{c}\text { - Possible TRPV1 channel } \\
\text { activation }\end{array}$ & $\begin{array}{l}\text { - Naloxone- and yohimbine- } \\
\text { sensitive antinociception } \\
\text { - Acute, neurogenic, and anti- } \\
\text { inflammatory pain models (hot- } \\
\text { plate, carrageenan, PGE }{ }_{2} \text {, } \\
\text { DbcAMP) } \\
\text { - Suggesting the involvement of } \\
\text { the opioid and noradrenergic } \\
\text { systems }\end{array}$ & $\begin{array}{c}\text { Duarte et al., } 1992 \\
\text { Heblinski et al., } 2020 \\
\text { Jansen et al., } 2019 \\
\text { Lorenzetti et al., } 1991 \\
\text { Paula-Freire et al., } 2013 \\
\text { Rao et al., } 1990\end{array}$ \\
\hline Geraniol & $\begin{array}{l}\text { - In SCI model, it increases } \\
\text { NeuN-positive cell count; } \\
\text { suppresses the expression of } \\
\text { GFAP and inducible nitric oxide } \\
\text { synthase; and reduces CD68- } \\
\text { positive cells, TNF- } \alpha \text { level, and } \\
\text { caspase-3 activity and levels of } \\
\text { malondialdehyde and } \\
\text { 3-nitrotyrosine } \\
\text { - Upregulates protein expression } \\
\text { of nuclear factor erythroid } \\
\text { 2-related factor } 2 \text { and heme } \\
\text { oxygenase } 1 \\
\text { - Downregulates protein } \\
\text { expression of the NMDA-1 }\end{array}$ & $\begin{array}{l}\text { - Dose-dependent, antiallodynic, } \\
\text { and anti-hyperalgesic } \\
\text { - Various pain models (writhing, } \\
\text { formalin, and glutamate tests) } \\
\text { - Opioid-dependent mechanism is } \\
\text { unclear; however, it seems to } \\
\text { interact with the GABAergic as } \\
\text { well as the serotonergic systems }\end{array}$ & $\begin{array}{c}\text { Chirumbolo and Bjørklund, } 2017 \\
\text { Hernandez-Leon et al., } 2020 \\
\text { Huang et al., } 2018 \\
\text { La Rocca et al., } 2017 \\
\text { Lei et al., } 2019 \\
\text { Lv et al., } 2017\end{array}$ \\
\hline
\end{tabular}


TABLE 1-Continued

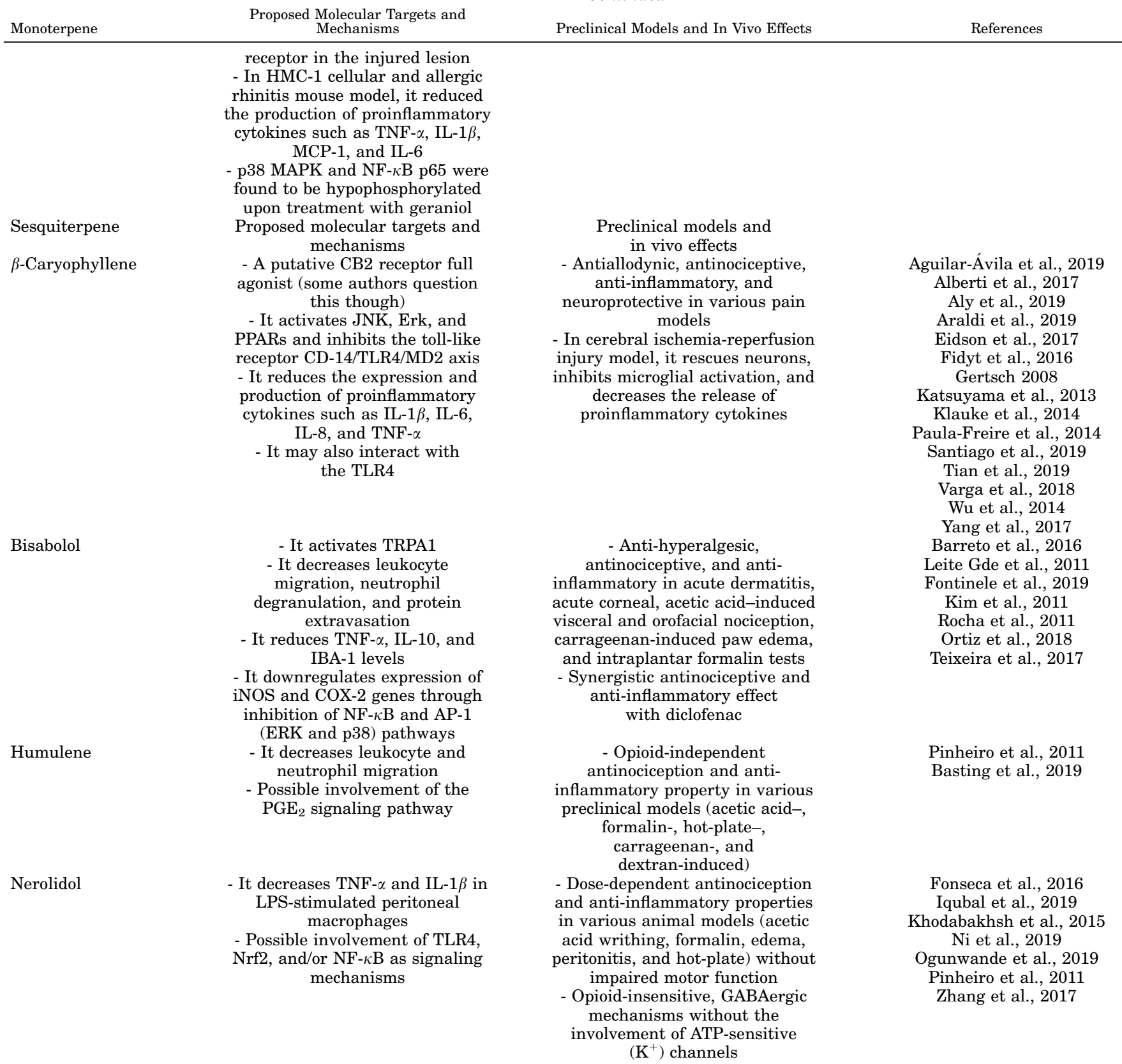

HMC-1, human mast cell line 1; IBA-1, ionized calcium-binding adapter molecule 1; IL-8, interleukin-8; MCP-1, monocyte chemoattractant protein 1; PPAR, peroxisome proliferator-activated receptor.

nociceptive behaviors to vehicle levels. These results indicate the involvement of peripheral and/or central opioid receptors. Of note, although this group observed an effect in hot-plate, and others did not (Huang et al., 2019), this group used the epoxide analog.

The evidence presented to date is quite variable for limonene. It appears that limonene reduces thermal measures of pain such as hot-plate and cold allodynia ineffectively but shows efficacy against inflammatory pain and neuropathic model-induced mechanical allodynia. The evidence for opioid receptor regulation is weak at best; however, there is an alternative hypothesis suggesting limonene regulation of adenosine 2a (A2a) receptors (Park et al., 2011) and $\mathrm{A} 2 \mathrm{a}$ and adenosine $2 \mathrm{~b}$ receptors (Patel et al., 2020), the latter potentially mediating some of its anti-inflammatory actions. Further work should address the nociceptive versus antinociceptive effects of limonene and how the different targets identified may contribute to the overall effect in each model.

2. Terpinene and Terpineol. Terpinenes are cyclic monoterpenes commonly found in Eucalyptus species, as well as minor components in C. sativa. Passos 
et al. (2015) found that $\gamma$-terpinene, which is a terpinene isoform, did not show toxicity at an oral dose of $2 \mathrm{~g} / \mathrm{kg}$ and induced measurable antinociception in formalin, glutamate, and capsaicin-treated animals. To investigate the mechanism of action, animals were also pretreated with the general opioid antagonist naloxone, glibenclamide (ATP-sensitive potassium channel inhibitor), atropine (muscarinic acetylcholine receptor antagonist), or mecamylamine (nonselective, noncompetitive antagonist at the nicotinic acetylcholine receptor). $\gamma$-Terpinene-induced antinociception was inhibited by all these drugs, suggesting multitargeting of various receptors. However, local, spinal, and supraspinal administration of $\gamma$-terpinene also blocked intraplantar glutamate-induced licking, demonstrating a multisite mode of action. In mice, oral pretreatment at doses of $25-50 \mathrm{mg} / \mathrm{kg}$ inhibited inflammation and peritonitis in acetic acid microvascular permeability and carrageenan models (Ramalho et al., 2015). As described above, Kim et al. (2013) showed anti-inflammatory effects with essential oil from fingered citron (C. media L. var sarcodactylis), which also contains $\gamma$-terpinene in a considerable amount ( $28.41 \%)$; thus, it may play a role in reducing inflammation.

$\alpha$-Terpineol, a cyclic monoterpenoid alcohol and a major constituent of tea tree oil (Melaleuca alternifolia), showed significant, dose-dependent antinociception in writhing and capsaicin-induced pain models and non-dose-dependent antinociception in formalin and hot-plate tests (Quintans-Junior et al., 2011). However, another study demonstrated no significant effect in the hot-plate assay up to $40 \mathrm{mg} / \mathrm{kg} \alpha$-terpineol (Parvardeh et al., 2016). $\alpha$-Terpineol (50-100 mg/ $\mathrm{kg}$, i.p.) partially inhibited hyperalgesia produced by intraplantar carrageenan, TNF- $\alpha, \mathrm{PGE}_{2}$, or dopamine (de Oliveira et al., 2012), although in all cases there was no dose dependence to the antinociceptive effect of $\alpha$-terpineol. Two recent in vivo studies investigated the mechanisms by which $\alpha$-terpineol mediates its antinociceptive effects. The first demonstrated that $\alpha$-terpineol can dose-dependently produce antinociception in the formalin model, significantly reducing nociceptive responses at $80 \mathrm{mg} / \mathrm{kg}$ (phase I) and at $40 \mathrm{mg} / \mathrm{kg}$ or $80 \mathrm{mg} / \mathrm{kg}$ (phase II) (Safaripour et al., 2018). Interestingly, the antinociceptive effect produced by $\alpha$-terpineol could be blocked by pretreatment with the nitrogen oxide synthase inhibitor L-NAME, the opioid antagonist naloxone, or the $\mathrm{K}_{\mathrm{ATP}}$ blocker glibenclamide. A partial blockade by the guanylyl cyclase inhibitor methylene blue was also observed. Lastly, pretreatment with the NO precursor L-arginine enhanced the antinociceptive activity of $\alpha$-terpineol, but only during the second phase of the formalin model, which is associated with inflammation. The second paper assessed the mechanisms of $\alpha$-terpineol antinociception in the chronic constriction injury (CCI) model in rats (Soleimani et al., 2019). This group observed a dose-dependent reduction in mechanical allodynia, cold allodynia, and thermal allodynia (Hargreaves test) after $\alpha$-terpineol treatment. These effects appeared to be mediated by $\alpha$-terpineol-mediated reductions in spinal proinflammatory cytokines IL- $1 \beta$ and TNF- $\alpha$ and reduced microglia activation in the spinal cord. Similarly, $\alpha$-terpineol from tea tree oil (M. alternifolia) was shown to produce anti-inflammatory effects in human macrophages exposed to LPS pretreatment through reduction in IL- $1 \beta$ but not TNF- $\alpha$ (Nogueira et al., 2014).

These studies highlight a common multimodal action by certain terpenes, including $\alpha$-terpineol, to elicit antinociception both directly (via opioid receptors or other mechanisms) and indirectly (via decreases in inflammation). It is interesting to note that $\alpha$-terpineol modulation of both pain behaviors and opioid receptors (see Cannabinoid and Terpene Interactions) depend, in part, on the nitrogen oxide synthase system, as L-NAME can mitigate both effects (Parvardeh et al., 2016; Safaripour et al., 2018).

3. Pinenes. $\alpha$-Pinene is a bicyclic monoterpene found in a vast majority of plants in nature. Not many papers have been published so far about the analgesic activity of pure $\alpha$-pinene. However, many studies have investigated the antinociceptive effects of several essential oils that contained this terpene in moderate to high content (up to 15\%-30\%) (Popovic et al., 2014; Khalilzadeh et al., 2015; Huang et al., 2019). In these studies, the oils proved to be antinociceptive, antiedematous, and anti-inflammatory in rat and mouse models. In one of these studies (Khalilzadeh et al., 2015), analgesic effects of the essential oil extract from Vitex agnus-castus (EOVAC) were determined in the tail immersion test, formalin, and acetic acid-induced visceral pain models in rats. EOVAC $(50 \mathrm{mg} / \mathrm{kg}$, s.c.) significantly reduced pain in a naloxone- and atropine-sensitive manner in both formalin and tail immersion tests, and the oil showed no toxicity or mortality at a dose of $5 \mathrm{~g} / \mathrm{kg}$ by the oral route. Their results suggested that the endogenous opioid and cholinergic system may play a role in the antinociceptive effects of EOVAC in these pain models. Care should be taken in interpreting these results because of the complex nature of the oil extracts.

Kim et al. (2015) found that $\alpha$-pinene exhibited anti-inflammatory properties in LPS-treated mouse peritoneal macrophages by inhibiting IL- 6 , TNF- $\alpha$, and NO production and suppressing MAPK and NF$\kappa \mathrm{B}$ activities. In the study by Liapi et al. (2007), $\beta$-pinene, as part of an essential oil of Eucalyptus camaldulensis, displayed supraspinal antinociception and reversed morphine-induced antinociception at a level equal to naloxone in tail-flick and hot-plate tests in rats. However, naloxone showed antinociception as well, confounding the test results. The authors suggested that it probably acts as a partial agonist at the 
$\mu$-opioid receptor. In another work performed by Sousa et al. (2008) using essential oil from dried leaves of Eremanthus erythropappus, of which the main terpene component is $\beta$-pinene (?23\%), the essential oil inhibited nociception in acetic acid-induced writhing, formalin, and hot-plate tests in mice at doses of 200 and $/$ or $400 \mathrm{mg} / \mathrm{kg}$. These doses also inhibited carrageenan-induced paw edema, intrapleural exudate volume, and leukocyte mobilization. These results suggested that $\beta$-pinene is analgesic and anti-inflammatory in the examined models. Similar antinociceptive and anti-inflammatory findings were reported for other $\beta$-pinenecontaining essential oils and Martinez et al. (2009), which further suggested the exclusion or involvement (Martinez et al., 2009) of the opioid and serotonergic systems.

A very recent pinene-related study carried out by Santiago et al. (2019) has reported on the entourage effect of the six most common cannabis terpenes $(\alpha-$ pinene, $\beta$-pinene, $\beta$-caryophyllene, linalool, limonene, and $\beta$-myrcene) using CB1/CB2 receptor expressing AtT20 cells and measuring potassium channel activity. In comparison with the standard cannabinoid $\Delta^{9}$ THC and CP55,940, they found that none of these terpenes changed membrane potential, none directly acted at the $\mathrm{CB} 1$ or $\mathrm{CB} 2$ receptor, and they did not affect desensitization at $30-100 \mu \mathrm{M}$ concentrations. They suggested that if the phytocannabinoid-terpene entourage effect exists, it is probably not regulated at the CB1 or CB2 receptor level for these pinenes or does not involve potassium channels.

4. Linalool. There is significant literature suggesting linalool has uses as an antinociceptive agent. These studies have observed significant effects in multiple modes/models of nociception, including evoked thermal nociception in nave animals (Peana et al., 2003, 2004a, 2006; Tashiro et al., 2016), nocifensive behaviors induced by chemical irritants (Peana et al., 2003, 2004a; Batista et al., 2008; Sakurada et al., 2011; Katsuyama et al., 2015; Tashiro et al., 2016), and hyperalgesic and allodynic responses in inflammatory and neuropathic models (Peana et al., 2004b; Batista et al., 2010; Katsuyama et al., 2012; Kuwahata et al., 2013; Li et al., 2016). Within these studies, a range of routes of administration have been assessed, including systemic (intraperitoneal or subcutaneous) (Batista et al., 2008, 2010; Peana et al., 2003, 2004a,b, 2006), oral (Batista et al., 2008), transdermal (Li et al., 2016), intrathecal (Batista et al., 2008), local (intraplantar) (Batista et al., 2008; Sakurada et al., 2011; Katsuyama et al., 2012, 2015; Kuwahata et al., 2013), and even through inhalation (intranasal) (Tashiro et al., 2016). The compiled literature provides compelling evidence for linalool acting as an antinociceptive compound, albeit with individual variability between studies.
This literature suggests that linalool demonstrates a significant ability to inhibit nociception and that this effect is generally due to peripheral modulation of nociceptors; however, multiple receptor mechanisms and sites of action have been explored. This is partially demonstrated by the antinociceptive capabilities of linalool administered locally into the paw. In this manner, linalool could block formalin-induced pain behaviors (Katsuyama et al., 2015), capsaicin-induced nocifensive behaviors (Sakurada et al., 2011), and even neuropathy-induced mechanical hyperalgesia and allodynia (Katsuyama et al., 2012; Kuwahata et al., 2013). Intraplantar linalool injection was less effective against glutamate-induced pain behaviors (Batista et al., 2008); however, this was likely due to the lower dose used (10-300 ng per paw), compared with the 1-10 $\mu \mathrm{g}$ per paw used in the other studies (Sakurada et al., 2011; Katsuyama et al., 2012, 2015; Kuwahata et al., 2013). Furthermore, in certain studies the antinociceptive activity of linalool was blocked with local and peripherally restricted naloxone (Sakurada et al., 2011; Katsuyama et al., 2012, 2015), further suggesting a significant peripheral mechanism of action involving opioid receptors. In some cases, the anti-hyperalgesic and antinociceptive effects of linalool have been ascribed to its capacity for blocking nitric oxide synthesis and in modulating adenosine (A1a and A2a) receptors (Peana et al., 2006). Others have suggested the involvement of opioid receptors (Peana et al., 2003; Katsuyama et al., 2012; 2015), dopaminergic transmission via D2 receptors, muscarinic M2 receptors, and downstream potassium channel opening (Peana et al., 2004a).

Although most studies have looked at systemic administration or the peripheral actions of linalool, a few have observed centrally mediated antinociception (Batista et al., 2008; Tashiro et al., 2016). The first study found a novel mechanism via inhalation of the linalool. In this study, both the olfactory bulb and hypothalamic orexin neurons were necessary for the antinociception mediated by linalool (Tashiro et al., 2016). Notably, other monoterpenes such as $\beta$-myrcene and $\beta$-pinene were ineffective via inhalation. In the second study, a moderate dose of linalool injected into the intrathecal space blocked intraplantar glutamate-induced pain behaviors (Batista et al., 2008).

Data indicate that linalool may interfere with several relevant elements of glutamatergic transmission, possibly through NMDA receptor interactions (Elisabetsky et al., 1999; Brum et al., 2001; Peana et al., 2004b). It showed a dose-dependent noncompetitive inhibition of $\left[{ }^{3} \mathrm{H}\right] \mathrm{MK} 801$ binding to NMDA receptors and competitive inhibition on glutamate-binding sites; but no effect was observed on $\left[{ }^{3} \mathrm{H}\right]$ muscimol binding on $\mathrm{GABA}_{\mathrm{A}}$ receptors (Brum et al., 2001). Batista et al. (2008) provided experimental evidence indicating that 
linalool generates antinociception against glutamateinduced pain in mice, possibly due to interaction with ionotropic glutamate receptors (i.e., AMPA, NMDA, and kainite).

Berliocchi et al. (2009) found linalool to be a potent antiallodynic agent in the spinal nerve ligation (SNL) model of neuropathic pain after acute and chronic administration. They found increased phospho-Akt levels in linalool-treated SNL animals, whereas no changes or minor changes were detected in SNL-only or sham animals, respectively, suggesting that Akt may play a role in linalool-induced antiallodynic effects in mice. Allodynia is often present with hyperalgesia, and Nascimento et al. (2014) found linalool and its $\beta$-cyclodextrin derivatized analog to be potent antihyperalgesic compounds in a mouse model of chronic noninflammatory muscle pain (fibromyalgia). Based on their immunofluorescence studies performed in specific brain areas of mice treated with the drugs, tramadol, or vehicle, the authors established that the locus coeruleus, nucleus raphe magnus, and the periaqueductal gray areas might be implicated in the anti-hyperalgesic effect of linalool and $\beta$-cyclodextrinlinalool.

Recent studies also indicated that linalool could influence voltage-gated $\mathrm{Na}^{+}$and $\mathrm{Ca}^{2+}$ channels and acts as a concentration-dependent antagonist of $\mathrm{GABA}_{\mathrm{A}}$ channels (Leal-Cardoso et al., 2010; Li et al., 2020). Donatello et al. (2020) found that essential oil from Lavandula angustifolia, which contains up to $30 \%$ linalool, reduced mechanical hyperalgesia in chronic inflammatory and neuropathic pain, which seemed to be mediated via peripheral and central opioid and CB2 receptors.

The antinociceptive properties of linalool likely involve both peripheral and central components. Within these areas, there are likely multiple receptor mechanisms. Reflective of the heterogeneity of targets, it is not surprising linalool is effective in a multitude of pain models. Further work is needed to determine the specific, or nonspecific, mechanisms that linalool utilizes to produce antinociception in a variety of models.

5. $\beta$-Myrcene. $\beta$-Myrcene is a monoterpene composed of two isoprene units and is commonly found in cannabis, hops, (Humulus lupulus), and essential oils of dozens of different aromatic plants. $\beta$-Myrcene has been studied mostly as a component of essential oils derived from a wide variety of plants. The first studies of $\beta$-myrcene in pain are from the early 1990s (Rao et al., 1990; Lorenzetti et al., 1991). The first study determined that $\beta$-myrcene injected intraperitoneally at a dose of $10-20 \mathrm{mg} / \mathrm{kg}$ could cause antinociception in both the hot-plate and writhing test (Rao et al., 1990). The second study expanded upon this, further showing a significant effect in the hot-plate test after oral administration of $90 \mathrm{mg} / \mathrm{kg} \beta$-myrcene as well as demonstrating an effect on writhing due to acetic acid and iloprost at a dose range of $15-405 \mathrm{mg} /$ $\mathrm{kg}$ (oral) (Lorenzetti et al., 1991). This group also used a modified Randall-Selitto to observe hyperalgesia induced by $\mathrm{PGE}_{2}$, isoprenaline, and DbcAMP. $\beta$-Myrcene was effective at blocking the hyperalgesia due to $\mathrm{PGE}_{2}$ and isoprenaline but not DbcAMP (Lorenzetti et al., 1991). Interestingly, in contrast to these data, the nociceptive effect of lower doses of DbcAMP were significantly inhibited by $\beta$-myrcene in the study reported by Duarte et al. (1992). A more recent study has confirmed $\beta$-myrcene's effect in the hot-plate test, as well as finding it antinociceptive in the formalin test (Paula-Freire et al., 2013). $\beta$-Myrcene was also shown to have antiallodynic and anti-hyperalgesic properties in the CCI neuropathic pain model when administered orally at $1-10 \mathrm{mg} / \mathrm{kg}$ over 2 weeks (Paula-Freire et al., 2016). Interestingly, this effect was naloxone-sensitive, similar to the results from Rao et al. (1990).

A recent paper (Jansen et al., 2019) revealed that $\beta$-myrcene can induce calcium influx through the activation of the rat TRPV1 channel, which was inhibited by the TRPV1 antagonist capsazepine. Moreover, $\beta$-myrcene provoked TRPV1 currents in the whole-cell patch-clamp configuration. Molecular docking analysis suggested a noncovalent interaction site between $\beta$-myrcene and TRPV1 and identified partially overlapping binding sites for $\beta$-myrcene and cannabidiol on rat TRPV1. Interestingly, other cannabis terpenes, including $\beta$-caryophyllene, limonene, $\alpha$-bisabolol, linalool, $\alpha$-humulene, pinene, camphene, and ocimene, did not show any effect on the TRPV1 channel; however, nerolidol induced weak TRPV1 activation. These results seem to confirm TRPV1 as a target of $\beta$-myrcene, but Heblinski et al. (2020) failed to repeat the $\beta$-myrcene-induced TRPV1 activation using human TRPV1 channel system. In view of this and the extremely limited number of papers published on the signaling characteristics of $\beta$-myrcene, the pharmacological target(s) of this monoterpene remain elusive.

6. Geraniol. Geraniol is a two-isoprene unit containing a monoterpenoid alcohol. It is a sweet smelling, minor component in Cannabis species and a plethora of other aromatic plants. It has been known to possess analgesic, anticancer, and anti-inflammatory properties (Chirumbolo and Bjørklund, 2017; Lei et al., 2019). A few recent studies have demonstrated that geraniol might be a promising analgesic for certain types of pain, such as the writhing, glutamate, and formalin tests. La Rocca et al. (2017) have recently published that geraniol exerts dose-dependent (12.5-50 mg/kg, i.p.) analgesic activity in writhing, formalin, glutamate, and isolated sciatic nerve models. The analgesic activity of geraniol was not reversible with naloxone $(5 \mathrm{mg} / \mathrm{kg}$, s.c.), suggesting a nonopioid mechanism. They also suggested that geraniol might modulate glutamatergic neurotransmission and 
peripheral nerve excitability and appeared to be more potent in inflammatory pain models.

Very recently, Hernandez-Leon et al. (2020) investigated the antinociceptive and anti-inflammatory properties of Tagetes lucida essential oil, which contains high amounts of geranyl-acetate $(49.9 \%)$, geraniol (7.9\%), and $\beta$-caryophyllene (6.3\%). The essential oil with geranyl-acetate and geraniol as well as purified $\beta$-caryophyllene was tested in a wide concentration range $(0.1-10 \mathrm{mg} / \mathrm{kg}, 3.2-32 \mathrm{mg} / \mathrm{kg}$, and $3.2-10 \mathrm{mg} /$ $\mathrm{kg}$, respectively) in writhing and formalin tests using metamizol $(80 \mathrm{mg} / \mathrm{kg})$, indomethacin $(20 \mathrm{mg} / \mathrm{kg})$, naloxone $(1 \mathrm{mg} / \mathrm{kg})$, flumazenil $(10 \mathrm{mg} / \mathrm{kg})$, WAY100635 ( $N$-[2-[4-(2-methoxyphenyl)-1-piperazinyl]ethyl]- $N$-(2pyridyl)cyclohexanecarboxamide; $0.16 \mathrm{mg} / \mathrm{kg}$ ), or LNAME $(20 \mathrm{mg} / \mathrm{kg})$ as controls in mice or rats. They found dose-dependent antinociceptive responses for both the essential oil and $\beta$-caryophyllene with evidence for opioid, GABAergic, and serotonergic as well as NO-related mechanisms.

The therapeutic effect of geraniol on functional recovery and neuropathic pain in rats with spinal cord injury (SCI) was investigated by $\mathrm{Lv}$ et al. (2017). Treatment of SCI rats with geraniol markedly improved locomotor function and reduced sensitivity to mechanical allodynia and thermal hyperalgesia, as well as increased NeuN-positive cell count, suppressed expression of glial fibrillary acidic protein, and reduced activity of caspase-3 in the injured region. Geraniol treatment in SCI rats also reduced levels of malondialdehyde and 3-nitrotyrosine and upregulated protein expression of nuclear factor erythroid 2-related factor 2 and heme oxygenase 1 . It suppressed expression of inducible nitric oxide synthase, downregulated protein expression of the NMDA-1 receptor, and reduced the number of CD68-positive cells and TNF- $\alpha$ in the injured region. They concluded that geraniol significantly promoted the recovery of neuronal function and attenuated neuropathic pain after SCI in rats.

Huang et al. (2018) recently studied the anti-inflammatory properties of geraniol in human mast cell line 1 cells challenged with the inflammatory phorbolester 12-myristate 13-acetate and A23187 (PMACI) as well as with ovalbumin in allergic rhinitis mice. Inflammatory molecules triggered the massive production of proinflammatory cytokines, such as TNF- $\alpha$, IL$1 \beta$, monocyte chemoattractant protein 1 (or chemokine ligand 2 -CCL2), IL-6, and histamine. Geraniol inhibited TNF- $\alpha$, IL- $1 \beta$, and IL- 6 protein and mRNA expression at concentrations of 40,80 , and $160 \mu \mathrm{M}$. In the ovalbumin-induced allergic rhinitis model, geraniol treatment was able to decrease allergic rhinitis biomarkers (ovalbumin-specific IgE and IL- $1 \beta$ as well as histamine) and nasal rub scores. Interestingly, p38 MAPK was found to be increasingly hypophosphorylated as geraniol dose was increased. A similar tendency was observed in the nuclear level of NF- $\kappa \mathrm{B}$ p65. Their data suggested that geraniol is a potent anti-inflammatory terpene and exerts its anti-inflammatory properties through blocking the MAPK/NF- $\kappa \mathrm{B}$ signaling pathways.

\section{B. Sesquiterpenes with Analgesic and Anti-Inflammatory Activities}

1. $\beta$-Caryophyllene. One of the most abundant terpenes in C. sativa extract is a bicyclic sesquiterpene alkene called $\beta$-caryophyllene (BCP). BCP has been widely studied and highly appreciated for its low toxicity and considerable safety profile (Sharma et al., 2016). It has been reported to target a wide array of molecules and receptors, resulting in anti-inflammatory, anticancer, and antinociceptive properties in different experimental models and diseases (Gertsch et al., 2008; Katsuyama et al., 2013; Klauke et al., 2014; Paula-Freire et al., 2014; Fidyt et al.,2016; Varga et al., 2018). One of its main targets was described to be the CB2 receptor, for which it is thought to act as a full agonist (Gertsch et al., 2008). Interestingly, in a very recent study investigating the entourage effects of different cannabis terpenes, BCP, together with five more terpenes, did not show considerable CB1 or CB2 activities and did not modulate the signaling of the phytocannabinoid agonist $\Delta^{9}$-THC (Santiago et al., 2019). The authors suggested that BCP (and the other terpenes) may activate CB1 and/or CB2 signaling pathways in which potassium channels are not involved, or more likely, BCP interacts with different molecular targets. BCP has also been reported to activate the ERK1/2 and JNK1/2 kinases and the peroxisome proliferator-activated receptors (Wu et al., 2014). $\mathrm{BCP}$ has also been reported to inhibit the toll-like receptor CD-14/TLR4/MD2 axis, decreasing the expression and production of proinflammatory cytokines such as IL-1 $\beta$, IL-6, interleukin- 8 , and TNF- $\alpha$. These effects have been further demonstrated in recent studies in which BCP has shown neuroprotective effects in in vitro and in vivo models of ischemic stroke and cerebral ischemia-reperfusion injury models by rescuing neurons, inhibiting microglial activation, and decreasing the release of proinflammatory cytokines (Yang et al., 2017; Tian et al., 2019).

BCP has been assessed in a few models of antinociception, including evoked thermal nociception in nave animals (Paula-Freire et al., 2014), nocifensive behaviors induced by acetic acid or capsaicin (Katsuyama et al., 2013; Hernandez-Leon et al., 2020), the formalin inflammatory pain model (Klauke et al., 2014; PaulaFreire et al., 2014; Hernandez-Leon et al., 2020), and multiple models of neuropathy causing allodynia and/ or hyperalgesia (Klauke et al., 2014; Paula-Freire et al., 2014; Segat et al., 2017; Aguilar-Ávila et al., 2019; Aly et al., 2019a). Only one study looked at antinociceptive thresholds to a thermal stimulus in nave 
animals, and in this study, BCP was effective after oral administration at doses from 1 to $10 \mathrm{mg} / \mathrm{kg}$ (Paula-Freire et al., 2014). Writhing behavior was also significantly reduced at a similar dose, $3.16 \mathrm{mg} / \mathrm{kg}$; however, this was via the intraperitoneal route (Hernandez-Leon et al., 2020). After local administration into the plantar surface of the mouse paw $(2.5-18 \mathrm{mg})$, $\mathrm{BCP}$ was able to significantly reduce biting and licking due to capsaicin injection, an effect involving peripheral opioid and cannabinoid receptors (Katsuyama et al., 2013).

The literature on neuropathic models and the formalin model shows mixed results. BCP appears to be effective at blocking mechanical allodynia regardless of the neuropathic model tested. In the paclitaxel-induced neuropathy model (Segat et al., 2017), chronic constriction injury model (Paula-Freire et al., 2014), partial sciatic nerve ligation model (Klauke et al., 2014), diabetic neuropathy (Aguilar-Ávila et al., 2019), and antiviral neuropathy model (Aly et al., 2019), BCP reduced mechanical allodynia to varying degrees. It was also shown to prevent the development of mechanical allodynia in the antiviral neuropathy model (Aly et al., 2019). However, BCP was either ineffective (Segat et al., 2017; Aguilar-Ávila et al., 2019) or weakly attenuated (Klauke et al., 2014; Paula-Freire et al., 2014) thermal hyperalgesia in the models tested.

2. Bisabolol. Bisabolol [ $\alpha-(-)$-bisabolol], also known as levomenol, is a monocyclic sesquiterpene alcohol and a minor terpene component in Cannabis sp. and a major component in chamomile (Matricaria recutita). Since it has been widely used in cosmetic products, it has been tested in many animal models of pain and inflammation. There is moderate to significant evidence that bisabolol acts as an antinociceptive agent. Its activity has been investigated in nave rodents in the hot-plate test (Rocha et al., 2011), in which it was ineffective, but also in models of neuropathic pain (Fontinele et al., 2019; Melo et al., 2019) and chemical irritant-induced (neurogenic or inflammatory) pain (Leite Gde et al., 2011, 2012; Rocha et al., 2011; Barreto et al., 2016; Melo et al., 2017; Ortiz et al., 2018; Fontinele et al., 2019). These studies, interestingly, examined the effect of bisabolol after oral administration at doses around $50 \mathrm{mg} / \mathrm{kg}$ or higher, which showed antinociceptive efficacy.

Although bisabolol displayed significant antinociception in several models of visceral pain (Leite Gde et al., 2011, 2012; Rocha et al., 2011), it displayed no dose-dependent relationship in these effects, suggestive of a nonspecific mechanism. Rocha et al. (2011) proposed an anti-inflammatory mechanism of pain reduction because of its ability to decrease leukocyte migration, neutrophil degranulation, protein extravasation, and the amount of TNF- $\alpha$ in the peritoneal cavity in response to carrageenan administration. In models of neuropathic pain, bisabolol effectively reduced mechanical allodynia (Melo et al., 2019) and cold allodynia (Fontinele et al., 2019). The mechanisms through which bisabolol may act to alleviate pain in these different models has not been thoroughly investigated, although some evidence suggests blockade of voltage-dependent sodium channels (Alves Ade et al., 2020) or TRPA1 antagonism (Melo et al., 2017), as it blocked both formalin- and cinnamaldehyde-induced orofacial pain. Molecular docking of bisabolol further suggested binding to TRPA1 (Melo et al., 2017). This study also found that the analgesic effects of bisabolol were insensitive to opioid, NO synthesis, and $\mathrm{K}_{\mathrm{ATP}}$ blockers.

In a recent study, the effects of an interaction between bisabolol and the nonsteroidal anti-inflammatory drug diclofenac on nociception/inflammation (formalin test), inflammation (carrageenan-induced paw inflammation), and gastric injury in rats were assessed (Ortiz et al., 2018). Combined bisabolol/nonsteroidal anti-inflammatory drug administration resulted in synergistic antinociceptive and anti-inflammatory effects. Importantly, when bisabolol was given together with diclofenac, diclofenac-induced gastric damage was minimal, suggesting a safer, combined therapeutic for inflammatory pain management.

Bisabolol complexed with $\beta$-cyclodextrin was tested in preclinical chronic pain models such as Freund's Complete Adjuvant and partial lesion of the sciatic nerve (Fontinele et al., 2019). Bisabolol and its formulated derivative were tested at $50 \mathrm{mg} / \mathrm{kg}$ (oral) for mechanical and thermal hyperalgesia, muscle strength, and motor coordination in mice. They also measured TNF- $\alpha$, IL-10, and ionized calcium-binding adapter molecule 1 (or AIF-1) levels from mouse spinal cords. Both compounds significantly reduced both types of hyperalgesia, as well as inflammatory cytokine production, and did not change force and motor coordination. Their study also revealed that $\beta$-cyclodextrin formulation enhanced bisabolol therapeutic potency.

Barreto et al. (2016) studied the analgesic and antiinflammatory properties of Stachys lavandulifolia Vahl (Lamiaceae) essential oil, which contains a high amount of bisabolol. Both the essential oil as well as purified bisabolol significantly reduced orofacial nociceptive behavior in mice and exhibited anti-inflammatory properties-namely, reduction of TNF- $\alpha$ and IL- $1 \beta$ levels. In line with these previous findings, Kim et al. (2011) also found strong anti-inflammatory effects for bisabolol. In their study in RAW264.7 macrophages, they observed reduced LPS-induced $\mathrm{NO}, \mathrm{PGE}_{2}, \mathrm{COX}-$ 2, iNOS, AP-1. and NF- $\kappa$ B levels and activities upon bisabolol pretreatment. Their results indicated that bisabolol exerts anti-inflammatory effects by downregulating expression of iNOS and COX-2 genes through inhibition of NF- $\kappa \mathrm{B}$ and AP-1 (ERK and p38 MAPK) pathways. 
3. Humulene. Humulene, otherwise called $\alpha$-humulene or $\alpha$-caryophyllene, is a three-isoprene-uni$\mathrm{t}$-containing monocyclic sesquiterpene, which is one of the most abundant terpenes in Cannabis species as well as in hops (H. lupulus). Interestingly, however, there are no studies that have investigated whether purified humulene is antinociceptive, and very little of its pharmacology is described. One recent exception is Jansen et al. (2019), in which the authors report a lack of interaction with the TRPV1 channel.

Essential oils from various aromatic plant species can contain humulene up to $40 \%$ of their total terpene composition; thus, studies with these oils may provide some potential insight into the role of this terpene. Interestingly, despite the fact that humulene is a major terpene component in cannabis and hops, only a few studies have reported its analgesic and anti-inflammatory properties, and all of them rely on the use of essential oils of various plant species in which humulene is in combination with other terpenes. This by necessity makes it difficult to evaluate the specific role of humulene. One of these studies was performed by Pinheiro et al. (2011) using essential oil of Peperomia serpens; this oil contains humulene at $11.5 \%$, as well as nerolidol $(38.0 \%)$, caryophyllene $(4.0 \%)$, and $\alpha$-eudesmol $(2.7 \%)$. They used rodent models of pain and inflammation, including acetic acid, formalin, and thermal models of nociception and carrageenanand dextran-induced paw edema, croton oil-induced ear edema, as well as rolling and adhesion-induced cell migration by carrageenan models of inflammation. Inflammatory models were used to assess the antinociceptive and anti-inflammatory properties of the essential oil. Oral pretreatment $(62.5-500 \mathrm{mg} / \mathrm{kg})$ with the essential oil significantly reduced writhing and licking behavior; effects were not significantly altered by naloxone administration, suggesting nonopioid mechanisms; notably, the naloxone dose used was low $(0.4 \mathrm{mg} / \mathrm{kg}$, s.c.), making results difficult to interpret. The essential oil inhibited edema formation, leukocyte and neutrophil migration, and rolling and adhesion of leukocytes, revealing strong anti-inflammatory properties.

In a very recent study performed by Basting et al. (2019) using the extract of Pterodon pubescens with the essential oil from Cordia verbenacea, which contain high amounts of humulene, trans-caryophyllene, and geranylgeraniol, the mixture demonstrated synergistic activity in the animal models and proved to be a potent antinociceptive and anti-inflammatory agent. The authors explained their findings, in part, with a reduction of the $\mathrm{PGE}_{2}$ pathway via COX inhibition. Because of its strong antinociceptive and antiinflammatory properties, this cannabis terpene deserves more attention and significantly more in vitro mechanistic and in vivo basic studies to reveal the real profile of this abundant and unique terpene.
4. Nerolidol. Nerolidol, also known as peruviol or penetrol, is an acyclic, three-isoprene unit containing a sesquiterpene alcohol and is present in considerable amounts in C. sativa and in many other aromatic plant species. Nerolidol has been reported to be antinociceptive and anti-inflammatory in various nociceptive and inflammatory animal models that have been described and discussed previously (Pinheiro et al., 2011; Khodabakhsh et al., 2015; Ogunwande et al., 2019). To investigate the mechanisms by which nerolidol exerts antinociceptive and anti-inflammatory actions, Fonseca et al. (2016) conducted animal experiments using mouse models of acetic acid-induced abdominal contractions, formalin- and carrageenan-induced paw edema, hot-plate, and Rotarod tests. Nerolidol was applied in a wide dose range of $200-400 \mathrm{mg} / \mathrm{kg}$ orally, and antinociceptive activity was evaluated. Motor coordination was measured by the Rotarod test. Treatments with nerolidol significantly reduced paw edema, acetic acid-induced abdominal contraction, and licking in the formalin test and did not impair motor function. The antinociceptive activity was suggested to be mediated by opioidinsensitive, GABAergic mechanisms without the involvement of $\mathrm{K}_{\mathrm{ATP}}$ channels. In the model of carrageenan-induced peritonitis, nerolidol reduced the influx of polymorphonuclear cells and the levels of TNF- $\alpha$ and IL- $1 \beta$ in LPS-stimulated peritoneal macrophages, suggesting the suppression of the production of proinflammatory cytokines. Others have also reported anti-inflammatory properties of nerolidol in various acute disease models, proposing the involvement of TLR4, nuclear factor erythroid 2-related factor 2 (Nrf2), and/or NF- $\kappa \mathrm{B}$ as possible signaling mechanisms (Zhang et al., 2017; Iqubal et al., 2019; Ni et al., 2019).

\section{Structure-Activity Relationships of Cannabis Terpenes and Terpene Analogs}

There are surprisingly few papers discussing cannabis terpene structure-activity relationships. Many of the receptor target(s) for terpenes are highly debated. It is thus challenging to directly model terpene-receptor interaction(s). Terpenes are often synthesized from the same or structurally similar precursor molecules, which then undergo specific head-to-tail, head-to-head, or tailto-tail conjugation; cyclization; phosphorylation; dephosphorylation; esterification; etherification; hydroxylation; amidation; or oxidative structural modifications to gain their final three-dimensional structures and thus biologic activities. Consequently, much of what is known about the molecular sites of action and signaling of terpenes comes from in vivo pharmacological approaches.

Designing terpene analogs with improved pharmacological/polypharmacological properties is of interest despite several obstacles. For example, the absence of 
functional groups other than $\mathrm{C}=\mathrm{C}$ double bonds makes isoprene(s) difficult or less attractive as lead compounds for derivatization. Terpenes might undergo oxidative metabolism, which eventually delivers functional groups into the molecule and changes terpene structures, resulting in completely different pharmacological properties (Foster et al., 2019). Despite their lipophilic nature, many terpenes and alkaloids from $C$. sativa possess polarized functional groups, which suggests the existence of specific terpene pharmacophores for target binding (Hanson 2001; Gertsch et al., 2008; Appendino et al., 2011; Fidyt et al., 2016). Thus, increasing terpene enzymatic and chemical stability may yield better derivatives.

To design and synthesize terpene analogs with polypharmacological properties, Chicca et al. (2014) described the functionalization and structural modification of $\beta$-caryophyllene, which resulted in a series of terpene analogs with synergistic, multifunctional properties. Many of their functionalized $\beta$-caryophyllene analogs not only retained CB2 receptor agonism but also reversibly inhibited fatty acid amide hydrolase activity without altering monoacylglycerol lipase and $\alpha, \beta$-hydrolase 6 and 12 functions. Very recently, a systematic review on the structure-activity relationship of essential oils and monoterpenes with antinociceptive properties was described by Assis et al. (2020). Their study summarized and revealed several terpene-receptor interactions, primarily based on docking studies.

Since the CB2 receptor might be implicated in pain and inflammatory diseases, and many cannabis terpenes are thought to target this receptor subtype and its negative allosteric site, Pandey et al. (2020) conducted a computational study. They used receptor modeling, site mapping, docking, molecular dynamics simulations, and binding free energy calculations to predict, characterize, and validate allosteric sites within the complex of the CB2 receptor with bound orthosteric agonist ligand CP55,940 and the putative negative allosteric CB2 modulator trans- $\beta$-caryophyllene. Binding of trans- $\beta$-caryophyllene to an allosteric binding pocket, altered the structure of the CB2-CP55,940 complex. It promoted strong $\pi-\pi$ interactions between Phe(117) and $\operatorname{Trp}(258)$ residues and reduced the binding free energy of CP55,940, confirming that trans- $\beta$-caryophyllene is a potent negative allosteric CB2 modulator. Thus, some terpenes may serve as cannabinoid allosteric modulators, necessitating further investigation into these cannabinoid/terpene interactions.

\section{Cannabinoid and Terpene Interactions}

This section will discuss the literature on whether terpenes modulate the effects of cannabis. Since the main psychoactive component of cannabis is $\Delta^{9}$-THC, primarily acting at the cannabinoid receptors (predominantly CB1), and since CBD is the second most highly occurring cannabinoid in Cannabis species, this discussion will emphasize literature involving terpene interactions with molecular and/or behavioral outcomes of $\Delta^{9}$-THC and CBD. However, discussion on other phytocannabinoid/terpene interactions will occur when literature is available. This overarching concept of terpene and phytocannabinoid(s) interaction is termed the "entourage effect" (Russo, 2019; Worth, 2019), although there are skeptics (Cogan, 2020). The goal of this section is to first describe the entourage effect and then examine the literature on cannabinoid/terpene interactions.

\section{A. Entourage Effect}

The overarching concept of the entourage effect is that the sum of all components within cannabis provides a superior therapeutic than individual components, such as just $\Delta^{9}$-THC. Initial speculation of the entourage effect came after a study found endogenous lipids were able to modulate the activity of an endogenous cannabinoid (Ben-Shabat et al., 1998). Subsequent investigation came in the form of perspective reviews (Russo and McPartland, 2003; Russo, 2011; 2019; Russo and Marcu, 2017), as well as investigating the interactions between different phytocannabinoids, mostly CBD and $\Delta^{9}$-THC (Johnson et al., 2010; Casey et al., 2017; Pamplona et al., 2018). However, more recently, a variety of studies have examined the role of terpenes in phytocannabinoid-mediated antitumor activity (Blasco-Benito et al., 2018), cell cytotoxicity (Namdar et al., 2019), and direct interactions with cannabinoid receptors (Santiago et al., 2019; Finlay et al., 2020). For an extensive review on the entourage effect and phytocannabinoid/terpene interactions, see Russo (2011).

\section{B. $\Delta^{9}$-Tetrahydrocannabinol and Terpene Interactions}

Several studies have attempted to understand whether the activity of $\Delta^{9}$-THC can be affected by terpenes found in Cannabis. These studies used in vitro approaches to examine the possible role of terpenes in CB1- and CB2-mediated potassium current modulation (Santiago et al., 2019) and radioligand binding and cAMP modulation at CB1 and CB2 receptors in human embryonic kidney cells (Finlay et al., 2020). Santiago et al. (2019) determined that $\alpha$-pinene, $\beta$-pinene, $\beta$-caryophyllene, linalool, limonene, and $\beta$-myrcene were not agonists at the CB1 or CB2 receptor when the output was hyperpolarization due to potassium currents. Furthermore, they demonstrated no allosteric activity by any terpene on $\Delta^{9}$-THC or CP55,940 activity. They thus concluded that any possible entourage effect was not dictated by terpene regulation of cannabinoid receptors. Of note, they did not observe any activity at CB2 by $\beta$-caryophyllene, contrary to earlier literature characterizing $\beta$-caryophyllene as a CB2 agonist (Gertsch et al., 2008). 
Finlay et al. (2020) used a similar set of terpenes, minus linalool. This study used radioligand binding and cAMP accumulation to determine whether terpenes bound and/or displayed cAMP inhibition via CB1 or CB2 receptors. In these experiments, in alignment with Santiago et al. (2019), the terpenes displayed no binding or activity at CB1 or CB2. Nor did they act in an allosteric fashion to modulate $\Delta^{9}$-THC. This study also did not detect $\beta$-caryophyllene-mediated activation of the CB2 receptor.

Another interesting study examined how terpenes found in a cannabis extract may modulate the antinociceptive activity of $\Delta^{9}$-THC in rats (Harris et al., 2019). In this study, animals were treated with extract with or without terpenes, $\Delta^{9}$-THC, or the full extract containing $\Delta^{9}$-THC and terpenes and were then tested in hot-plate, tail-flick, and acetic acid writhing assays. Animals treated with $\Delta^{9}$-THC or the full extract containing terpenes and equivalent doses of $\Delta^{9}$ THC had similar profiles of antinociception in all models. The extract containing just terpenes had no effect. The authors suggested that $\Delta^{9}$-THC is driving antinociception of the full extract and that added terpenes did not modify this activity.

These studies suggest that although terpenes may have significant antinociceptive properties (discussed above), it is likely that these properties are not modulated through direct interactions at cannabinoid receptors, nor does it appear they will modify antinociception induced by cannabinoids such as $\Delta^{9}$-THC. However, these studies are limited and do not rule out an interaction definitively. Higher concentrations of terpenes than those used in these studies may be necessary, and likely are, to achieve a significant effect. Overall, the evidence for any interactions between $\Delta^{9}$-THC and terpenes is extremely limited, and of the literature available, there are insufficient data to suggest any meaningful interaction. It is likely that higher doses of terpenes than have been used in these extracts, and the effect of different routes of administration, are needed to determine whether an entourage effect occurs.

\section{Cannabidiol and Terpene Interactions}

The literature on CBD interactions with terpenes is limited. In a meta-analysis investigating the effectiveness of CBD extracts (containing other phytocompounds) versus pure CBD on alleviating childhood seizures, the authors demonstrated potential CBD/ terpene interaction (Pamplona et al., 2018). The CBD extracts were more effective at lower doses than pure CBD in reducing seizure, which was associated with fewer side effects. However, as this was a post hoc analysis, it remains unknown which components of the CBD extract were driving these effects. Most of the studies analyzed came from parental reporting and, thus, specific components within the CBD extracts are unknown, and in one case, the CBD extract was a purified CBD extract containing a 20:1 ratio of CBD:THC and lacking terpenes. At the molecular level, also described in previous sections, one study investigated the effects of CBD and terpene cotreatment on binding and activity of CBD (Finlay et al., 2020). They demonstrated that the terpenes tested had no orthosteric or allosteric interactions when dosed with CBD at the $\mathrm{CB} 1$ or $\mathrm{CB} 2$ receptor, as with their $\Delta^{9}$-THC results; CBD actions are discussed below.

An in vivo study observing the difference between CBD, $\Delta^{9}-\mathrm{THC}$, or a $C$. sativa high-CBD extract (containing other phytocompounds) demonstrated that the antinociceptive properties of the CBD extract were greater than CBD or $\Delta^{9}$-THC alone in a chronic constriction injury model of neuropathic pain (Comelli et al., 2008). Furthermore, combining pure CBD and pure $\Delta^{9}$-THC in a similar ratio to the high-CBD extract could not recapitulate the greater effect of the extract, suggesting other noncannabinoid contributions. They also state that although a single dose of CBD could not alleviate the neuropathic pain, a single dose of the CBD extract could reduce thermal hyperalgesia comparable to $\Delta^{9}$-THC, but data were not provided. The antinociceptive effects of the CBD extract could be blocked with a TRPV1 antagonist but not a CB1 or CB2 antagonist. The authors in Comelli et al. (2008) also accounted for potential pharmacokinetic aspects and observed a significant reduction in cytochrome P450 (2B1/2 isoform) levels after treatment with the high-CBD extract. Treatment with CBD, $\Delta^{9}$ THC, or CBD and $\Delta^{9}$-THC combination caused no change. However, when assessing P-glycoprotein (PGP) inhibition, the CBD extract caused an inhibition identical to pure CBD at equal doses. Thus, CBD appears to be the component of the high-CBD extract modulating P-GP activity, but the mechanism of cytochrome $\mathrm{P} 450$ inhibition is likely an unidentified phytocompound in the high-CBD extract. These data suggest that minor extract components may confer increased benefit compared with the parent CBD and THC compounds, although terpene content in the extracts was not provided.

\section{Terpene Interactions with Other Analgesics}

There have been several studies examining how different terpenes may interact with established analgesics, such as morphine, to modify their analgesic activity and side effect profile. Several studies have shown that linalool can interact with morphine to enhance antinociception against capsaicin (Sakurada et al., 2011) and in mechanical allodynia after a partial sciatic nerve ligation injury (Kuwahata et al., 2013). In Sakurada et al. (2011), the antinociception of intraplantar linalool was enhanced after intraperitoneal or intrathecal morphine treatment. Because the effect was seen with morphine in both routes of administration, this suggests an additivity at 
different targets versus direct localized interactions at the receptor level. However, in Kuwahata et al. (2013), both compounds were injected locally, and the combination displayed an enhanced antiallodynic effect compared with morphine alone. It is noteworthy that the effect of linalool can be blocked, at least partially, by the opioid receptor antagonist naloxone (Sakurada et al., 2011), suggesting a potentially shared mechanism to these effects.

Interestingly, linalool has also been suggested to modulate some of the side effects of morphine, including tolerance and physical dependence determined that linalool dose-dependently blocked the induction of tolerance, when assessed in tail-flick, and physical dependence/withdrawal parameters. However, these effects were only significant at doses $>75 \mathrm{mg} / \mathrm{kg}$ for tolerance and at $100 \mathrm{mg} / \mathrm{kg}$ for physical dependence. Furthermore, treating animals with linalool after they had already been chronically treated with morphine was able to significantly mitigate tolerance and physical dependence at all doses tested. Further studies demonstrated linalool could block conditioned place preference induced by morphine dose-independently (Pourtaqi et al., 2017). In this study, linalool, at doses of $25 \mathrm{mg} / \mathrm{kg}$ and $50 \mathrm{mg} / \mathrm{kg}$, could also block reinstatement of morphine conditioned place preference. A very similar paradigm was explored utilizing $\alpha$-terpineol, which at doses between 5 and $20 \mathrm{mg} / \mathrm{kg}$ was able to block both the induction and expression of morphine dependence (Parvardeh et al., 2016). Only the induction of morphine tolerance, and not the expression, could be blocked by $\alpha$-terpineol in this study. Importantly, $\alpha$-terpineol alone was not antinociceptive in the hot-plate test they used. Although the data are limited to the few studies on terpene/analgesic interactions, there appears to be much interest in further elucidating how these interactions are occurring and whether they are of therapeutic value.

\section{E. Considerations for Interpreting Terpene Findings}

One major difficulty with assessing the function of terpenes in vitro and in vivo is their highly lipophilic nature. Small lipophilic compounds generally have poor selectivity and have a strong propensity to interact and disrupt membranes. Furthermore, endogenous cannabinoid ligands are lipids formed on demand from membrane lipids. It is thus plausible that increasing membrane fluidity shifts the equilibrium to favor active states of GPCRs (Yoshida et al., 2019). Therefore, terpene treatment, as a result of their lipophilic nature, may increase the basal activity of receptors in general. Whether terpene interactions occur on-target, synergistically at other targets, or through pharmacokinetics or pharmacodynamics, and whether they are relevant to human cannabis use, is still to be determined.

Although terpenes are typically given at high doses ( $>50 \mathrm{mg} / \mathrm{kg}$, systemic) in the literature and are found at lower concentrations in cannabis flower preparations, there is still precedent for terpene-mediated physiologic outcomes after using cannabis. First, new concentrated preparations of cannabis oil and cannabis tinctures have been able to increase terpene content up to 10-fold over that found in cannabis flower preparations (Sexton et al., 2018). Moreover, these highly concentrated extracts have not been used in the previously discussed literature on the entourage effect. Second, it has recently been appreciated that multifunctional compounds with reduced potency for their multiple targets may confer therapeutic benefit by synergistically acting at multiple sites to produce a much larger on-target therapeutic effect and reduced on-target side effect burden (Pang et al., 2012). Indeed, this approach was used to develop a novel analgesic in phase III clinical trials (Pang et al., 2012). It was demonstrated in previous sections that many of these terpenes do indeed have many modes of action. Thus, in a cannabis preparation containing a dozen terpenes ranging from $0.1 \%$ to $2 \%$ of the total content (see Fig. 2 in Sexton et al. (2018)), it is plausible that a multitarget synergy with main cannabis constituents may indeed occur. However, much more rigorous approaches are needed to determine whether terpene content in cannabis is physiologically relevant beyond a sensory experience for cannabis users.

\section{Therapeutic Potential of Cannabis Terpenes}

Terpenes, as a class of compounds, are generally recognized as safe by the Food and Drug Administration. This means there is long-term scientific evidence for the safety and use of these compounds. This status has allowed terpenes to be extensively used in cosmetics, household cleaning products, and general hygiene products. Thus, toxicity associated with terpenes is relatively low. However, terpenes, including those found in cannabis, have a plethora of indications outside of their analgesic properties, which has been extensively reviewed elsewhere (Russo and Marcu, 2017).

Terpenes and essential oils have been used for their known properties as anxiolytics and antidepressants (Zhang and Yao, 2019; Agatonovic-Kustrin et al., 2020). Lavender, and its major constituent, linalool, have been shown to have significant anxiolytic and sedative effects through multiple mechanisms (Linck et al., 2010; Souto-Maior et al., 2011; Chioca et al., 2013; Harada et al., 2018). Anxiolytic and sedative effects have also been shown utilizing a lemon oil vapor, high in limonene content (Komiya et al., 2006), and after inhalation of $\alpha$-pinene (Satou et al., 2014) or terpinolene (Ito and Ito, 2013). Similarly, $\beta$-myrcene and limonene are highly sedative, both impacting Rotarod performance and increasing barbiturate-induced sleeping time (do Vale et al., 2002). However, the evidence is ambiguous, as another study demonstrated no change in barbiturate-induced sleeping time by 
limonene (do Amaral et al., 2007). $\beta$-Caryophyllene can produce anxiolytic- and antidepressant-like effects in mice as well through a CB2-dependent mechanism (Bahi et al., 2014), which may benefit patients with chronic pain.

There is significant overlap in the therapeutic profile of these terpenes. Many appear to have significant analgesic and anti-inflammatory effects, as described in detail above, as well as sedative-like properties. It is thus likely that although they may induce significant analgesia and anti-inflammatory effects, a significant side effect and potentially confounding variable in these studies will be sedative, anxiolytic, and antidepressive actions. However, it is well understood that pain and depression and anxiety are comorbid disorders that impact how one or the other can develop (de Heer et al., 2014). Therefore, these cognitive side effects described, aside from the analgesic properties of terpenes, may provide an increased therapeutic value.

\section{Pharmacokinetics of Cannabis Terpenes and Impact on Pain Treatment}

The pharmacological effects of terpenes in an intact biologic system, like any drug, are dictated by pharmacokinetic (PK) properties and potential drug-drug interactions. Phytocannabinoids such as $\Delta^{9}$-THC, CBD, and cannabinol are known to inhibit a variety of cytochrome P450 enzymes, including CYP1A/1B1, CYP2D6, CYP2C9, and CYP3A4/5 (Comelli et al., 2008; Yamaori et al., 2010; Cox et al., 2019; Bansal et al., 2020), as well as the drug transporters P-GP and breast cancer resistance protein (Comelli et al., 2008; Tournier et al., 2010). This activity alone can modify the activity of a variety of compounds that are also metabolized or transported by these proteins. Indeed, it has been shown that a variety of terpenes, including those discussed above (terpinolene and $\beta$-pinene), can modulate the transport of digitoxin by P-GP (Yoshida et al., 2006). Other prevalent terpenes found in cannabis ( $\beta$-myrcene, linalool, geraniol, and $\alpha$-pinene) had no effect on P-GP transport (Yoshida et al., 2005, 2006). Although terpinolene and $\beta$-pinene could inhibit P-GP, a follow-up study determined they had no effect on breast cancer resistance protein activity (Yoshida et al., 2008).

These studies highlight the importance of assessing not only the pharmacodynamic interactions that phytocannabinoids and terpenes may have but also PK. These interactions with metabolic and transport enzymes will likely modify the exposure of phytocannabinoids and their metabolites to regions relevant for pain intervention. The PK properties of select terpenes, as reported to date in mouse, rat, or human trials, are reviewed below.

\section{A. Routes of Administration}

The modality of recreational and medicinal cannabis use is variable and directly influences the rate of absorption of components. The pharmacokinetics of THC and CBD after inhalation (smoking, dabbing, and controlled vaporization) oral consumption, buccal, and transdermal are reported and fully reviewed by Gonçalves et al. (2019); a summary is provided below. Like THC and CBD, mono- and sesquiterpenes have poor water solubility and thus limited bioavailability, making dermal and mucosal application favored routes of administration (de Matos et al., 2019), followed by buccal and vaporization. To increase bioavailability, efforts to improve absorption are under investigation. One strategy has been to chemically package terpenes to increase their oral absorption as well as shelf stability (Shi et al., 2016); packaging includes encapsulation by solid nanoparticles (de Matos et al., 2019), nanostructured lipids, and microemulsions (Camargo et al., 2020), to name a few. With increases in bioavailability of terpenes via these methods (Cal, 2006), greater brain uptake and transport across the blood-brain barrier has been observed, which may account for their efficacy against pain and inflammation in some studies discussed above.

\section{B. Pharmacokinetics of Monoterpenes}

1. Limonene. Limonene pharmacokinetics are the most frequently reported of the terpenes and include data from mice, rats, and humans. In mice, limonene was detected in the nanograms-per-milliliter range after both oral and inhaled dosing with a $t_{1 / 2}$ of ?3 hours (oral) and 0.98 hours (inhaled). Peak plasma levels occurred within 30 minutes of dosing for each route. In rats, limonene dosing $(200 \mathrm{mg} / \mathrm{kg})$ orally showed a biphasic kinetic profile with an initial half-life of $34 \mathrm{mi}-$ nutes and a terminal $t_{1 / 2}$ of 280 minutes with $43 \%$ bioavailability (Chen et al., 1998). Tissue distribution of natural limonene in rats mirrored that in mice (Hamada et al., 2002). Comparison of PK parameters after dermal application in rats and humans indicated low absorption of $<12 \%$ and $0.16 \%$, respectively (Hamada et al., 2002). In humans, limonene PK has been largely assessed after dermal application, with one study investigating oral administration. In the latter, limonene absorption and plasma detection were rapid; metabolites were detected within 0.7 hours (Schmidt and Göen 2017). As in rodents, human tissue distribution included the liver, kidney, and blood (Vigushin et al., 1998). These studies evidence the importance of formulation of limonene in microemulsions and nanoparticle preparation to increase brain penetrance and stability of limonene in all species investigated. These formulations are still under investigation for clinical use. 
2. Terpinene/Terpineol. Terpinene/terpineol can result from biotransformation of limonene, pinenes, and geraniol, in addition to natural occurrence (Bicas et al., 2008; Lee et al., 2015; Molina et al., 2019). In rats, an investigation of plasma-to-skin absorption showed minimal distribution of terpinene after intravenous injection (Chooluck et al., 2013). Beyond these studies, however, the PK profiles for terpinene/terpineol are poorly described in vivo using mammalian systems.

3. Pinenes. $\alpha$-Pinenes and $\beta$-pinenes have been investigated minimally in isolation. Two studies in mice indicated that pinenes readily penetrate the brain, with no preference for specific nuclei after inhaled exposure (Satou et al., 2014). Inhalation in human trials showed linear accumulation of $\alpha$-pinene in the lungs (?60\%) with limited urinary excretion; a long half-life of this terpene was attributed to adipose accumulation, expected with lipophilic compounds (Falk et al., 1990). In contrast, oral application in humans revealed a rapid metabolism of the parent compound and excretion of metabolites within 1.5 hours of dosing (Schmidt and Göen, 2017). No studies were identified using nano- or emulsion packaged pinenes in PK analysis.

4. Linalool. Free linalool is reported to have poor bioavailability, with a half-life of 44 minutes after oral administration in rats. Intranasal application of linalool showed rapid onset and absorption in the rodent brain as determined by GC/MS, bypassing the limitations of metabolism and uptake during first pass (Barrera-Sandoval et al., 2019). Full elimination was achieved in the plasma within 70 minutes (Shi et al., 2016). Encapsulation of linalool in nanolipids in this same study increased bioavailability $>350 \%$, with plasma levels above $2000 \mathrm{ng} / \mathrm{ml}$. In a separate study, similar effects were seen when linalool was packed with $\beta$-cyclodextrin and given intragastrically (Camargo et al., 2020).

Human studies of linalool PK have been evaluated after inhalation, intranasal, topical, and oral administration. Plasma levels of linalool in healthy volunteers were lowest after inhalation (average $10 \mathrm{ng} / \mathrm{ml}$, peak: 30 minutes) as compared with dermal application (7-72 ng/ml, 45 minutes) using Headspace solid microextraction (HS-SPME) and headspace (HS) GC/MS (Friedl et al., 2010). Assessment of oral linalool PK in human has been performed as an extract (lavender oil) (Doroshyenko et al., 2013); thus, discrete values for isolated linalool were not obtained.

5. $\beta$-Myrcene. There is limited literature for $\beta$-myrcene PK. The plasma concentration of $\beta$-myrcene after oral administration ( $1 \mathrm{~g} / \mathrm{kg}$ body weight) in rats based upon human dosing (17-70 g), the rodent exposure equivalents was $? 15 \mu \mathrm{g} / \mathrm{ml}$, with an elimination time of 4.5 hours [reviewed by Tisserand and Young (2014)]. In a study conducted by the National Institute of Environmental Health Sciences, $\beta$-myrcene was detected in adipose, brain, liver, kidney, and in the testis. However, studies following other routes of administration are lacking.

6. Geraniol. Geraniol dosed in rats showed pseudo first-order kinetics with a calculated half-life of ?13 minutes after intravenous dosing. Oral dosing with a geraniol emulsion indicated a bioavailability of $92 \%$ with cerebrospinal fluid levels detected in the micrograms-per-milliliter range within 1 hour (Pavan et al., 2018). In the same study, a fiber-adsorbed formulation of geraniol had ?16\% bioavailability after oral dosing. Together, these studies illustrate the benefits of encapsulating terpenes to increase bioavailability. In humans, no pharmacokinetic data for geraniol have been reported.

\section{Pharmacokinetics of Sesquiterpenes}

1. $\beta$-Caryophyllene. Of the sesquiterpenes, $\mathrm{BCP}$ is among the best characterized in terms of bioactivity against pain and inflammation. BCP is acid-sensitive and volatile, as described above, and has low oral bioavailability; thus, encapsulation strategies have been employed. In lower species (i.e., Drosophila melanogaster), BCP has been studied as part of an essential oil application, although this is beyond the scope of the current review (de Oliveira et al., 2019). BCP prepared in $\beta$-cyclodextrin and then dosed orally to rats showed a faster time of onset and higher $C_{\max }$ as compared with free BCP; oral bioavailability was increased 2.6fold. In a separate study, the PK profile of BCP in alcohol was determined in rats and dogs using three formulation approaches. The volumes of distribution of BCP in alcohol in rats and dogs were determined to be high and low, respectively. Oral bioavailability was $<7 \%$ in rats and $<0.5 \%$ in dogs regardless of formulation, indicating species differences (He et al., 2018) in overall adsorption, distribution, metabolism, excretion (ADME) but low uptake overall. In humans, BCP PK has been succinctly reviewed by Santos et al. (2018), which overall suggests low BCP bioavailability and the requirement of formulation to improve its clinical utility.

2. Bisabolol. A search for information of bisabolol PK identified 10 publications, of which one investigated bisabolol uptake alone. This study showed that topical application of bisabolol was enhanced after radiofrequency microporation (Kim et al., 2012). A second study in nude mice using radiolabeled bisabolol (levomenol) showed a topical $t_{1 / 2}$ of approximately 5 hours (Hahn and Hölzl, 1987). Detailed PK analysis of bisabolol is lacking in the current literature.

3. Humulene. Humulene dosed both orally and topically in mice is reported to have rapid absorption ( $<30$ minute) with distribution to the liver, spleen, kidney, heart, and brain (Chaves et al., 2008). Notably, the oral bioavailability of $\alpha$-humulene was nearly 
$18 \%$, despite a very short $t_{1 / 2}$ after oral (16.87 minutes) and intravenous (1.8 minutes) dosing. Elimination of $\alpha$-humulene was achieved within 2 hours of intravenous dosing and 12 hours after oral administration, as reported by Heinlein and Buettner (2012). Identified metabolites of $\alpha$-humulene include $\alpha$-terpineol and linalool, which may account for some bioactivity attributed to humulene (Heinlein and Buettner, 2012).

4. Nerolidol. The PK profile of nerolidol is described in a limited fashion. However, Chan et al. (2016) succinctly reviews what is known, and we refer the reader to their publication. In brief, Chan et al. note, “...the level of nerolidol was observed in the plasma (of BALB/ c mice) with its maximum concentration of ?0.27 \pm 0.07 $\mu \mathrm{g} / \mathrm{mL}$ within $30 \mathrm{~min}$ after oral administration (1000 $\mathrm{mg} / \mathrm{kg}$ ) and remained constant for up to $3 \mathrm{~h}$ after administration, reaching a maximum concentration of ?0.35 $\pm 0.05 \mu \mathrm{g} / \mathrm{mL}$ after $6 \mathrm{~h}$ of administration." The first pass eliminated nearly all nerolidol after oral administration as compared with intraperitoneal, suggesting low oral bioavailability; similar effects were seen in rats and rabbits. Their review includes suggested starting points for clinical trial doses of nerolidol.

\section{Terpenes as Penetration Enhancers}

Much work in the area of PK with terpenes has emphasized their role in increasing uptake of other compounds when administered as a compilation (e.g., essential oil, curated mix) (Yamane et al., 1995). The most frequent use of terpenes as an adjunct is to enhance skin penetration of analgesics (Nokhodchi et al., 2007; Kigasawa et al., 2009; Furuishi et al., 2013; Bektaş et al., 2014) and anti-inflammatory agents (Senyigit et al., 2009); most of the terpenes listed above have been implicated in this approach. For example, limonene and bisabolol have been implicated as enhancers of the antimigraine agent sumatriptan (Femenía-Font et al., 2005). Other examples are the use of bisabolol to increase skin permeance of propranolol (Cui et al., 2011), linalool for naproxen skin penetrance (Guo et al., 2016), and BCP for naproxen skin permeance (Akbari et al., 2015). Given their use as adjuncts for increased drug uptake (Schmitt et al., 2009), it is critical to elucidate the pharmacokinetic profile of isolated terpenes to determine potential negative outcomes or unintended biologic interactions.

\section{E. Terpene Metabolism}

Terpene synthases are responsible for the production of terpenes, including those from cannabis, whereas during administration, terpenes are metabolized by CYP450 enzymes (Chen et al., 2011). Specifically, CYP1A2, CYP2A6, and CYP3A4 have been implicated in the metabolism of mono- and sesquiterpenes (Haigou and Miyazawa, 2012; Lněničková et al., 2018). Notably, CBD is reported to block cytochrome P450 enzymes, as described above. In a separate study, BCP and $\alpha$-humulene inhibited all CYP3A enzymes without blocking carbonyl-reducing enzymes or conjugation enzymes, further suggesting that terpene administration may extend the life of drugs typically metabolized by these enzymes (Nguyen et al., 2017). However, this idea of adverse drug-drug interactions by terpenes was contested by Šadibolová et al. (2019) as 1) IC $_{50}$ values were determined to be in micromolar concentrations for several cytochromes P450, including CYP3A4 and CYP2C; 2) expression changes of these liver enzymes were low or absent after exposure to terpenes; and 3) enzyme activity was impacted $<50 \%$.

After oral administration, $\beta$-myrcene inhibited CYP3A enzymes without increasing liver enzyme expression and induced CYP2A isozymes (Kauderer et al., 1991; Tisserand and Young, 2014). Degradation of $\beta$-myrcene creates mercaptoline and benzenes, as well as linalool. Linalool was well tolerated and did not inhibit or induce CYP1A2, 2C9, 2C19, 2D6, and $3 \mathrm{~A} 4$ in a trial of healthy volunteers in a clinical trial (Doroshyenko et al., 2013). Metabolites of limonene in humans include terpineol, perillic acid, dihydroperillic acid, limonene-1,8-diol, and limonene-1,2 diol.

\section{F. Terpene Excretion}

Given the low rates of absorption and bioavailability of unchanged terpenes, measures of excretion have largely been of terpene emulsions or nanolipids. Terpenes have been found in breath, urine, and fecal samples in studies of elimination depending on the route of administration. For example, limonene excretion is largely renal $(>80 \%)$, with fecal levels under the limit of detection after oral administration (FalkFilipsson et al., 1993; Schmidt and Göen, 2017). Inhaled limonene is excreted unchanged in air, with limited urinary detection $(<0.01 \%)$. Overall, terpenes are primarily eliminated by the liver and kidney.

In summary, the pharmacokinetic profiling of isolated terpenes from cannabis is limited and warrants further investigation given the emerging evidence of bioactivities against pain and inflammation. These studies should incorporate the common routes of administration of cannabis. In addition, PK studies should be performed in the presence of clinically used analgesics to determine drug-drug interactions at both the site of action and in metabolism to elucidate synergistic/entourage effects.

\section{Clinical Evidence for Terpene Efficacy in Pain}

Robust preclinical literature using animal models provides solid evidence that terpene compounds could have efficacy in pain relief as described above. 
However, there is little solid, clinical evidence that these findings in animals translate to humans. Interpretation of clinical studies that have been performed to address this question are hindered by methodological limitations that complicate analysis. Clinical limitations include a small sample size, typically on the order of ?20 participants, with a within-subjects or non-placebo-controlled design. Another significant issue is defining the test compound used in a chemical sense. Several studies use essential oils, which do have a heavy terpene content but also contain other chemical constituents that could contribute to the observed effect. Some of these studies also use an inhalation route of administration, meaning that dose and exposure is not standardized between participants. An exemplar of these limitations is a recent study examining the use of medicinal cannabis among chronic pain, arthritis, and migraine patients. This study found significant strain preferences among the participants for managing their chronic pain, and these strains correlate to specific terpene profiles that differ from the nonpreferred strains. However, these patients used whole plants; thus, the presence of THC, CBD, flavonoids, and other components prevents solid conclusions as to the role of terpenes in this study (Baron et al., 2018).

Despite these limitations, multiple clinical reports support the preclinical evidence and provide a reason to believe that terpenes could promote pain relief in humans. Studies using essential oils from citrus (limonene), lavender (linalool), and rose (geraniol) have been performed. Citrus oil inhalation improved depressive behavior and normalized immune function; such an effect would be expected to provide benefits in pain as a result of the known role of antidepressants in providing pain relief (Komori et al., 1995). Another study found that lavender oil inhalation lessened the use of morphine among patients undergoing gastric banding surgery; this study did use a type of placebo control group using baby oil; however, the lack of scent in this oil would make it not as effective as a placebo (Kim et al., 2007). Another placebo-controlled study showed that rose oil reduced pain in migraine patients, although notably, only in the "hot" symptom cluster group (Niazi et al., 2017). Lavender oil showed greater improvements than orthotics or placebo in a trial of carpal tunnel syndrome (Eftekharsadat et al., 2018). Rose oil inhalation also showed significant improvements for labor pain in pregnant women (Hamdamian et al., 2018); this observation was replicated in a group of Thai women undergoing labor. Related to labor pain, both rose and lavender oils reduced anxiety and pain in women after C-section surgery (Abbasijahromi et al., 2020). This same type of rose oil was also effective in reducing pain and anxiety in burn patients, which synergized with the Benson relaxation technique (Daneshpajooh et al., 2019). Lavender oil further reduced pain for vascular access in hemodialysis patients as well as dental anxiety and pain in children (Taşan et al., 2019; Arslan et al., 2020).

These studies are limited, as described above, because of the general use of the inhalation route and the presence of multiple terpenes and other constituents in the essential oils. However, they also show surprising efficacy across multiple patient populations, pain types, and modalities of both pain and anxiety. Thus, the potential efficacy to these essential oil preparations for controlling pain is notable; given that terpenes are heavy constituents in these essential oils, they may play a role in the observed pain relief. One caution however is that it is very difficult to effectively design placebo controls for these studies. By their nature, terpenes have a strong scent, which will be missing from carrier oil vehicles and similar placebo controls. This sensory experience can further contribute to the well known efficacy of placebo treatments in pain, abetted by potential psychologic/cognitive effects of the sensory experience. Well controlled studies, perhaps using synthetic nonterpene sources of scent, will be needed to untangle these effects. Little has been reported on studies with a null result, although there is a well known bias against the publication of negative findings. Essential oils in pain are further reviewed elsewhere (de Cássia da Silveira E Sá et al., 2017).

There have also been studies performed with defined terpenes and routes of administration. The synthetic terpenoid epomediol was given by infusion (400-600 mg/day, i.v.) to patients with chronic hepatopathy, which resulted in improvements to both pain symptoms and liver function (Mazzeo et al., 1988). Daily oral administration of $900 \mathrm{mg}$ of sobrerol, an oxidation product of pinene, improved headache over placebo in patients with chronic rhinosinusitis, although this could have been secondary to mucolytic properties (Bellussi et al., 1990). The diterpene ginkgolide B $(60 \mathrm{mg}$, oral) was shown to reduce or even eliminate the pain phase in patients with migraine aura (Allais et al., 2013). Although less defined than the above studies, a polyterpene extract was shown to reduce pain in patients with peripheral diabetic neuropathy (Semprini et al., 2018). A small number of mutually reinforcing clinical studies suggest that terpenes can manage chronic prostatitis/chronic pelvic pain syndrome. The defined terpene blend Rowatinex (200 mg, oral, three times per day) was shown to produce greater pain relief than ibuprofen in men with this condition (Lee et al., 2006). A similar result was found using an essential oil, which produced greater relief than placebo (Ying et al., 2019). A more extensive review of various phytotherapies for this 
condition can be found in $\mathrm{Hu}$ et al. (2019). These studies using defined terpenes or terpene blends provide further support that terpene compounds have potential as a pain management strategy in humans.

Overall, the clinical evidence, although limited, is suggestive that terpene compounds can produce pain relief in humans. This hypothesis is strengthened by the preclinical evidence reviewed above. Together, the available evidence suggests that terpene compounds must be tested in rigorously designed clinical trials. Defined terpenes with defined doses and routes of administration must be tested in placebo-controlled randomized trials to fully test whether these compounds could be effective nonopioid, noncannabinoid pain therapies.

\section{Conclusions and Further Research}

The current opioid epidemic and recent statistics from the World Health Organization have provided clear evidence that pain is a significant public health concern and burden in the United States; worldwide statistics, unfortunately, show similar trends. Pain is a prominent and complex symptom of many underlying diseases and disorders. Chronic and cancer-related pain are two of the most common and main reasons for adults to seek medical care, and each have been linked to restrictions in daily activities and reduced quality of life. Despite the severity and high prevalence of such pain-related disorders, their effective clinical management is still a challenge. Current opioid-based analgesics are poorly efficacious for chronic and cancer-related pain and are often accompanied by serious side effects such as tolerance, dependence, and respiratory depression. Although scientists have made considerable efforts and progress in recent years to clarify and better understand cellular-, signaling- and network-level mechanisms of pain, which have suggested new and alternative targets for pain management, these results have not yet yielded improved pain therapies and approaches.

Cannabis species have been used to treat various conditions in traditional medicine for thousands of years. Modern clinical trials and studies have confirmed its efficacy for many different disorders, including pain. The recent legislation decriminalizing use of medical and/or recreational marijuana in many states within the United States, and with the widespread availability and popularity of cannabis extracts, oils, and other related products, has increased the utility of cannabis as a possible alternative medication and source of valuable compounds and drug candidates. Although its two most abundant, widely studied, and clinically important constituents are $\Delta^{9}$-THC and CBD, Cannabis sp. contains hundreds of different mono- and sesquiterpenes, many of which have been demonstrated to possess anticancer, anti-inflammatory, or antimicrobial effects in various experimental models. Many of its terpenes have already been suggested to be adjunctive medications for different pain conditions and diseases. However, the pharmacology (PK/Pharmacodynamics-PD), signaling properties, analgesic efficacies, and interactions with opioids or other pain medications of cannabis terpenes remain poorly explored. Despite a limited base of knowledge, even a quick search of the World Wide Web suggests that users are looking for chemovars with select THC/CBD/terpene profiles, underscoring the need to determine the value of these terpenes in cannabis-mediated pain relief.

Although many cannabis terpenes or terpenoids showed analgesic activity in various preclinical models as part of essential oils from different plant sources, the relative lack of pain-related studies with purified terpenes compels in-depth investigations. Although a small number of promising clinical studies, mostly with essential oils or terpene mixtures, suggest that cannabis terpenes and terpenoids could produce effective pain relief in patients with cancer, migraine, arthritis, neuropathic, or other types of pain, possibly either alone or together with opioids in a synergistic manner, future studies should encompass basic research, preclinical, and clinical trials to determine the short and long-term therapeutic benefits of cannabis terpenes. Moreover, these future studies will need to consider appropriate placebos that account for odor and include the psychologic component of terpene-mediated outcomes. Overall, cannabis terpenes have a high potential for pain management, alone or as adjunctive therapeutics, and are attractive compounds for the development of terpene-based analgesics given their generally-recognized-as-safe status with low side effect and toxicity profiles.

\section{Authorship Contributions \\ Wrote or contributed to the writing of the manuscript: Liktor- Busa, Keresztes, LaVigne, Streicher, Largent-Milnes.}

\section{References}

Abbasijahromi A, Hojati H, Nikooei S, Jahromi HK, Dowlatkhah HR, Zarean V, Farzaneh M, and Kalavani A (2020) Compare the effect of aromatherapy using lavender and Damask rose essential oils on the level of anxiety and severity of pain following C-section: A double-blinded randomized clinical trial. $J$ Complement Integr Med 17. https://doi.org/10.1515/jcim-2019-0141.

Agatonovic-Kustrin S, Kustrin E, Gegechkori V, and Morton DW (2020) Anxiolytic terpenoids and aromatherapy for anxiety and depression. Adv Exp Med Biol 1260:283-296

Aguilar-Ávila DS, Flores-Soto ME, Tapia-Vázquez C, Pastor-Zarandona OA, LópezRoa RI, and Viveros-Paredes JM (2019) $\beta$-Caryophyllene, a natural sesquiterpene attenuates neuropathic pain and depressive-like behavior in experimental diabetic mice. J Med Food 22:460-468.

Aizpurua-Olaizola O, Soydaner U, Öztürk E, Schibano D, Simsir Y, Navarro P, Etxebarria N, and Usobiaga A (2016) Evolution of the cannabinoid and terpene content during the growth of cannabis sativa plants from different chemotypes. J Nat Prod 79:324-331.

Akbari J, Saeedi M, Farzin D, Morteza-Semnani K, and Esmaili Z (2015) Transdermal absorption enhancing effect of the essential oil of Rosmarinus officinalis on percutaneous absorption of $\mathrm{Na}$ diclofenac from topical gel. Pharm Biol 53:1442-1447.

Alberti TB, Barbosa WL, Vieira JL, Raposo NR, and Dutra RC (2017) (-)- $\beta$-Caryophyllene, a CB2 receptor-selective phytocannabinoid, suppresses motor paralysis and neuroinflammation in a murine model of multiple sclerosis. Int J Mol Sci 18:691.

Allais G, D'Andrea G, Maggio M, and Benedetto C (2013) The efficacy of ginkgolide $\mathrm{B}$ in the acute treatment of migraine aura: an open preliminary trial. Neurol Sci 34 (Suppl 1):S161-S163. 
Allen KD, McKernan K, Pauli C, Roe J, Torres A, and Gaudino R (2019) Genomic characterization of the complete terpene synthase gene family from Cannabis sativa. PLoS One 14:e0222363.

Alves P, Amaral C, Teixeira N, and Correia-da-Silva G (2020) Cannabis sativa: much more beyond $\Delta^{9}$-tetrahydrocannabinol. Pharmacol Res 157:104822.

Aly E, Khajah MA, and Masocha W (2019) $\beta$-Caryophyllene, a CB2-receptorselective phytocannabinoid, suppresses mechanical allodynia in a mouse model of antiretroviral-induced neuropathic pain. Molecules 25:106.

Amorim JL, Simas DL, Pinheiro MM, Moreno DS, Alviano CS, da Silva AJ, and Fernandes PD (2016) Anti-inflammatory properties and chemical characterization of the essential oils of four citrus species. PLoS One 11:e0153643.

Andre CM, Hausman JF, and Guerriero G (2016) Cannabis sativa: the plant of the thousand and one molecules. Front Plant Sci 7:19.

Appendino G, Chianese G, and Taglialatela-Scafati O (2011) Cannabinoids: occurrence and medicinal chemistry. Curr Med Chem 18:1085-1099.

Araldi D, Bogen O, Green PG, and Levine JD (2019) Role of nociceptor toll-like receptor 4 (TLR4) in opioid-induced hyperalgesia and hyperalgesic priming. $J$ Neurosci 39:6414-6424.

Araújo-Filho HG, Pereira EWM, Rezende MM, Menezes PP, Araújo AAS, Barreto RSS, Martins AOBPB, Albuquerque TR, Silva BAF, Alcantara IS, et al. (2017) Dlimonene exhibits superior antihyperalgesic effects in a $\beta$-cyclodextrin-complexed form in chronic musculoskeletal pain reducing Fos protein expression on spinal cord in mice. Neuroscience 358:158-169.

Arslan I, Aydinoglu S, and Karan NB (2020) Can lavender oil inhalation help to overcome dental anxiety and pain in children? A randomized clinical trial. Eur $J$ Pediatr 179:985-992.

Assis DB, Aragão Neto HC, da Fonsêca DV, de Andrade HHN, Braga RM, Badr N, Maia MDS, Castro RD, Scotti L, Scotti MT, et al. (2020) Antinociceptive activity of chemical components of essential oils that involves docking studies: a review. Front Pharmacol 11:777.

Aviram J and Samuelly-Leichtag G (2017) Efficacy of cannabis-based medicines for pain management: a systematic review and meta-analysis of randomized controlled trials. Pain Physician 20:E755-E796.

Bahi A, Al Mansouri S, Al Memari E, Al Ameri M, Nurulain SM, and Ojha S (2014) $\beta$-Caryophyllene, a CB2 receptor agonist produces multiple behavioral changes relevant to anxiety and depression in mice. Physiol Behav 135:119-124.

Bakro F, Jedryczka M, Wielgusz K, Sgorbini B, Inchingolo R, and Cardenia V (2020) Simultaneous determination of terpenes and cannabidiol in hemp (Cannabis sativa L.) by fast gas chromatography with flame ionization detection. J Sep Sci 43:2817-2826.

Ballantyne JC, Kalso E, and Stannard C (2016) WHO analgesic ladder: a good concept gone astray. BMJ 352:i20.

Bansal S, Maharao N, Paine MF, and Unadkat JD (2020) Predicting the potential for cannabinoids to precipitate pharmacokinetic drug interactions via reversible inhibition or inactivation of major cytochromes P450. Drug Metab Dispos 48:1008-1017 10.1124/dmd.120.000073.

Baron EP, Lucas P, Eades J, and Hogue O (2018) Patterns of medicinal cannabis use, strain analysis, and substitution effect among patients with migraine, headache, arthritis, and chronic pain in a medicinal cannabis cohort. J Headache Pain 19:37.

Barrera-Sandoval AM, Osorio E, and Cardona-Gómez GP (2019) Microglial-targeting induced by intranasal linalool during neurological protection postischemia. Eur $J$ Pharmacol 857:172420

Barreto RSS, Quintans JSS, Amarante RKL, Nascimento TS, Amarante RS, Barreto AS, Pereira EWM, Duarte MC, Coutinho HDM, Menezes IRA et al. (2016) Evidence for the involvement of TNF- $\alpha$ and IL-1 $\beta$ in the antinociceptive and anti-inflammatory activity of Stachys lavandulifolia Vahl. (Lamiaceae) essential oil and (-)- $\alpha$-bisabolol, its main compound, in mice. $J$ Ethnopharmacol 191:9-18.

Basting RT, Spindola HM, Sousa IMO, Queiroz NCA, Trigo JR, de Carvalho JE, and Foglio MA (2019) Pterodon pubescens and Cordia verbenacea association promotes a synergistic response in antinociceptive model and improves the antiinflammatory results in animal models. Biomed Pharmacother 112:108693.

Batista PA, Werner MF, Oliveira EC, Burgos L, Pereira P, Brum LF, and Santos AR (2008) Evidence for the involvement of ionotropic glutamatergic receptors on the antinociceptive effect of (-)-linalool in mice. Neurosci Lett 440:299-303.

Batista PA, Werner MF, Oliveira EC, Burgos L, Pereira P, Brum LF, Story GM, and Santos AR (2010) The antinociceptive effect of (-)-linalool in models of chronic inflammatory and neuropathic hypersensitivity in mice. J Pain 11:1222-1229.

Bektaş A, Cevher E, Güngör S, and Ozsoy Y (2014) Design and evaluation of polysaccharide-based transdermal films for the controlled delivery of nifedipine. Chem Pharm Bull (Tokyo) 62:144-152.

Bellussi L, Manini G, Buccella MG, and Cacchi R (1990) Evaluation of the efficacy and safety of sobrerol granules in patients suffering from chronic rhinosinusitis. $J$ Int Med Res 18:454-459.

Ben-Shabat S, Fride E, Sheskin T, Tamiri T, Rhee MH, Vogel Z, Bisogno T, De Petrocellis L, Di Marzo V, and Mechoulam R (1998) An entourage effect: inactive endogenous fatty acid glycerol esters enhance 2-arachidonoyl-glycerol cannabinoid activity. Eur $J$ Pharmacol 353:23-31.

Berliocchi L, Russo R, Levato A, Fratto V, Bagetta G, Sakurada S, Sakurada T, Mercuri NB, and Corasaniti MT (2009) (-)-Linalool attenuates allodynia in neuropathic pain induced by spinal nerve ligation in c57/bl6 mice. Int Rev Neurobiol 85:221-235.

Bicas JL, Barros FF, Wagner R, Godoy HT, and Pastore GM (2008) Optimization of $\mathrm{R}-(+)$-alpha-terpineol production by the biotransformation of $\mathrm{R}-(+)$-limonene. $J$ Ind Microbiol Biotechnol 35:1061-1070.

Blasco-Benito S, Seijo-Vila M, Caro-Villalobos M, Tundidor I, Andradas C, GarcíaTaboada E, Wade J, Smith S, Guzmán M, Pérez-Gómez E, et al. (2018) Appraising the "entourage effect": Antitumor action of a pure cannabinoid versus a botanical drug preparation in preclinical models of breast cancer. Biochem Pharmacol 157:285-293.

Bonini SA, Premoli M, Tambaro S, Kumar A, Maccarinelli G, Memo M, and Mastinu A (2018) Cannabis sativa: a comprehensive ethnopharmacologica review of a medicinal plant with a long history. J Ethnopharmacol 227:300-315.

Booth JK, Page JE, and Bohlmann J (2017) Terpene synthases from Cannabis sativa. PLoS One 12:e173911.

Booth JK and Bohlmann J (2019) Terpenes in Cannabis sativa - from plant genome to humans. Plant Sci 284:67-72.

Brum LF, Elisabetsky E, and Souza D (2001) Effects of linalool on [(3)H]MK801 and $[(3) \mathrm{H}]$ muscimol binding in mouse cortical membranes. Phytother Res 15:422-425.

Cal K (2006) How does the type of vehicle influence the in vitro skin absorption and elimination kinetics of terpenes? Arch Dermatol Res 297:311-315.

Camargo SF, Medeiros CF, Santos VV, Quintans-Júnior LJ, Azeredo FJ, and Silva DF (2020) Pharmacokinetics and antihypertensive effect of linalool is improved after incorporation in $\beta$-cyclodextrin as a drug delivery system. FASEB J 34:1-1. Capano A, Weaver R, and Burkman E (2020) Evaluation of the effects of CBD hemp extract on opioid use and quality of life indicators in chronic pain patients: a prospective cohort study. Postgrad Med 132:56-61.

Carliner H, Brown QL, Sarvet AL, and Hasin DS (2017) Cannabis use, attitudes, and legal status in the U.S.: a review. Prev Med 104:13-23.

Casano S, Grassi G, Martini V, and Michelozzi M (2011) Variations in terpene profiles of dierent strains of Cannabis sativa L. Acta Hortic (925):115-122.

Casey SL, Atwal N, and Vaughan CW (2017) Cannabis constituent synergy in a mouse neuropathic pain model. Pain 158:2452-2460.

Chan WK, Tan LT, Chan KG, Lee LH, and Goh BH (2016) Nerolidol: a sesquiterpene alcohol with multi-faceted pharmacological and biological activities. Molecules 21:529.

Chandra S, Lata H, Khan IA, and ElSohly MA (2017) Cannabis sativa L.: Botany and Horticulture, in Cannabis sativa L. - Botany and Biotechnology (Chandra S, Lata H, and ElSohly MA, eds) pp 79-100, Springer.

Chaves JS, Leal PC, Pianowisky L, and Calixto JB (2008) Pharmacokinetics and tissue distribution of the sesquiterpene alpha-humulene in mice. Planta Med 74:1678-1683.

Chen F, Tholl D, Bohlmann J, and Pichersky E (2011) The family of terpene synthases in plants: a mid-size family of genes for specialized metabolism that is highly diversified throughout the kingdom. Plant $J$ 66:212-229.

Chen H, Chan KK, and Budd T (1998) Pharmacokinetics of d-limonene in the rat by GC-MS assay. J Pharm Biomed Anal 17:631-640.

Chicca A, Caprioglio D, Minassi A, Petrucci V, Appendino G, Taglialatela-Scafati O, and Gertsch J (2014) Functionalization of $\beta$-caryophyllene generates nove polypharmacology in the endocannabinoid system. ACS Chem Biol 9:1499-1507.

Chioca LR, Ferro MM, Baretta IP, Oliveira SM, Silva CR, Ferreira J, Losso EM, and Andreatini R (2013) Anxiolytic-like effect of lavender essential oil inhalation in mice: participation of serotonergic but not GABAA/benzodiazepine neurotransmission. J Ethnopharmacol 147:412-418.

Chirumbolo S and Bjørklund G (2017) The antinociceptive activity of geraniol. Basic Clin Pharmacol Toxicol 120:105-107.

Chooluck K, Singh RP, Sathirakul K, and Derendorf H (2013) Plasma and dermal pharmacokinetics of terpinen-4-ol in rats following intravenous administration. Pharmazie 68:135-140.

Cogan PS (2020) The 'entourage effect' or 'hodge-podge hashish': the questionable rebranding, marketing, and expectations of cannabis polypharmacy. Expert Rev Clin Pharmacol 13:835-845, 10.1080/17512433.2020.1721281.

Comelli F, Giagnoni G, Bettoni I, Colleoni M, and Costa B (2008) Antihyperalgesic effect of a Cannabis sativa extract in a rat model of neuropathic pain: mechanisms involved. Phytother Res 22:1017-1024.

Cox EJ, Maharao N, Patilea-Vrana G, Unadkat JD, Rettie AE, McCune JS, and Paine MF (2019) A marijuana-drug interaction primer: precipitants, pharmacology, and pharmacokinetics. Pharmacol Ther 201:25-38.

Cui Y, Li L, Zhang L, Li J, Gu J, Gong H, Guo P, and Tong W (2011) Enhancement and mechanism of transdermal absorption of terpene-induced propranolol hydrochloride. Arch Pharm Res 34:1477-1485.

Dahlhamer J, Lucas J, Zelaya C, Nahin R, Mackey S, DeBar L, Kerns R, Von Korff M, Porter L, and Helmick C (2018) Prevalence of chronic pain and high impact chronic pain among adults - United States, 2016. MMWR Morb Mortal Wkly Rep 67:1001-1006.

Daneshpajooh L, Najafi Ghezeljeh T, and Haghani H (2019) Comparison of the effects of inhalation aromatherapy using Damask Rose aroma and the Benson relaxation technique in burn patients: a randomized clinical trial. Burns 45:1205-1214

Da Porto C, Decorti D, and Natolino A (2014) Ultrasound-assisted extraction of volatile compounds from industrial Cannabis sativa L. inflorescences. Int J Appl Res Nat Prod 7:8-14.

de Almeida AA, Silva RO, Nicolau LA, de Brito TV, de Sousa DP, Barbosa AL, de Freitas RM, Lopes LD, Medeiros JR, and Ferreira PM (2017) Physiopharmacological investigations about the anti-inflammatory and antinociceptive efficacy of (+)-limonene epoxide. Inflammation 40:511-522.

de Cássia da Silveira E Sá R, Lima TC, da Nóbrega FR, de Brito AEM, and de Sousa DP (2017) Analgesic-like activity of essential oil constituents: an update. Int J Mol Sci 18:2392.

de Heer EW, Gerrits MM, Beekman AT, Dekker J, van Marwijk HW, de Waal MW, Spinhoven P, Penninx BW, and van der Feltz-Cornelis CM (2014) The association of depression and anxiety with pain: a study from NESDA. PLoS One 9:e106907. de Matos SP, Teixeira HF, de Lima ÁAN, Veiga-Junior VF, and Koester LS (2019 Essential oils and isolated terpenes in nanosystems designed for topical administration: a review. Biomolecules 9:138.

de Oliveira MG, Marques RB, de Santana MF, Santos AB, Brito FA, Barreto EO, De Sousa DP, Almeida FR, Badauê-Passos Jr D, Antoniolli AR, et al. (2012) 
$\alpha$-terpineol reduces mechanical hypernociception and inflammatory response. Basic Clin Pharmacol Toxicol 111:120-125.

de Oliveira MRC, Barros LM, Duarte AE, Gabriely de Lima Silva M, da Silva BAF, Oliveira Brito Pereira Bezerra A, Oliveira Tintino CDM, Afonso Pereira de Oliveira V, Boligon AA, Kamdem JP, et al. (2019) GC-MS chemical characterization and in vitro evaluation of antioxidant and toxic effects using Drosophila melanogaster model of the essential oil of Lantana montevidensis (Spreng) Briq. Medicina (Kaunas) 55:194.

do Amaral JF, Silva MI, Neto MR, Neto PF, Moura BA, de Melo CT, de Araújo FL, de Sousa DP, de Vasconcelos PF, de Vasconcelos SM, et al. (2007) Antinociceptive effect of the monoterpene R-(+)-limonene in mice. Biol Pharm Bull 30:1217-1220. Donatello NN, Emer AA, Salm DC, Ludtke DD, Bordignon SASR, Ferreira JK Salgado ASI, Venzke D, Bretanha LC, Micke GA, et al. (2020) Lavandula angustifolia essential oil inhalation reduces mechanical hyperalgesia in a model of inflammatory and neuropathic pain: the involvement of opioid and cannabinoid receptors. $J$ Neuroimmunol 340:577145.

Doroshyenko O, Rokitta D, Zadoyan G, Klement S, Schläfke S, Dienel A, Gramatté T, Lück H, and Fuhr U (2013) Drug cocktail interaction study on the effect of the orally administered lavender oil preparation silexan on cytochrome P450 enzymes in healthy volunteers. Drug Metab Dispos 41:987-993.

do Vale TG, Furtado EC, Santos Jr JG, and Viana GS (2002) Central effects of citral, myrcene and limonene, constituents of essential oil chemotypes from Lippia alba (Mill.) n.e. Brown. Phytomedicine 9:709-714.

Duarte IDG, dos Santos IR, Lorenzetti BB, and Ferreira SH (1992) Analgesia by direct antagonism of nociceptor sensitization involves the arginine-nitric oxidecGMP pathway. Eur J Pharmacol 217:225-227.

Eftekharsadat B, Roomizadeh P, Torabi S, Heshmati-Afshar F, Jahanjoo F, and Babaei-Ghazani A (2018) Effectiveness of Lavendula stoechas essential oil in treatment of mild to moderate carpal tunnel syndrome: a randomized controlled trial. J Hand Ther 31:437-442.

Eidson LN, Inoue K, Young LJ, Tansey MG, and Murphy AZ (2017) Toll-like receptor 4 mediates morphine-induced neuroinflammation and tolerance via soluble tumor necrosis factor signaling. Neuropsychopharmacology 42:661-670.

Elisabetsky E, Brum LF, and Souza DO (1999) Anticonvulsant properties of linalool in glutamate-related seizure models. Phytomedicine 6:107-113.

Elzinga S, Fishchedick J, Podkolinski R, and Raber JC (2015) Cannabinoids and terpenes as chemotaxonomic markers in Cannabis. Nat Prod Chem Res 3:4.

Erkelens JL and Hazekamp A (2014) That which we call Indica, by any other name would smell as sweet. Cannabis Cannabinoid Res 9:9-15.

Falk AA, Hagberg MT, Löf AE, Wigaeus-Hjelm EM, and Wang ZP (1990) Uptake, distribution and elimination of alpha-pinene in man after exposure by inhalation. Scand $J$ Work Environ Health 16:372-378.

Falk-Filipsson A, Löf A, Hagberg M, Hjelm EW, and Wang Z (1993) d-limonene exposure to humans by inhalation: uptake, distribution, elimination, and effects on the pulmonary function. J Toxicol Environ Health 38:77-88.

Femenía-Font A, Balaguer-Fernández C, Merino V, Rodilla V, and López-Castellano A (2005) Effect of chemical enhancers on the in vitro percutaneous absorption of sumatriptan succinate. Eur J Pharm Biopharm 61:50-55.

Fidyt K, Fiedorowicz A, Strzadała L, and Szumny A (2016) $\beta$-caryophyllene and $\beta$-caryophyllene oxide-natural compounds of anticancer and analgesic properties. Cancer Med 5:3007-3017.

Finlay DB, Sircombe KJ, Nimick M, Jones C, and Glass M (2020) Terpenoids from cannabis do not mediate an entourage effect by acting at cannabinoid receptors. Front Pharmacol 11:359.

Fischedick JT (2017) Identification of terpenoid chemotypes among high (-)-trans$\Delta^{9}$-tetrahydrocannabinol-producing Cannabis sativa L. cultivars. Cannabis Cannabinoid Res 2:34-47.

Fischedick JT, Hazekamp A, Erkelens T, Choi YH, and Verpoorte R (2010) Metabolic fingerprinting of Cannabis sativa L., cannabinoids and terpenoids for chemotaxonomic and drug standardization purposes. Phytochemistry 71:2058-2073.

Flores-Sanchez IJ and Verpoorte R (2008) Secondary metabolism in Cannabis. Phytochem Rev 7:615-639.

Fonsêca DV, Salgado PR, de Carvalho FL, Salvadori MG, Penha AR, Leite FC, Borges CJ, Piuvezam MR, Pordeus LC, Sousa DP, et al. (2016) Nerolidol exhibits antinociceptive and anti-inflammatory activity: involvement of the GABAergic system and proinflammatory cytokines. Fundam Clin Pharmacol 30:14-22.

Fontinele LL, Heimfarth L, Pereira EWM, Rezende MM, Lima NT, Barbosa Gomes de Carvalho YM, Afonso de Moura Pires E, Guimarães AG, Bezerra Carvalho MT, de Souza Siqueira Barreto R, et al. (2019) Anti-hyperalgesic effect of $(-)$ - $\alpha$-bisabolol and (-)- $\alpha$-bisabolol/ $\beta$-cyclodextrin complex in a chronic inflammatory pain model is associated with reduced reactive gliosis and cytokine modulation. Neurochem Int 131:104530.

Ford TC, Hayley AC, Downey LA, and Parrott AC (2017) Cannabis: an overview of its adverse acute and chronic effects and its implications. Curr Drug Abuse Rev 10:6-18

Foster BC, Abramovici H, and Harris CS (2019) Cannabis and cannabinoids: kinetics and interactions. Am J Med 132:1266-1270.

Friedl SM, Oedendorfer K, Kitzer S, Reznicek G, Sladek G, and Heuberger E (2010) Comparison of liquid-liquid partition, HS-SPME and static HS GC/MS analysis for the quantification of (-)-linalool in human whole blood samples. Nat Prod Commun 5:1447-1452.

Furuishi T, Kato Y, Fukami T, Suzuki T, Endo T, Nagase H, Ueda H, Tomono K (2013) Effect of terpenes on the skin permeation of lomerizine dihydrochloride. $J$ Pharm Pharm Sci 16: 551-563.

Gaskin DJ and Richard P (2012) The economic costs of pain in the United States. $J$ Pain 13:715-724.

Gertsch J (2008) Anti-inflammatory cannabinoids in diet: towards a better understanding of $\mathrm{CB}(2)$ receptor action? Commun Integr Biol 1:26-28.
Gertsch J, Leonti M, Raduner S, Racz I, Chen JZ, Xie XQ, Altmann KH, Karsak M, and Zimmer A (2008) Beta-caryophyllene is a dietary cannabinoid. Proc Nat Acad Sci USA 105:9099-9104.

Gertsch J, Pertwee RG, and Di Marzo V (2010) Phytocannabinoids beyond the Cannabis plant - do they exist? Br J Pharmacol 160:523-529.

Giese MW, Lewis MA, Giese L, and Smith KM (2015) Development and validation of a reliable and robust method for the analysis of cannabinoids and terpenes in Cannabis. J AOAC Int 98:1503-1522.

Gonçalves J, Rosado T, Soares S, Simão AY, Caramelo D, Luís Â, Fernández N, Barroso M, Gallardo E, and Duarte AP (2019) Cannabis and its secondary metabolites: their use as therapeutic drugs, toxicological aspects, and analytical determination. Medicines (Basel) 6:31.

Gunnewich N, Page JE, Köllner TG, Degenhardt J, and Kutchan TM (2007) Functional expression and characterization of trichome-specific (-)-limonene synthase and (+)- $\alpha$-pinene synthase from Cannabis sativa. Nat Prod Commun 2:223-232.

Guo X, Rong Y, Zhang L, and Ye JC (2016) Enhancing effect of chiral enhancer linalool on skin permeation of naproxen. Zhongguo Yi Xue Ke Xue Yuan Xue Bao 38:55-61.

Gureje O, Von Korff M, Simon GE, and Gater R (1998) Persistent pain and wellbeing: a World Health Organization study in primary care. JAMA 280:147-151.

Hahn B and Hölzl J (1987) [Absorption, distribution and metabolism of [14C]levomenol in the skin]. Arzneimittelforschung 37:716-720.

Haigou R and Miyazawa M (2012) Metabolism of (+)-terpinen-4-ol by cytochrome P450 enzymes in human liver microsomes. J Oleo Sci 61:35-43.

Hamada M, Uezu K, Matsushita J, Yamamoto S, and Kishino Y (2002) Distribution and immune responses resulting from oral administration of D-limonene in rats. J Nutr Sci Vitaminol (Tokyo) 48:155-160.

Hamdamian S, Nazarpour S, Simbar M, Hajian S, Mojab F, and Talebi A (2018) Effects of aromatherapy with Rosa damascena on nulliparous women's pain and anxiety of labor during first stage of labor. J Integr Med 16:120-125.

Hanson JR (2001) The development of strategies for terpenoid structure determination. Nat Prod Rep 18:607-617.

Hanuš LO, Meyer SM, Muñoz E, Taglialatela-Scafati O, and Appendino G (2016) Phytocannabinoids: a unified critical inventory. Nat Prod Rep 33:1357-1392.

Harada H, Kashiwadani H, Kanmura Y, and Kuwaki T (2018) Linalool odorinduced anxiolytic effects in mice. Front Behav Neurosci 12:241.

Harris HM, Rousseau MA, Wanas AS, Radwan MM, Caldwell S, Sufka KJ, and ElSohly MA (2019) Role of cannabinoids and terpenes in cannabis-mediated analgesia in rats. Cannabis Cannabinoid Res 4:177-182.

Hazekamp A and Fischedick JT (2012) Cannabis - from cultivar to chemovar. Drug Test Anal 4:660-667.

Hazekamp A, Tejkalová K, and Papadimitriou S (2016) Cannabis: from cultivar to chemovar II-a metabolomics approach to Cannabis classification. Cannabis Cannabinoid Res 1:202-215.

He J, Zhou S, Li X, Wang C, Yu Y, Chen X, and Lu Y (2018) Pharmacokinetic evaluation of $\beta$-caryophyllene alcohol in rats and beagle dogs. Xenobiotica 48:845-850

Heblinski M, Santiago M, Fletcher C, Stuart J, Connor M, McGregor IS, and Arnold JC (2020) Terpenoids commonly found in Cannabis sativa do not modulate the actions of phytocannabinoids or endocannabinoids on TRPA1 and TRPV1 channels. Cannabis Cannabinoid Res 5:305-317, 10.1089/can.2019.0099.

Heinlein A and Buettner A (2012) Monitoring of biotransformation of hop aroma compounds in an in vitro digestion model. Food Funct 3:1059-1067.

Henschke N, Kamper SJ, and Maher CG (2015) The epidemiology and economic consequences of pain. Mayo Clin Proc 90:139-147.

Hernandez-Leon A, González-Trujano ME, Narváez-González F, Pérez-Ortega G, Rivero-Cruz F, and Aguilar MI (2020) Role of $\beta$-caryophyllene in the antinociceptive and anti-inflammatory effects of Tagetes lucida Cav. essential oil. Molecules 25:675.

Hill KP (2015) Medical marijuana for treatment of chronic pain and other medical and psychiatric problems: a clinical review. JAMA 313:2474-2483.

Hillig KW (2004) A chemotaxonomic analysis of terpenoid variation in Cannabis. Biochem Syst Ecol 32:875-891.

Hillig KW and Mahlberg PG (2004) A chemotaxonomic analysis of cannabinoid variation in Cannabis (Cannabaceae). Am J Bot 91:966-975.

Hosseinzadeh H, Imenshahidi M, Hosseini M, and Razavi BM (2012) Effect of linalool on morphine tolerance and dependence in mice. Phytother Res 26:1399-1404.

Hu M, Wazir J, Ullah R, Wang W, Cui X, Tang M, and Zhou X (2019) Phytotherapy and physical therapy in the management of chronic prostatitis-chronic pelvic pain syndrome. Int Urol Nephrol 51:1081-1088.

Huang AC and Osbourn A (2019) Plant terpenes that mediate below-ground interactions: prospects for bioengineering terpenoids for plant protection. Pest Manag Sci 75:2368-2377.

Huang XL, Li XJ, Qin QF, Li YS, Zhang WK, and Tang HB (2019) Antiinflammatory and antinociceptive effects of active ingredients in the essential oils from Gynura procumbens, a traditional medicine and a new and popular food material. J Ethnopharmacol 239:111916.

Huang Y, Yang XL, Ni YH, and Xu ZM (2018) Geraniol suppresses proinflammatory mediators in phorbol 12-myristate 13-acetate with A23187 induced HMC-1 cells. Drug Des Devel Ther 12:2897-2903.

Hussain T, Plunkett B, Ejaz M, Espley RV, and Kayser O (2018) Identification of putative precursor genes for the biosynthesis of cannabinoid-like compound in Radula marginata. Front Plant Sci 9:537.

Ibrahim EA, Wang M, Radwan MM, Wanas AS, Majumdar CG, Avula B, Wang YH Khan IA, Chandra S, Lata H, et al. (2019) Analysis of terpenes in Cannabis sativa L. using GC/MS: method development, validation, and application. Planta Med 85:431-438. 
Iqubal A, Sharma S, Najmi AK, Syed MA, Ali J, Alam MM, and Haque SE (2019) Nerolidol ameliorates cyclophosphamide-induced oxidative stress, neuroinflammation and cognitive dysfunction: plausible role of Nrf2 and NF- $\kappa$ B. Life Sci 236:116867.

Ito $\mathrm{K}$ and Ito $\mathrm{M}$ (2013) The sedative effect of inhaled terpinolene in mice and its structure-activity relationships. J Nat Med 67:833-837.

Jansen C, Shimoda LMN, Kawakami JK, Ang L, Bacani AJ, Baker JD, Badowski C, Speck M, Stokes AJ, Small-Howard AL, et al. (2019) Myrcene and terpene regulation of TRPV1. Channels (Austin) 13:344-366.

Jin D, Jin S, Yu Y, Lee C, and Chen J (2017) Classification of Cannabis cultivars marketed in Canada for medical purposes by quantification of cannabinoids and terpenes using HPLC-DAD and GC-MS. J Anal Bioanal Tech 8:349.

Johnson JR, Burnell-Nugent M, Lossignol D, Ganae-Motan ED, Potts R, and Fallon MT (2010) Multicenter, double-blind, randomized, placebo-controlled, parallel-group study of the efficacy, safety, and tolerability of THC:CBD extract and THC extract in patients with intractable cancer-related pain. $J$ Pain Symptom Manage 39:167-179.

Kaimoto T, Hatakeyama Y, Takahashi K, Imagawa T, Tominaga M, and Ohta T (2016) Involvement of transient receptor potential A1 channel in algesic and analgesic actions of the organic compound limonene. Eur J Pain 20:1155-1165.

Katsuyama S, Kuwahata H, Yagi T, Kishikawa Y, Komatsu T, Sakurada T, and Nakamura H (2012) Intraplantar injection of linalool reduces paclitaxel-induced acute pain in mice. Biomed Res 33:175-181.

Katsuyama S, Mizoguchi H, Kuwahata H, Komatsu T, Nagaoka K, Nakamura H, Bagetta G, Sakurada T, and Sakurada S (2013) Involvement of peripheral cannabinoid and opioid receptors in $\beta$-caryophyllene-induced antinociception. Eur J Pain 17:664-675.

Katsuyama S, Otowa A, Kamio S, Sato K, Yagi T, Kishikawa Y, Komatsu T, Bagetta G, Sakurada T, and Nakamura H (2015) Effect of plantar subcutaneous administration of bergamot essential oil and linalool on formalin-induced nociceptive behavior in mice. Biomed Res 36:47-54.

Kauderer B, Zamith H, Paumgartten FJR, and Speit G (1991) Evaluation of the mutagenicity of $\beta$-myrcene in mammalian cells in vitro. Environ Mol Mutagen 18:28-34.

Khalilzadeh E, Vafaei Saiah G, Hasannejad H, Ghaderi A, Ghaderi S, Hamidian G, Mahmoudi R, Eshgi D, and Zangisheh M (2015) Antinociceptive effects, acute toxicity and chemical composition of Vitex agnus-castus essential oil. Avicenna $J$ Phytomed 5:218-230

Khodabakhsh P, Shafaroodi H, and Asgarpanah J (2015) Analgesic and antiinflammatory activities of Citrus aurantium L. blossoms essential oil (neroli) involvement of the nitric oxide/cyclic-guanosine monophosphate pathway. J Nat Med 69:324-331.

Kigasawa K, Kajimoto K, Watanabe M, Kanamura K, Saito A, and Kogure K (2009) In vivo transdermal delivery of diclofenac by ion-exchange iontophoresis with geraniol. Biol Pharm Bull 32:684-687.

Kim DS, Lee HJ, Jeon YD, Han YH, Kee JY, Kim HJ, Shin HJ, Kang J, Lee BS, Kim SH, et al. (2015) Alpha-pinene exhibits anti-inflammatory activity through the suppression of MAPKs and the NF- $\kappa$ B pathway in mouse peritoneal macrophages. Am J Chin Med 43:731-742.

Kim J, Jang JH, Lee JH, Choi JK, Park WR, Bae IH, Bae J, and Park JW (2012) Enhanced topical delivery of small hydrophilic or lipophilic active agents and epidermal growth factor by fractional radiofrequency microporation. Pharm Res 29:2017-2029.

Kim JT, Ren CJ, Fielding GA, Pitti A, Kasumi T, Wajda M, Lebovits A, and Bekker A (2007) Treatment with lavender aromatherapy in the post-anesthesia care unit reduces opioid requirements of morbidly obese patients undergoing laparoscopic adjustable gastric banding. Obes Surg 17:920-925.

Kim KN, Ko YJ, Yang HM, Ham YM, Roh SW, Jeon YJ, Ahn G, Kang MC, Yoon WJ, Kim D, et al. (2013) Anti-inflammatory effect of essential oil and its constituents from fingered citron (Citrus medica L. var. sarcodactylis) through blocking JNK, ERK and NF- $\kappa$ B signaling pathways in LPS-activated RAW 264.7 cells. Food Chem Toxicol 57:126-131.

Kim S, Jung E, Kim JH, Park YH, Lee J, and Park D (2011) Inhibitory effects of (-)- $\alpha$-bisabolol on LPS-induced inflammatory response in RAW264.7 macrophages. Food Chem Toxicol 49:2580-2585

Klauke AL, Racz I, Pradier B, Markert A, Zimmer AM, Gertsch J, and Zimmer A (2014) The cannabinoid $\mathrm{CB}_{2}$ receptor-selective phytocannabinoid betacaryophyllene exerts analgesic effects in mouse models of inflammatory and neuropathic pain. Eur Neuropsychopharmacol 24:608-620.

Komiya M, Takeuchi T, and Harada E (2006) Lemon oil vapor causes an anti-stress effect via modulating the 5-HT and DA activities in mice. Behav Brain Res 172:240-249.

Komori T, Fujiwara R, Tanida M, Nomura J, and Yokoyama MM (1995) Effects of citrus fragrance on immune function and depressive states. Neuroimmunomodulation 2:174-180.

Koppel BS, Brust JC, Fife T, Bronstein J, Youssof S, Gronseth G, and Gloss D (2014) Systematic review: efficacy and safety of medical marijuana in selected neurologic disorders: report of the Guideline Development Subcommittee of the American Academy of Neurology. Neurology 82:1556-1563.

Kuwahata H, Komatsu T, Katsuyama S, Corasaniti MT, Bagetta G, Sakurada S, Sakurada T, and Takahama K (2013) Peripherally injected linalool and bergamot essential oil attenuate mechanical allodynia via inhibiting spinal ERK phosphorylation. Pharmacol Biochem Behav 103:735-741.

Langley PC (2011) The prevalence, correlates and treatment of pain in the European Union. Curr Med Res Opin 27:463-480.

La Rocca V, da Fonsêca DV, Silva-Alves KS, Ferreira-da-Silva FW, de Sousa DP, Santos PL, Quintans-Júnior LJ, Leal-Cardoso JH, and de Almeida RN (2017) Geraniol induces antinociceptive effect in mice evaluated in behavioural and electrophysiological models. Basic Clin Pharmacol Toxicol 120:22-29.

Leal-Cardoso JH, da Silva-Alves KS, Ferreira-da-Silva FW, dos Santos-Nascimento T, Joca HC, de Macedo FH, de Albuquerque-Neto PM, Magalhães PJ, Lahlou S,
Cruz JS, et al. (2010) Linalool blocks excitability in peripheral nerves and voltage-dependent $\mathrm{Na}+$ current in dissociated dorsal root ganglia neurons. Eur $J$ Pharmacol 645:86-93.

Lee CB, Ha US, Lee SJ, Kim SW, and Cho YH (2006) Preliminary experience with a terpene mixture versus ibuprofen for treatment of category III chronic prostatitis/chronic pelvic pain syndrome. World $J$ Urol 24:55-60.

Lee SY, Kim SH, Hong CY, Park SY, and Choi IG (2015) Biotransformation of (-)- $\alpha$-pinene and geraniol to $\alpha$-terpineol and p-menthane-3,8-diol by the white rot fungus, Polyporus brumalis. J Microbiol 53:462-467.

Lei Y, Fu P, Jun X, and Cheng P (2019) Pharmacological properties of geraniol - a review. Planta Med 85:48-55.

Leite Gde O, Fernandes CN, de Menezes IR, da Costa JG, and Campos AR (2012) Attenuation of visceral nociception by $\alpha$-bisabolol in mice: investigation of mechanisms. Org Med Chem Lett 2:18.

Leite Gde O, Leite LH, Sampaio RdeS, Araruna MK, de Menezes IR, da Costa JG, and Campos AR (2011) (-)- $\alpha$-Bisabolol attenuates visceral nociception and inflammation in mice. Fitoterapia 82:208-211.

Lewis MA, Russo EB, and Smith KM (2018) Pharmacological foundations of cannabis chemovars. Planta Med 84:225-233.

Li AS, Iijimaa A, Huanga J, Li QX, and Chena Y (2020) Putative mode of action of the monoterpenoids linalool, methyl eugenol, estragole, and citronellal on ligandgated ion channels. Engineering 6:541-545.

Li XJ, Yang YJ, Li YS, Zhang WK, and Tang HB (2016) $\alpha$-Pinene, linalool, and 1-octanol contribute to the topical anti-inflammatory and analgesic activities of frankincense by inhibiting COX-2. J Ethnopharmacol 179:22-26.

Liapi C, Anifandis G, Chinou I, Kourounakis AP, Theodosopoulos S, and Galanopoulou P (2007) Antinociceptive properties of 1,8-Cineole and beta-pinene, from the essential oil of Eucalyptus camaldulensis leaves, in rodents [published correction appears in Planta Med (2008) 74:789]. Planta Med 73:1247-1254.

Lima DK, Ballico LJ, Rocha Lapa F, Goncalves HP, de Souza LM, Iacomini M, Werner MF, Baggio CH, Pereira IT, da Silva LM, et al. (2012) Evaluation of the antinociceptive, anti-inflammatory and gastric antiulcer activities of the essential oil from Piper aleyreanum C.DC in rodents. $J$ Ethnopharmaco 142:274-282.

Linck VM, da Silva AL, Figueiró M, Caramão EB, Moreno PR, and Elisabetsky E (2010) Effects of inhaled Linalool in anxiety, social interaction and aggressive behavior in mice. Phytomedicine 17:679-683.

Lněničková $\mathrm{K}$, Svobodová $\mathrm{H}$, Skálová $\mathrm{L}$, Ambrož M, Novák $\mathrm{F}$, and Matoušková $\mathrm{P}$ (2018) The impact of sesquiterpenes $\beta$-caryophyllene oxide and trans-nerolidol on xenobiotic-metabolizing enzymes in mice in vivo. Xenobiotica 48:1089-1097.

Lorenzetti BB, Souza GEP, Sarti SJ, Santos Filho D, and Ferreira SH (1991) Myrcene mimics the peripheral analgesic activity of lemongrass tea J Ethnopharmacol 34:43-48.

Lv Y, Zhang L, Li N, Mai N, Zhang Y, and Pan S (2017) Geraniol promotes functional recovery and attenuates neuropathic pain in rats with spinal cord injury. Can J Physiol Pharmacol 95:1389-1395.

Madyastha KM and Srivatsan V (1988) Biotransformations of alpha-terpineol in the rat: its effects on the liver microsomal cytochrome P-450 system. Bull Environ Contam Toxicol 41:17-25.

Manchikanti L, Helm 2nd S, Fellows B, Janata JW, Pampati V, Grider JS, and Boswell MV (2012) Opioid epidemic in the United States. Pain Physician 15(3, Suppl)ES9-ES38.

Mander L and Liu HW (2010) Comprehensive Natural Products II - Chemistry and Biology, Ed. 1st. Elsevier, Kidlington.

Maroon J and Bost J (2018) Review of the neurological benefits of phytocannabinoids. Surg Neurol Int 9:91.

Martínez AL, González-Trujano ME, Pellicer F, López-Muñoz FJ, and Navarrete A (2009) Antinociceptive effect and GC/MS analysis of Rosmarinus officinalis L. essential oil from its aerial parts. Planta Med 75:508-511.

Maule WJ (2015) Medical uses of marijuana (Cannabis sativa): fact or fallacy? $\mathrm{Br}$ J Biomed Sci 72:85-91.

Mazzeo F, Bernocchi D, Cavalli C, and Manini G (1988) Preliminary report on activity and tolerability of epomediol, administered by intravenous infusion, in patients with chronic hepatopathies. J Int Med Res 16:237-243.

McPartland JM (2017) Cannabis sativa and Cannabis indica versus "Sativa" and "Indica", in Cannabis sativa L. - Botany and Biotechnology (Chandra S, Lata H, and ElSohly MA, eds) pp 101-121, Springer.

McPartland JM (2018) Cannabis systematics at the levels of family, genus, and species. Cannabis Cannabinoid Res 3:203-212.

Meehan-Atrash J, Luo W, and Strongin RM (2017) Toxicant formation in dabbing: the terpene story. ACS Omega 2:6112-6117.

Melo LT, Duailibe MA, Pessoa LM, da Costa FN, Vieira-Neto AE, de Vasconcellos Abdon AP, and Campos AR (2017) (-)- $\alpha$-Bisabolol reduces orofacial nociceptive behavior in rodents. Naunyn Schmiedebergs Arch Pharmacol 390:187-195.

Melo LT, Panchalingam V, Cherkas P, Campos AR, Avivi-Arber L, and Sessle BJ (2019) (-)- $\alpha$-Bisabolol reduces nociception and trigeminal central sensitisation in acute orofacial neuropathic pain induced by infraorbital nerve injury. Life Sci 227:122-128.

Micalizzi G, Vento F, Alibrando F, Donnarumma D, Dugo P, and Mondello L (2021) Cannabis Sativa L.: a comprehensive review on the analytical methodologies for cannabinoids and terpenes characterization. J Chromatogr A 1637:461864.

Molina G, Pessôa MG, Bicas JL, Fontanille P, Larroche C, and Pastore GM (2019) Optimization of limonene biotransformation for the production of bulk amounts of $\alpha$-terpineol. Bioresour Technol 294:122180.

Morales P, Hurst DP, and Reggio PH (2017) Molecular targets of the phytocannabinoids: a complex picture. Prog Chem Org Nat Prod 103:103-131.

Mücke M, Phillips T, Radbruch L, Petzke F, and Häuser W (2018) Cannabis-based medicines for chronic neuropathic pain in adults. Cochrane Database Syst Rev 3:CD012182 
Mudge EM, Brown PN, and Murch SJ (2019) The terroir of cannabis: terpene metabolomics as a tool to understand Cannabis sativa selections. Planta Med 85:781-796.

Nahin RL, Sayer B, Stussman BJ, and Feinberg TM (2019) Eighteen-year trends in the prevalence of, and health care use for, noncancer pain in the United States: data from the medical expenditure panel survey. J Pain 20:796-809.

Namdar D, Voet H, Ajjampura V, Nadarajan S, Mayzlish-Gati E, Mazuz M, Shalev N, and Koltai H (2019) Terpenoids and phytocannabinoids co-produced in Cannabis Sativa strains show specific interaction for cell cytotoxic activity. Molecules 24:3031.

Nascimento SS, Camargo EA, DeSantana JM, Araújo AA, Menezes PP, LuccaJúnior W, Albuquerque-Júnior RL, Bonjardim LR, and Quintans-Júnior LJ (2014) Linalool and linalool complexed in $\beta$-cyclodextrin produce antihyperalgesic activity and increase Fos protein expression in animal model for fibromyalgia. Naunyn Schmiedebergs Arch Pharmacol 387:935-942.

Nguyen LT, Myslivečková Z, Szotáková B, Špičáková A, Lněničková K, Ambrož M, Kubíček V, Krasulová K, Anzenbacher P, and Skálová L (2017) The inhibitory effects of $\beta$-caryophyllene, $\beta$-caryophyllene oxide and $\alpha$-humulene on the activities of the main drug-metabolizing enzymes in rat and human liver in vitro. Chem Biol Interact 278:123-128.

Ni YL, Shen HT, Su CH, Chen WY, Huang-Liu R, Chen CJ, Chen SP, and Kuan YH (2019) Nerolidol suppresses the inflammatory response during lipopolysaccharideinduced acute lung injury via the modulation of antioxidant enzymes and the AMPK/Nrf-2/HO-1 pathway. Oxid Med Cell Longev 2019:9605980.

Niazi M, Hashempur MH, Taghizadeh M, Heydari M, and Shariat A (2017) Efficacy of topical rose (Rosa damascena Mill.) oil for migraine headache: a randomized double-blinded placebo-controlled cross-over trial. Complement Ther Med 34:35-41.

Nogueira MNM, Aquino SG, Rossa Junior C, and Spolidorio DMP (2014) Terpinen4 -ol and alpha-terpineol (tea tree oil components) inhibit the production of IL- $1 \beta$, IL-6 and IL-10 on human macrophages. Inflamm Res 63:769-778.

Nokhodchi A, Sharabiani K, Rashidi MR, and Ghafourian T (2007) The effect of terpene concentrations on the skin penetration of diclofenac sodium. Int $J$ Pharm 335:97-105.

NTP/NIH; Review of Toxicological Literature for beta-Myrcene (123-35-3) p. 8-3 (1997).

Nuutinen T (2018) Medicinal properties of terpenes found in Cannabis sativa and Humulus lupulus. Eur J Med Chem 157:198-228.

Ogunwande IA, Avoseh ON, Olasunkanmi KN, Lawal OA, Ascrizzi R, and Flamini G (2019) Chemical composition, anti-nociceptive and anti-inflammatory activities of essential oil of Bougainvillea glabra. $J$ Ethnopharmacol 232:188-192.

Ortiz MI, Cariño-Cortés R, Ponce-Monter HA, Castañeda-Hernández G, and Chávez-Piña AE (2018) Pharmacological interaction of $\alpha$-bisabolol and diclofenac on nociception, inflammation, and gastric integrity in rats. Drug Dev Res 79:29-37.

Pamplona FA, da Silva LR, and Coan AC (2018) Potential clinical benefits of cbdrich Cannabis extracts over purified CBD in treatment-resistant epilepsy: observational data meta-analysis. Front Neurol 9:759.

Pandey P, Roy KK, and Doerksen RJ (2020) Negative allosteric modulators of cannabinoid receptor 2: protein modeling, binding site identification and molecular dynamics simulations in the presence of an orthosteric agonist. $J$ Biomol Struct Dyn 38:32-47.

Pang MH, Kim Y, Jung KW, Cho S, and Lee DH (2012) A series of case studies: practical methodology for identifying antinociceptive multi-target drugs. Drug Discov Today 17:425-434.

Paré PW and Tumlinson JH (1999) Plant volatiles as a defense against insect herbivores. Plant Physiol 121:325-332.

Park HM, Lee JH, Yaoyao J, Jun HJ, and Lee SJ (2011) Limonene, a natural cyclic terpene, is an agonistic ligand for adenosine $\mathrm{A}(2 \mathrm{~A})$ receptors. Biochem Biophys Res Commun 404:345-348.

Parvardeh S, Moghimi M, Eslami P, and Masoudi A (2016) $\alpha$-Terpineol attenuates morphine-induced physical dependence and tolerance in mice: role of nitric oxide. Iran J Basic Med Sci 19:201-208.

Passos FF, Lopes EM, de Araújo JM, de Sousa DP, Veras LM, Leite JR, and Almeida FR (2015) Involvement of cholinergic and opioid system in $\gamma$-terpinenemediated antinociception. Evid Based Complement Alternat Med 2015:829414.

Patel M, Narke D, Kurade M, Frey KM, Rajalingam S, Siddiquee A, Mustafa SJ, Ledent C, and Ponnoth DS (2020) Limonene-induced activation of A2a adenosine receptors reduces airway inflammation and reactivity in a mouse model of asthma, Puringerg Singal, 10.1007/s11302-020-09697-z.

Paula-Freire LI, Andersen ML, Molska GR, Köhn DO, and Carlini ELA (2013) Evaluation of the antinociceptive activity of Ocimum gratissimum L. (Lamiaceae) essential oil and its isolated active principles in mice. Phytother Res 27:1220-1224

Paula-Freire LI, Andersen ML, Gama VS, Molska GR, and Carlini EL (2014) The oral administration of trans-caryophyllene attenuates acute and chronic pain in mice. Phytomedicine 21:356-362.

Paula-Freire LI, Molska GR, Andersen ML, and Carlini EL (2016) Ocimum gratissimum essential oil and its isolated compounds (eugenol and myrcene) reduce neuropathic pain in mice. Planta Med 82:211-216.

Pavan B, Dalpiaz A, Marani L, Beggiato S, Ferraro L, Canistro D, Paolini M, Vivarelli F, Valerii MC, Comparone A, et al. (2018) Geraniol pharmacokinetics, bioavailability and its multiple effects on the liver antioxidant and xenobioticmetabolizing enzymes. Front Pharmacol 9:18

Peana AT, D’Aquila PS, Chessa ML, Moretti MDL, Serra G, and Pippia P (2003) (-)-Linalool produces antinociception in two experimental models of pain. Eur $J$ Pharmacol 460:37-41.

Peana AT, De Montis MG, Nieddu E, Spano MT, D'Aquila PS, and Pippia P (2004a) Profile of spinal and supra-spinal antinociception of (-)-linalool. Eur J Pharmacol 485:165-174.
Peana AT, De Montis MG, Sechi S, Sircana G, D’Aquila PS, and Pippia P (2004b) Effects of (-)-linalool in the acute hyperalgesia induced by carrageenan, L-glutamate and prostaglandin E2. Eur J Pharmacol 497:279-284.

Peana AT, Rubattu P, Piga GG, Fumagalli S, Boatto G, Pippia P, and De Montis MG (2006) Involvement of adenosine A1 and A2A receptors in (-)-linalool-induced antinociception. Life Sci 78:2471-2474.

Peirs C and Seal RP (2016) Neural circuits for pain: recent advances and current views. Science 354:578-584.

Piccinelli AC, Morato PN, Dos Santos Barbosa M, Croda J, Sampson J, Kong X, Konkiewitz EC, Ziff EB, Amaya-Farfan J, and Kassuya CA (2017) Limonene reduces hyperalgesia induced by gp120 and cytokines by modulation of IL-1 $\beta$ and protein expression in spinal cord of mice. Life Sci 174:28-34.

Piccinelli AC, Santos JA, Konkiewitz EC, Oesterreich SA, Formagio AS, Croda J, Ziff EB, and Kassuya CA (2015) Antihyperalgesic and antidepressive actions of (R)-(+)-limonene, $\alpha$-phellandrene, and essential oil from Schinus terebinthifolius fruits in a neuropathic pain model. Nutr Neurosci 18:217-224.

Pinheiro BG, Silva AS, Souza GE, Figueiredo JG, Cunha FQ, Lahlou S, da Silva JK, Maia JG, and Sousa PJ (2011) Chemical composition, antinociceptive and anti-inflammatory effects in rodents of the essential oil of Peperomia serpens (Sw.) Loud. J Ethnopharmacol 138:479-486.

Polacek C, Christopher R, Mann M, Udall M, Craig T, Deminski M, and Sathe NA (2020) Healthcare professionals' perceptions of challenges to chronic pain management. Am J Manag Care 26:e135-e139.

Pollastro F, De Petrocellis L, Schiano-Moriello A, Chianese G, Heyman H, Appendino G, and Taglialatela-Scafati O (2017) Amorfrutin-type phytocannabinoids from Helichrysum umbraculigerum. Fitoterapia 123:13-17.

Pollio A (2016) The name of Cannabis: a short guide for nonbotanists. Cannabis Cannabinoid Res 1:234-238.

Popović V, Petrović S, Tomić M, Stepanović-Petrović R, Micov A, Pavlović-Drobac M, Couladis M, and Niketić M (2014) Antinociceptive and anti-edematous activities of the essential oils of two Balkan endemic Laserpitium species. Nat Prod Commun 9:125-128.

Pourtaqi N, Imenshahidi M, Razavi BM, and Hosseinzadeh H (2017) Effect of linalool on the acquisition and reinstatement of morphine-induced conditioned place preference in mice. Avicenna J Phytomed 7:242-249.

Quintans-Júnior LJ, Oliveira MG, Santana MF, Santana MT, Guimarães AG, Siqueira JS, De Sousa DP, and Almeida RN (2011) $\alpha$-Terpineol reduces nociceptive behavior in mice. Pharm Biol 49:583-586.

Ramalho TR, Oliveira MT, Lima AL, Bezerra-Santos CR, and Piuvezam MR (2015) Gamma-terpinene modulates acute inflammatory response in mice. Planta Med 81:1248-1254

Rao VSN, Menezes AMS, and Viana GSB (1990) Effect of myrcene on nociception in mice. J Pharm Pharmacol 42:877-878.

Richins RD, Rodriguez-Uribe L, Lowe K, Ferral R, and O'Connell MA (2018) Accumulation of bioactive metabolites in cultivated medical Cannabis. PLoS One 13:e0201119.

Rocha NF, Rios ER, Carvalho AM, Cerqueira GS, Lopes AdeA, Leal LK, Dias ML, de Sousa DP, and de Sousa FC (2011) Anti-nociceptive and anti-inflammatory activities of (-)- $\alpha$-bisabolol in rodents. Naunyn Schmiedebergs Arch Pharmaco 384:525-533.

Romano LL and Hazekamp A (2013) Cannabis oil: chemical evaluation of an upcoming cannabis-based medicine. Cannabis Cannabinoid Res 1:1-11.

Romero-Sandoval EA, Fincham JE, Kolano AL, Sharpe BN, and Alvarado-Vázquez PA (2018) Cannabis for chronic pain: challenges and considerations. Pharmacotherapy 38:651-662.

Ross SA and ElSohly MA (1996) The volatile oil composition of fresh and air-dried buds of Cannabis sativa. J Nat Prod 59:49-51.

Russo EB (2007) History of cannabis and its preparations in saga, science, and sobriquet. Chem Biodivers 4:1614-1648.

Russo EB (2011) Taming THC: potential cannabis synergy and phytocannabinoidterpenoid entourage effects. $\mathrm{Br}$ J Pharmacol 163:1344-1364.

Russo EB (2019) The case for the entourage effect and conventional breeding of clinical cannabis: no "strain," no gain. Front Plant Sci 9:1969.

Russo EB and Marcu J (2017) Cannabis pharmacology: the usual suspects and a few promising leads. Adv Pharmacol 80:67-134

Russo EB and McPartland JM (2003) Cannabis is more than simply delta(9)tetrahydrocannabinol. Psychopharmacology (Berl) 165:431-432, author reply 433-434

Russo EB, Jiang HE, Li X, Sutton A, Carboni A, del Bianco F, Mandolino G, Potter DJ, Zhao YX, Bera S, et al. (2008) Phytochemical and genetic analyses of ancient cannabis from Central Asia. J Exp Bot 59:4171-4182.

Šadibolová M, Zárybnický T, Smutný T, Pávek P, Šubrt Z, Matoušková P, Skálová L, and Boušová I (2019) Sesquiterpenes are agonists of the pregnane $\mathrm{x}$ receptor but do not induce the expression of phase I drug-metabolizing enzymes in the human liver. Int J Mol Sci 20:4562.

Safaripour S, Nemati Y, Parvardeh S, Ghafghazi S, Fouladzadeh A, and Moghimi M (2018) Role of l-arginine/SNAP/NO/cGMP/K $\mathrm{K}_{\mathrm{ATP}}$ channel signalling pathway in antinociceptive effect of $\alpha$-terpineol in mice. $J$ Pharm Pharmacol 70:507-515.

Sakurada T, Mizoguchi H, Kuwahata H, Katsuyama S, Komatsu T, Morrone LA Corasaniti MT, Bagetta G, and Sakurada S (2011) Intraplantar injection of bergamot essential oil induces peripheral antinociception mediated by opioid mechanism. Pharmacol Biochem Behav 97:436-443.

Santiago M, Sachdev S, Arnold JC, McGregor IS, and Connor M (2019) Absence of entourage: terpenoids commonly found in Cannabis sativa do not modulate the functional activity of $\Delta^{9}-\mathrm{THC}$ at human $\mathrm{CB}_{1}$ and $\mathrm{CB}_{2}$ receptors. Cannabis Cannabinoid Res 4:165-176.

Santos PS, Oliveira TCR, R Júnior LM, Figueiras A, and Nunes LCC (2018) $\beta$-caryophyllene delivery systems: enhancing the oral pharmacokinetic and stability. Curr Pharm Des 24:3440-3453. 
Satou T, Kasuya H, Maeda K, and Koike K (2014) Daily inhalation of $\alpha$-pinene in mice: effects on behavior and organ accumulation. Phytother Res 28:1284-1287.

Sawler J, Stout JM, Gardner KM, Hudson D, Vidmar J, Butler L, Page JE, and Myles S (2015) The genetic structure of marijuana and hemp. PLoS One 10:e0133292

Schappert SM and Burt CW (2006) Ambulatory care visits to physician offices, hospital outpatient departments, and emergency departments: United States, 2001-02. Vital Health Stat 13 (159):1-66.

Schmidt L and Göen T (2017) R-Limonene metabolism in humans and metabolite kinetics after oral administration. Arch Toxicol 91:1175-1185.

Schmitt S, Schaefer UF, Doebler L, and Reichling J (2009) Cooperative interaction of monoterpenes and phenylpropanoids on the in vitro human skin permeation of complex composed essential oils. Planta Med 75:1381-1385.

Schmitz N and Richert L (2020) Pharmacists and the future of cannabis medicine. $J$ Am Pharm Assoc (2003) 60:207-211.

Segat GC, Manjavachi MN, Matias DO, Passos GF, Freitas CS, Costa R, and Calixto JB (2017) Antiallodynic effect of $\beta$-caryophyllene on paclitaxel-induced peripheral neuropathy in mice. Neuropharmacology 125:207-219.

Semprini R, Martorana A, Ragonese M, and Motta C (2018) Observational clinical and nerve conduction study on effects of a nutraceutical combination on painful diabetic distal symmetric sensory-motor neuropathy in patients with diabetes type 1 and type 2. Minerva Med 109:358-362.

Senyiğit T, Padula C, Ozer O, and Santi P (2009) Different approaches for improving skin accumulation of topical corticosteroids. Int J Pharm 380:155-160.

Sexton M, Shelton K, Haley P, and West M (2018) Evaluation of cannabinoid and terpenoid content: cannabis flower compared to supercritical $\mathrm{CO} 2$ concentrate. Planta Med 84:234-241.

Sharma C, Al Kaabi JM, Nurulain SM, Goyal SN, Kamal MA, and Ojha S (2016) Polypharmacological properties and therapeutic potential of $\beta$-caryophyllene: a dietary phytocannabinoid of pharmaceutical promise. Curr Pharm Des 22:3237-3264.

Shi F, Zhao Y, Firempong CK, and Xu X (2016) Preparation, characterization and pharmacokinetic studies of linalool-loaded nanostructured lipid carriers. Pharm Biol 54:2320-2328.

Small E (2015) Evolution and classification of Cannabis sativa (marijuana, hemp) in relation to human utilization. Bot Rev 81:189-294.

Small E and Beckstead HD (1973) Letter: cannabinoid phenotypes in Cannabis sativa. Nature 245:147-148.

Smith BH, Elliott AM, Chambers WA, Smith WC, Hannaford PC, and Penny K (2001) The impact of chronic pain in the community. Fam Pract 18:292-299.

Soleimani M, Sheikholeslami MA, Ghafghazi S, Pouriran R, and Parvardeh S (2019) Analgesic effect of $\alpha$-terpineol on neuropathic pain induced by chronic constriction injury in rat sciatic nerve: Involvement of spinal microglial cells and inflammatory cytokines. Iran J Basic Med Sci 22:1445-1451.

Sousa OV, Silvério MS, Del-Vechio-Vieira G, Matheus FC, Yamamoto CH, and Alves MS (2008) Antinociceptive and anti-inflammatory effects of the essential oil from Eremanthus erythropappus leaves. J Pharm Pharmacol 60:771-777.

Souto-Maior FN, de Carvalho FL, de Morais LC, Netto SM, de Sousa DP, and de Almeida RN (2011) Anxiolytic-like effects of inhaled linalool oxide in experimental mouse anxiety models. Pharmacol Biochem Behav 100:259-263.

Tanvisut R, Traisrisilp K, and Tongsong T (2018) Efficacy of aromatherapy for reducing pain during labor: a randomized controlled trial. Arch Gynecol Obste 297:1145-1150.

Taşan E, Ovayolu O, and Ovayolu N (2019) The effect of diluted lavender oil inhalation on pain development during vascular access among patients undergoing haemodialysis. Complement Ther Clin Pract 35:177-182.

Tashiro S, Yamaguchi R, Ishikawa S, Sakurai T, Kajiya K, Kanmura Y, Kuwaki T, and Kashiwadani H (2016) Odour-induced analgesia mediated by hypothalamic orexin neurons in mice. Sci Rep 6:37129.

Teixeira GF, Costa FN, and Campos AR (2017) Corneal antinociceptive effect of (-)- $\alpha$-bisabolol. Pharm Biol 55:1089-1092

Thomas MA (2003) Pain management - the challenge. Ochsner J 5:15-21.

Tian X, Liu H, Xiang F, Xu L, and Dong Z (2019) $\beta$-Caryophyllene protects against ischemic stroke by promoting polarization of microglia toward M2 phenotype via the TLR4 pathway. Life Sci 237:116915.

Tisserand R and Young R (2014) Essential Oil Safety, Ed. 2nd. Churchill Livingstone, St. Louis.
Tournier N, Chevillard L, Megarbane B, Pirnay S, Scherrmann JM, and Declèves X (2010) Interaction of drugs of abuse and maintenance treatments with human Pglycoprotein (ABCB1) and breast cancer resistance protein (ABCG2). Int $J$ Neuropsychopharmacol 13:905-915.

Turner SE, Williams CM, Iversen L, and Whalley BJ (2017) Molecular pharmacology of phytocannabinoids. Prog Chem Org Nat Prod 103:61-101.

Vadivelu N, Kai AM, Kodumudi V, Sramcik J, and Kaye AD (2018) The opioid crisis: a comprehensive overview. Curr Pain Headache Rep 22:16.

van de Donk T, Niesters M, Kowal MA, Olofsen E, Dahan A, and van Velzen M (2019) An experimental randomized study on the analgesic effects of pharmaceutical-grade cannabis in chronic pain patients with fibromyalgia. Pain 160:860-869.

VanDolah HJ, Bauer BA, and Mauck KF (2019) Clinicians' guide to cannabidiol and hemp oils. Mayo Clin Proc 94:1840-1851.

Varga ZV, Matyas C, Erdelyi K, Cinar R, Nieri D, Chicca A, Nemeth BT, Paloczi J, Lajtos T, Corey L, et al. (2018) $\beta$-Caryophyllene protects against alcoholic steatohepatitis by attenuating inflammation and metabolic dysregulation in mice. Br J Pharmacol 175:320-334.

Ventafridda V, Saita L, Ripamonti C, and De Conno F (1985) WHO guidelines for the use of analgesics in cancer pain. Int $J$ Tissue React 7:93-96.

Vigushin DM, Poon GK, Boddy A, English J, Halbert GW, Pagonis C, Jarman M, and Coombes RC; Cancer Research Campaign Phase I/II Clinical Trials Committee (1998) Phase I and pharmacokinetic study of D-limonene in patients with advanced cancer. Cancer Chemother Pharmacol 42:111-117.

Volkow ND, Baler RD, Compton WM, and Weiss SR (2014) Adverse health effects of marijuana use. $N$ Engl J Med 370:2219-2227.

Worth T (2019) Cannabis's chemical synergies. Nature 572:S12-S13.

Wu C, Jia Y, Lee JH, Jun HJ, Lee HS, Hwang KY, and Lee SJ (2014) transCaryophyllene is a natural agonistic ligand for peroxisome proliferator-activated receptor- $\alpha$. Bioorg Med Chem Lett 24:3168-3174.

Yamane MA, Williams AC, and Barry BW (1995) Terpene penetration enhancers in propylene glycol/water co-solvent systems: effectiveness and mechanism of action. J Pharm Pharmacol 47 (12A):978-989.

Yamaori S, Kushihara M, Yamamoto I, and Watanabe K (2010) Characterization of major phytocannabinoids, cannabidiol and cannabinol, as isoform-selective and potent inhibitors of human CYP1 enzymes. Biochem Pharmacol 79:1691-1698.

Yang J, Bauer BA, Wahner-Roedler DL, Chon TY, and Xiao L (2020) The modified WHO analgesic ladder: is it appropriate for chronic non-cancer pain? J Pain Res 13:411-417.

Yang M, Lv Y, Tian X, Lou J, An R, Zhang Q, Li M, Xu L, and Dong Z (2017) Neuroprotective effect of $\beta$-caryophyllene on cerebral ischemia-reperfusion injury via regulation of necroptotic neuronal death and inflammation: in vivo and in vitro. Front Neurosci 11:583.

Ying J, Zhou MJ, Chen HY, Chen L, Zhang W, Ji J, Yu C, and Zhang ZJ (2019) Effect of essential oil on patients with chronic prostatitis/chronic pelvic pain syndrome: a pilot randomized controlled trial. Chin J Integr Med 25:91-95.

Yoshida N, Koizumi M, Adachi I, and Kawakami J (2006) Inhibition of Pglycoprotein-mediated transport by terpenoids contained in herbal medicines and natural products. Food Chem Toxicol 44:2033-2039.

Yoshida N, Takada T, Yamamura Y, Adachi I, Suzuki H, and Kawakami J (2008) Inhibitory effects of terpenoids on multidrug resistance-associated protein 2 - and breast cancer resistance protein-mediated transport. Drug Metab Dispos 36:1206-1211.

Yoshida N, Takagi A, Kitazawa H, Kawakami J, and Adachi I (2005) Inhibition of P-glycoprotein-mediated transport by extracts of and monoterpenoids contained in Zanthoxyli fructus. Toxicol Appl Pharmacol 209:167-173.

Yoshida K, Nagatoishi S, Kuroda D, Suzuki N, Murata T, and Tsumoto K (2019) Phospholipid membrane fluidity alters ligand binding activity of a G proteincoupled receptor by shifting the conformational equilibrium. Biochemistry 58:504-508.

Zhang L, Sun D, Bao Y, Shi Y, Cui Y, and Guo M (2017) Nerolidol protects against LPS-induced acute kidney injury via inhibiting TLR4/NF- $\kappa$ B signaling. Phytother Res 31:459-465.

Zhang N and Yao L (2019) Anxiolytic effect of essential oils and their constituents: a review. J Agric Food Chem 67:13790-13808. 